\title{
Evaluating the climate and air quality impacts of short-lived pollutants
}

\author{
A. Stohl ${ }^{1}$, B. Aamaas ${ }^{2}$, M. Amann ${ }^{3}$, L. H. Baker ${ }^{4}$, N. Bellouin ${ }^{4}$, T. K. Berntsen ${ }^{2}$, O. Boucher ${ }^{5}$, R. Cherian ${ }^{6}$, \\ W. Collins ${ }^{4,7}$, N. Daskalakis ${ }^{8,9}$, M. Dusinska ${ }^{1}$, S. Eckhardt ${ }^{1}$, J. S. Fuglestvedt ${ }^{2}$, M. Harju ${ }^{1}$, C. Heyes ${ }^{3}$, Ø. Hodnebrog ${ }^{2}$,

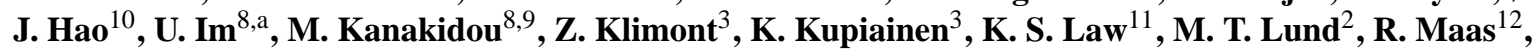 \\ C. R. MacIntosh ${ }^{4}$, G. Myhre ${ }^{2}$, S. Myriokefalitakis ${ }^{8,9}$, D. Olivié ${ }^{13}$, J. Quaas ${ }^{6}$, B. Quennehen ${ }^{11}$, J.-C. Raut ${ }^{11}$, \\ S. T. Rumbold ${ }^{7}$, B. H. Samset ${ }^{2}$, M. Schulz ${ }^{13}$, Ø. Seland ${ }^{13}$, K. P. Shine ${ }^{4}$, R. B. Skeie ${ }^{2}$, S. Wang ${ }^{10}$, K. E. Yttri ${ }^{1}$, and \\ T. $\mathbf{Z h u}^{14}$ \\ ${ }^{1}$ NILU - Norwegian Institute for Air Research, Kjeller, Norway \\ ${ }^{2}$ Center for International Climate and Environmental Research - Oslo (CICERO), Oslo, Norway \\ ${ }^{3}$ International Institute for Applied Systems Analysis (IIASA), Laxenburg, Austria \\ ${ }^{4}$ Department of Meteorology, University of Reading, Reading, UK \\ ${ }^{5}$ LATMOS, Université Pierre et Marie Curie (UPMC)/CNRS, Paris, France \\ ${ }^{6}$ Institute for Meteorology, Universität Leipzig, Leipzig Germany \\ ${ }^{7}$ Met Office Hadley Centre, Exeter, UK \\ ${ }^{8}$ Environmental Chemical Processes Laboratory, Department of Chemistry, University of Crete, Heraklion, Crete, Greece \\ ${ }^{9}$ FORTH, ICE-HT, Platani, Patras, Greece \\ ${ }^{10}$ School of Environment, Tsinghua University, Beijing, China \\ ${ }^{11}$ Sorbonne Universités, UPMC Univ. Paris 06, Université Versailles St-Quentin, CNRS/INSU, LATMOS-IPSL, Paris, France \\ ${ }^{12}$ RIVM - National Institute for Public Health and the Environment, Bilthoven, the Netherlands \\ ${ }^{13}$ Norwegian Meteorological Institute, Oslo, Norway \\ ${ }^{14}$ State Key Laboratory for Environmental Simulation and Pollution Control, College of Environmental Sciences and \\ Engineering, Peking University, Beijing, China \\ ${ }^{a}$ now at: Aarhus University, Department of Environmental Science, 4000 Roskilde, Denmark
}

Correspondence to: A. Stohl (ast@ nilu.no)

Received: 7 May 2015 - Published in Atmos. Chem. Phys. Discuss.: 3 June 2015

Revised: 31 August 2015 - Accepted: 4 September 2015 - Published: 24 September 2015

\begin{abstract}
This paper presents a summary of the work done within the European Union's Seventh Framework Programme project ECLIPSE (Evaluating the Climate and Air Quality Impacts of Short-Lived Pollutants). ECLIPSE had a unique systematic concept for designing a realistic and effective mitigation scenario for short-lived climate pollutants (SLCPs; methane, aerosols and ozone, and their precursor species) and quantifying its climate and air quality impacts, and this paper presents the results in the context of this overarching strategy. The first step in ECLIPSE was to create a new emission inventory based on current legislation (CLE) for the recent past and until 2050. Substantial progress compared to previous work was made by including previously
\end{abstract}

unaccounted types of sources such as flaring of gas associated with oil production, and wick lamps. These emission data were used for present-day reference simulations with four advanced Earth system models (ESMs) and six chemistry transport models (CTMs). The model simulations were compared with a variety of ground-based and satellite observational data sets from Asia, Europe and the Arctic. It was found that the models still underestimate the measured seasonality of aerosols in the Arctic but to a lesser extent than in previous studies. Problems likely related to the emissions were identified for northern Russia and India, in particular. To estimate the climate impacts of SLCPs, ECLIPSE followed two paths of research: the first path calculated radiative 
forcing (RF) values for a large matrix of SLCP species emissions, for different seasons and regions independently. Based on these RF calculations, the Global Temperature change Potential metric for a time horizon of 20 years $\left(\mathrm{GTP}_{20}\right)$ was calculated for each SLCP emission type. This climate metric was then used in an integrated assessment model to identify all emission mitigation measures with a beneficial air quality and short-term (20-year) climate impact. These measures together defined a SLCP mitigation (MIT) scenario. Compared to CLE, the MIT scenario would reduce global methane $\left(\mathrm{CH}_{4}\right)$ and black carbon (BC) emissions by about 50 and $80 \%$, respectively. For $\mathrm{CH}_{4}$, measures on shale gas production, waste management and coal mines were most important. For non- $\mathrm{CH}_{4} \mathrm{SLCPs}$, elimination of high-emitting vehicles and wick lamps, as well as reducing emissions from gas flaring, coal and biomass stoves, agricultural waste, solvents and diesel engines were most important. These measures lead to large reductions in calculated surface concentrations of ozone and particulate matter. We estimate that in the EU, the loss of statistical life expectancy due to air pollution was 7.5 months in 2010 , which will be reduced to 5.2 months by 2030 in the CLE scenario. The MIT scenario would reduce this value by another 0.9 to 4.3 months. Substantially larger reductions due to the mitigation are found for China (1.8 months) and India (11-12 months). The climate metrics cannot fully quantify the climate response. Therefore, a second research path was taken. Transient climate ensemble simulations with the four ESMs were run for the CLE and MIT scenarios, to determine the climate impacts of the mitigation. In these simulations, the CLE scenario resulted in a surface temperature increase of $0.70 \pm 0.14 \mathrm{~K}$ between the years 2006 and 2050. For the decade 2041-2050, the warming was reduced by $0.22 \pm 0.07 \mathrm{~K}$ in the MIT scenario, and this result was in almost exact agreement with the response calculated based on the emission metrics (reduced warming of $0.22 \pm 0.09 \mathrm{~K}$ ). The metrics calculations suggest that non- $\mathrm{CH}_{4}$ SLCPs contribute $\sim 22 \%$ to this response and $\mathrm{CH}_{4} 78 \%$. This could not be fully confirmed by the transient simulations, which attributed about $90 \%$ of the temperature response to $\mathrm{CH}_{4}$ reductions. Attribution of the observed temperature response to non- $\mathrm{CH}_{4} \mathrm{SLCP}$ emission reductions and $\mathrm{BC}$ specifically is hampered in the transient simulations by small forcing and co-emitted species of the emission basket chosen. Nevertheless, an important conclusion is that our mitigation basket as a whole would lead to clear benefits for both air quality and climate. The climate response from BC reductions in our study is smaller than reported previously, possibly because our study is one of the first to use fully coupled climate models, where unforced variability and sea ice responses cause relatively strong temperature fluctuations that may counteract (and, thus, mask) the impacts of small emission reductions. The temperature responses to the mitigation were generally stronger over the continents than over the oceans, and with a warming reduction of $0.44 \mathrm{~K}(0.39$ $0.49) \mathrm{K}$ the largest over the Arctic. Our calculations suggest particularly beneficial climate responses in southern Europe, where surface warming was reduced by about $0.3 \mathrm{~K}$ and precipitation rates were increased by about $15(6-21) \mathrm{mm} \mathrm{yr}^{-1}$ (more than $4 \%$ of total precipitation) from spring to autumn. Thus, the mitigation could help to alleviate expected future drought and water shortages in the Mediterranean area. We also report other important results of the ECLIPSE project.

\section{Introduction}

The United Nations Framework Convention on Climate Change (UNFCCC) requires climate policies to "be costeffective so as to ensure global benefits at the lowest possible cost" and that "policies and measures should ... be comprehensive ... [and] ... cover all relevant sources, sinks and reservoirs". This was made operational by the Kyoto Protocol, which sets limits on emissions of six different greenhouse gases (GHGs), or groups of GHGs - carbon dioxide $\left(\mathrm{CO}_{2}\right), \mathrm{CH}_{4}$, nitrous oxide $\left(\mathrm{N}_{2} \mathrm{O}\right)$, perfluorocarbons (PFCs), hydrofluorocarbons (HFCs) and sulfur hexafluoride $\left(\mathrm{SF}_{6}\right)$. Collectively these are often known as "the Kyoto gases" or the "Kyoto basket"1. $\mathrm{CO}_{2}$ is the most important anthropogenic driver of global warming, with additional significant contributions from $\mathrm{CH}_{4}$ and $\mathrm{N}_{2} \mathrm{O}$. However, other anthropogenic emissions capable of causing climate change are not covered by the Kyoto Protocol. Some are covered by other protocols, e.g. emissions of chlorofluorocarbons (CFCs) and hydrochlorofluorocarbons (HCFCs) are regulated by the Montreal Protocol, because of their role in stratospheric ozone $\left(\mathrm{O}_{3}\right)$ depletion. But there are others, notably several short-lived components that give strong contributions to climate change that are excluded from existing climate agreements.

In the present study we investigate climate and air quality impacts of the emissions of $\mathrm{CH}_{4}$, which has a lifetime of about $9 \pm 1$ years (Prather et al., 2012) and a number of much shorter-lived components (atmospheric lifetimes of months or less) which directly or indirectly (via formation of other short-lived species) influence the climate (Myhre et al., 2013a):

- Methane is a greenhouse gas with a radiative efficiency (in $\mathrm{W} \mathrm{m}^{-2} \mathrm{ppbv}^{-1}$ ) roughly 26 times greater than that of $\mathrm{CO}_{2}$ at current concentrations. It is relatively wellmixed in the atmosphere and has both natural and anthropogenic sources. It is also a precursor of $\mathrm{O}_{3}$ and stratospheric water vapour.

\footnotetext{
${ }^{1}$ Note that, formally, only species given values of Global Warming Potentials (GWP) in IPCC's Second Assessment Report were controlled during the first commitment period (2008-2012) of the Kyoto Protocol. The second commitment period (2013-2020), via the Doha Amendment, also includes $\mathrm{NF}_{3}$ in the list of greenhouse gases, and uses GWP values from the IPCC's Fourth Assessment Report. The Doha Amendment is currently not in force, as it awaits ratification by a sufficient number of parties.
} 
- Black carbon (BC, also commonly known as soot), a product of incomplete combustion of fossil fuels and biomass, affects climate via several mechanisms (Bond et al., 2013). It causes warming through absorption of sunlight and by reducing surface albedo when deposited on snow. BC also affects clouds, with a consequent (but highly uncertain) impact on their distribution and radiative properties (Boucher et al., 2013).

- Tropospheric $\mathrm{O}_{3}$ is a greenhouse gas produced by chemical reactions from the emissions of the precursors $\mathrm{CH}_{4}$, carbon monoxide (CO), non- $\mathrm{CH}_{4}$ volatile organic compounds (NMVOCs) and nitrogen oxides $\left(\mathrm{NO}_{x}\right)$. Emissions of these same precursors also impact on hydroxyl radical $(\mathrm{OH})$ concentrations with further impacts especially on $\mathrm{CH}_{4}$.

- Several components have cooling effects on climate, mainly sulfate aerosol formed from sulfur dioxide $\left(\mathrm{SO}_{2}\right)$ and ammonia $\left(\mathrm{NH}_{3}\right)$, nitrate aerosol formed from $\mathrm{NO}_{x}$ and $\mathrm{NH}_{3}$, and organic aerosol (OA) which can be directly emitted or formed from gas-to-particle conversion of NMVOCs. They cause a direct cooling by scattering solar radiation and alter the radiative properties of clouds, very likely leading to further cooling.

We refer to these substances as short-lived climate pollutants (SLCPs) as they also have detrimental impacts on air quality, directly or via formation of secondary pollutants (Kirtman et al., 2013). Notice that we include the precursors of $\mathrm{O}_{3}$ and secondary aerosols in our definition of SLCPs. We also include $\mathrm{CH}_{4}$ in our study even though it is included in the Kyoto Protocol, because of its relatively short lifetime compared to that of $\mathrm{CO}_{2}$ and its importance for air quality via the formation of $\mathrm{O}_{3}$. We do not include HFCs in our definition of SLCPs, as they have no significant impact on air quality and can be regulated from a climate policy perspective alone. For SLCPs, on the other hand, cost-effective environmental policy measures should be designed such that they optimise both the climate and air quality responses (Schmale et al., 2014). In some instances, control of the emissions of a species is expected to reduce future warming and improve air quality at the same time - a "win-win" situation (Anenberg et al., 2012); in others, the control of emissions may be conflicting, in the sense that it could increase warming while improving air quality (or vice versa) - in this case, emission control involves a "trade-off" between the impacts.

The net climate impact since pre-industrial times of all short-lived components other than $\mathrm{CH}_{4}$ together is very likely to be cooling due primarily to sulfate aerosols (Myhre et al., 2013a). Whilst SLCP reductions are clearly beneficial for air quality, elimination of all current non- $\mathrm{CH}_{4}$ SLCP emissions would thus very likely lead to extra warming. Nevertheless, targeted emission reductions of selected SLCPs which cause warming (either directly or via formation of secondary species) have the potential to reduce global warming on a short timescale, as well as improving air quality. They may also reduce the rate of warming (Myhre et al., 2011; Shindell et al., 2012) that is important, for example, for the adaptation of ecosystems to climate change (as recognised by UNFCCC Art. 2) and is expected to accelerate in the near future (Smith et al., 2015). Reducing these selected SLCP emissions might be effective to help avoid (or at least delay) certain undesired impacts of climate change (e.g. rapid sea ice loss in the Arctic; Quinn et al., 2008). At least, optimised SLCP emission reductions could help to reduce the undesired extra climate warming caused by air quality policy measures that often do not consider climate impacts.

There are many studies that explore possibilities and effects of reductions of short-lived components (e.g. Brasseur and Roeckner, 2005; Rypdal et al., 2009a; Kopp and Mauzerall, 2010; Penner et al., 2010; Unger et al., 2010; Shindell et al., 2012; Bond et al., 2013; Bowerman et al., 2013; Rogelj et al., 2014). Given the interest from policymakers in the abatement of SLCPs, an urgent challenge is to determine the exact climate impacts of the different species involved (e.g. Penner et al., 2010). BC has received particular attention as a component for which a specific emission reduction might have an immediate climate benefit (e.g. Bond and Sun, 2005; Boucher and Reddy, 2008; Grieshop et al., 2009; Rypdal et al., 2009b; Berntsen et al., 2010; Bond et al., 2013).

For designing a successful SLCP emission abatement strategy, the key $\mathrm{CH}_{4}$ sources are relatively straightforward to deal with because their emission profile is dominated by $\mathrm{CH}_{4}$ (e.g. venting of natural gas, rice paddies). Combustion sources, however, emit a mix of many different SLCPs (e.g. $\mathrm{BC}, \mathrm{OA}, \mathrm{NO}_{x}, \mathrm{SO}_{2}$ ) as well as $\mathrm{CO}_{2}$. This makes it difficult to reduce the emissions of warming agents (e.g. BC) alone, as their control often also leads to removal of co-emitted cooling agents (e.g. $\mathrm{OA}, \mathrm{SO}_{2}$ ). To achieve a climate benefit, abatement strategies will be most effective if they target sources with a high fraction of warming species in their emissions (e.g. diesel vehicles) (Unger et al., 2010).

\subsection{Climate effects of SLCPs}

There are several distinct issues that have to be addressed in considering the impact of any proposed SLCP abatement strategy. First, there are large uncertainties in estimates of the climate effects of SLCPs (see e.g. Myhre et al., 2013a) and thus also in the effects of emission reductions. These apply particularly to the impact of aerosols on cloud properties (e.g. Quaas et al., 2009; Boucher et al., 2013), but there are also difficulties in evaluating direct radiative effects of aerosols.

Second, the climate impact of short-lived components, even when averaged globally, can depend strongly on location and time (e.g. summer vs. winter) of emissions (Fuglestvedt et al., 1999; Wild et al., 2001; Berntsen et al., 2005, 2006; Koch et al., 2007; Naik et al., 2005; Reddy and Boucher, 2007; Shindell and Faluvegi, 2009). For wellmixed gases (e.g. Kyoto gases), a single globally valid value 
of Global Warming Potentials (GWP; see Sect. 1.2 for more details) can be calculated for a chosen time horizon, and then used to give the so-called " $\mathrm{CO}_{2}$-equivalent" emissions of a gas. By contrast, for the non- $\mathrm{CH}_{4}$ SLCPs, the GWP depends significantly on when and where the emission occurs. Not only does this complicate the calculation of GWPs, but also it introduces an additional dimension into the framing of climate policy. For instance, the importance of location for $\mathrm{BC}$ emissions has received much attention in this context (Ramanathan and Carmichael, 2008; Shindell and Faluvegi, 2009).

Third, inhomogeneity in the climate response to radiative forcing (RF) is important for SLCPs. The geographical pattern of RF due to the non- $\mathrm{CH}_{4}$ SLCPs is generally concentrated close to the source of emission, and hence is quite distinct from the global-scale forcing due to the Kyoto gases. The extent to which these heterogeneous forcing patterns will trigger different climate responses compared to well-mixed gases is an unresolved scientific issue, even though the climate response generally occurs on larger spatial scales (but mainly in the hemisphere where the forcing takes place; Joshi et al., 2003; Shindell et al., 2010) than the forcing itself. One example of the issue of inhomogeneity of response concerns the effects of absorption of solar radiation by $\mathrm{BC}$ in the Arctic atmosphere. Flanner (2013) has shown that in the Arctic BC located at low altitudes causes a strong local surface warming, but BC located at higher altitudes causes a surface cooling, which is due to the reduced solar radiation reaching the surface. Another important example is emissions of $\mathrm{NO}_{x}$ as these lead to a shorter-lived (and hence more localised) positive $\mathrm{RF}$ due to increases in $\mathrm{O}_{3}$ and a longer-lived (and hence more global) negative RF due to the increased rate of destruction of $\mathrm{CH}_{4}$. This means that metrics based on global-mean quantities may be poorly representative of the local impacts of an emission as the response depends on both region and timescale (Shine et al., 2005; Lund et al., 2012).

Fourth, SLCPs may have other effects on climate that go beyond global-mean temperature (Andrews et al., 2010; Kvalevåg et al., 2013) such as through changes in the hydrological cycle (Gedney et al., 2014) and in the atmospheric circulation. For example, in south-east Europe there are indications that changes in the radiation budget through direct and indirect effects of aerosols have caused circulation, precipitation and evaporation changes (Lelieveld et al., 2002; Tragou and Lascaratos, 2003). Thus, even a cooling component may cause unwanted climate impacts (Shindell, 2015).

Finally, there are important interdependencies between SLCPs and long-term climate change. The climate (and air quality) impacts of SLCPs depend on the atmosphere into which they are emitted - future changes in temperature, humidity, cloud amount, surface albedo, circulation and atmospheric composition are likely to change these impacts (Isaksen et al., 2009). Acting in the other direction, changes in SLCP emissions can impact vegetation via changes in air quality (Sitch et al., 2007; Collins et al., 2010), nutrient depo- sition (Mahowald, 2011; Wang et al., 2015) or photosynthetic active radiation (Mercado et al., 2009), thereby altering the terrestrial carbon budget and hence future $\mathrm{CO}_{2}$ concentrations and thus giving the SLCPs a much longer term impact.

Taking the above points into account, the short lifetimes and regional dependence of the climate impact of SLCP emissions make these species fundamentally different to the long-lived GHGs regulated under the Kyoto Protocol and these impacts and metric values are much more uncertain (Myhre et al., 2013a). Furthermore, cooling aerosols may have partly compensated the warming due to well-mixed greenhouse gases in the past, and this masking effect must be considered when determining the sensitivity of the climate system directly from observations (Knutti and Hegerl, 2008; Skeie et al., 2014). This also reduces our ability to calculate future global warming (e.g. Andreae et al., 2005; Meinshausen et al., 2009; Penner et al., 2010). Thus, there is an urgent need to understand and quantify the role that these components may play in international efforts to reduce global warming (Jackson, 2009; Berntsen et al., 2010; Arneth et al., 2009; Rypdal et al., 2009b; Molina et al., 2009; Unger et al., 2010).

\subsection{Climate metrics to characterise the effect of SLCPs}

The Kyoto Protocol to the UNFCCC is a multi-gas climate treaty that required a method to place emissions of different gases on a common scale. It adopted the GWP with a 100year time horizon, $\mathrm{GWP}_{100}$, from the IPCC (Intergovernmental Panel on Climate Change) Second Assessment Report as a metric in order to derive so-called $\mathrm{CO}_{2}$-equivalents for non- $\mathrm{CO}_{2}$ gas emissions. The GWP has since then been widely used in implementing the Kyoto Protocol, and for other purposes. However, it was not designed with a particular climate policy in mind, and as a result, GWP may not be the best choice for all particular policy objectives (e.g. Tanaka et al., 2009; Fuglestvedt et al., 2010; Myhre et al., 2013a; Pierrehumbert, 2014).

The GWP gives the RF due to a pulse emission of a gas or aerosol, integrated over some time horizon, relative to that of $\mathrm{CO}_{2}$. The choice of time horizon has a significant impact on the metric value of an emission (e.g. Skodvin and Fuglestvedt, 1997; Shine, 2009; Fuglestvedt et al., 2010; Aamaas et al., 2013) and is a value-laden choice. The time-integrated nature of the GWP means that it retains the memory of short-lived emissions even at long-time horizons, when their forcing and most of the response have subsided.

Several alternatives to the GWP have been proposed and of these, the Global Temperature change Potential (GTP) (Shine et al., 2005, 2007; Fuglestvedt et al., 2010) has attracted most attention (e.g. Reisinger et al., 2010; Boucher and Reddy, 2008; Gillett and Matthews, 2010; Collins et al., 2013). The GTP gives the global-mean surface temperature change some time after a pulse emission, relative to that of $\mathrm{CO}_{2}$. In contrast to the GWP, it uses temperature as the indicator and is 
an "end point", rather than an "integrative", metric. Therefore, it does not retain the memory of short-lived emissions in the same way as the GWP. Difficulties with the GTP include its dependence on the climate sensitivity and on the method of incorporating the ocean's thermal response (Shine et al., 2007; Fuglestvedt et al., 2010; Olivié and Peters, 2013).

The GTP may be more appropriate to target-based climate policies (UNEP/WMO, 2011) where the aim is to keep temperature change below some given limit, such as the $2{ }^{\circ} \mathrm{C}$ limit in the UNFCCC's Copenhagen Accord. The choice of time horizon is then no longer so arbitrary, but is linked to the time at which, for example, $2^{\circ} \mathrm{C}$ is likely to be reached. This use of the GTP (Shine et al., 2007; Berntsen et al., 2010; Tanaka et al., 2013) mimics the behaviour of more complex (but less transparent) metrics based on integrated assessment models (Manne and Richels, 2001).

In its 5th Assessment Report, the IPCC assessed scientific aspects of climate metrics and their applicability in policy making. It was emphasised that the most appropriate metric and time horizon will depend on which aspects of climate change are considered most important to a particular application. The assessment also pointed out that there are limitations and inconsistencies related to the treatment of indirect effects and feedbacks (e.g. climate-carbon cycle feedbacks) in climate metrics. In this study, we have adopted $\mathrm{GTP}_{20}$, the GTP over a 20-year time horizon, as our key metric, after careful consideration of alternatives (see Sect. 3.4).

\subsection{Air quality impacts of SLCPs}

The impact of SLCPs on air quality occurs at both the local and regional scale. While local emissions contribute to episodes of high pollution levels which can cause acute health effects, the long-range transport of air pollutants or their precursors even over intercontinental distances (e.g. Stohl and Trickl, 1999; Dentener et al., 2010) can increase the background concentrations upon which pollution episodes are superimposed. This is also important because there is increasing evidence of harmful effects of long-term exposure to particulate matter (PM), $\mathrm{O}_{3}$, deposited acidifying compounds and nitrogen to human health and vegetation (Anenberg et al., 2012). Thus, the impact of SLCPs on air quality is complex and requires quantification on local to global scales. At an international level, these aspects, including emission regulation, are covered by the UNECE Convention on Long-Range Transboundary Air Pollution (CLRTAP) and its protocols including the Gothenburg Protocol and its amendments.

The International Agency for Research on Cancer classified outdoor air pollution as carcinogenic to humans with sufficient evidence that it causes lung cancer. A positive association with an increased risk of bladder cancer was also demonstrated. It has been estimated that air pollution caused 223000 deaths from lung cancer worldwide in 2010 (Anenberg et al., 2012; Lim et al., 2012). Air quality guidelines for various substances published by different agencies are listed in Table 1.

Ozone and PM are the most problematic air pollutants with regard to effects on human health (EEA, 2013). Ozone can, through impairment of lung function, lead to premature deaths and increased hospitalisation (West et al., 2006). PM was classified as carcinogenic to humans (IARC, 2015; Grosse, 2013). It is estimated, for instance, that an increase of $10 \mu \mathrm{g} \mathrm{m}^{-3}$ in the concentrations of $\mathrm{PM}_{10}$ (PM with diameter smaller than $10 \mu \mathrm{m}$ ) will increase cardiopulmonary mortality by $9 \%$ (Pope III et al., 1995). Different aerosol types are considered when assessing climate impacts, whereas air quality legislation is based on the concept of total mass concentrations of particulate matter - either as $\mathrm{PM}_{2.5}$ or $\mathrm{PM}_{10}$. It is, however, likely that human health impacts also depend on PM composition. For instance, according to the World Health Organization (WHO), epidemiological evidence indicates an association of daily variation in BC concentrations with short and long-term adverse health effects such as cardiovascular mortality, and cardiopulmonary hospital admissions. Additionally, BC was classified as possibly carcinogenic to humans (Group 2B) (WHO, 2012). However, concentrationresponse functions for individual $\mathrm{PM}$ components still need to be established. Thus, neither BC nor ultrafine particles are currently covered specifically by EU guidelines (WHO, 2013).

\section{Scope and overall concept}

The purpose of this paper is to present a summary of the work done within the European Union's Seventh Framework Programme project ECLIPSE (Evaluating the Climate and Air Quality Impacts of Short-Lived Pollutants). ECLIPSE had a unique systematic concept for designing a realistic and effective SLCP mitigation scenario and quantifying its climate and air quality impacts, which is schematically shown in Fig. 1. Other papers describe particular aspects of the ECLIPSE work in more detail, while we here present key ECLIPSE results in the context of this overarching strategy and overall conclusions of the project.

The first step in ECLIPSE was to create a new set of global baseline emissions for the recent past and future (see Sect. 3.1, top of Fig. 1). These emission data were used for present-day reference simulations with Earth system models (ESMs) and chemistry transport models (CTMs). The model simulations were compared extensively with a variety of global ground-based and satellite observational data sets, in particular in three target areas (China, Europe and the Arctic; see Sect. 3.2) to evaluate their capabilities to simulate SLCP concentrations.

To study the climate impacts of SLCPs, ECLIPSE followed two paths of research. The first path (the outer part of the spiral in Fig. 1) calculated RF values for a large matrix of SLCP species emissions, for different seasons and regions in- 
Table 1. Air quality standards for Europe (European Union reference values), WHO air quality guidelines (AQG), US-EPA National Ambient Air Quality Standards (NAAQS) and the Environmental Quality Standards (EQS) and guideline values for air pollutants in Japan. Values in brackets give time period for which the guideline is defined.

\begin{tabular}{|c|c|c|c|c|}
\hline Pollutants & EU reference levels ${ }^{\mathrm{a}}$ & WHO AQG ${ }^{b}$ & USEPA NAAQS $^{c}$ & Japan EQS ${ }^{\mathrm{d}}$ \\
\hline $\mathrm{PM}_{2.5}$ & $20 \mu \mathrm{g} \mathrm{m}^{-3}$ (year) & $10 \mu \mathrm{g} \mathrm{m}^{-3}$ (year) & $12 \mu \mathrm{g} \mathrm{m}^{-3}$ (year) & $15 \mu \mathrm{g} \mathrm{m}^{-3}$ (year) \\
\hline $\mathrm{PM}_{10}$ & $40 \mu \mathrm{g} \mathrm{m}^{-3}$ (day) & $20 \mu \mathrm{g} \mathrm{m}^{-3}$ (year) & $150 \mu \mathrm{g} \mathrm{m}^{-3}$ (day) & $100 \mu \mathrm{g} \mathrm{m}^{-3}\left(\right.$ day, $\left.\mathrm{SPM}^{\mathrm{e}}\right)$ \\
\hline $\mathrm{O}_{3}$ & $120 \mu \mathrm{g} \mathrm{m}^{-3}(8 \mathrm{~h})$ & $100 \mu \mathrm{g} \mathrm{m}^{-3}(8 \mathrm{~h})$ & $0.075 \mathrm{ppm}(8 \mathrm{~h})$ & $118 \mu \mathrm{g} \mathrm{m}^{-3}\left(1 \mathrm{~h}^{\mathrm{f}}\right)$ \\
\hline $\mathrm{NO}_{2}$ & $40 \mu \mathrm{g} \mathrm{m}^{-3}$ (year) & $40 \mu \mathrm{g} \mathrm{m}^{-3}$ (year) & 53 ppb (year) & $75-113 \mu \mathrm{g} \mathrm{m}^{-3}(1 \mathrm{~h})$ \\
\hline $\mathrm{SO}_{2}$ & $125 \mu \mathrm{g} \mathrm{m}^{-3}$ (day) & $20 \mu \mathrm{g} \mathrm{m}^{-3}$ (day) & $75 \mathrm{ppb}(1 \mathrm{~h})$ & $105 \mu \mathrm{g} \mathrm{m}^{-3}$ (1 day) \\
\hline $\mathrm{CO}$ & $10 \mathrm{mg} \mathrm{m}^{-3}(8 \mathrm{~h})$ & $10 \mathrm{mg} \mathrm{m}^{-3}(8 \mathrm{~h})$ & 9 ppm $(8 \mathrm{~h})$ & $10 \mathrm{ppm}(1 \mathrm{~h})$ \\
\hline
\end{tabular}

${ }^{a}$ EEA (2013), Indicator CSI 004; ${ }^{\text {b }}$ WHO Air Quality Guidelines (WHO, 2006); ${ }^{\mathrm{c}}$ US-EPA National Ambient Air Quality Standards (http://www.epa.gov/air/criteria.html\#3, last access: 16 April 2014). ${ }^{\mathrm{d}}$ Environmental Quality Standards (EQS) and guideline values for air pollutants in Japan (Kawamoto et al., 2011). ${ }^{\text {e }} 100 \%$ efficiency cut-off at $10 \mu \mathrm{m}$ while $\mathrm{PM}_{10}$ is defined as $50 \%$ efficiency cut-off at $10 \mu \mathrm{m}$ aerodynamic diameter (Kawamoto et al., 2011). ${ }^{\mathrm{f}}$ Photochemical oxidants $\left(\mathrm{O}_{x}\right)$ (Kawamoto et al., 2011).

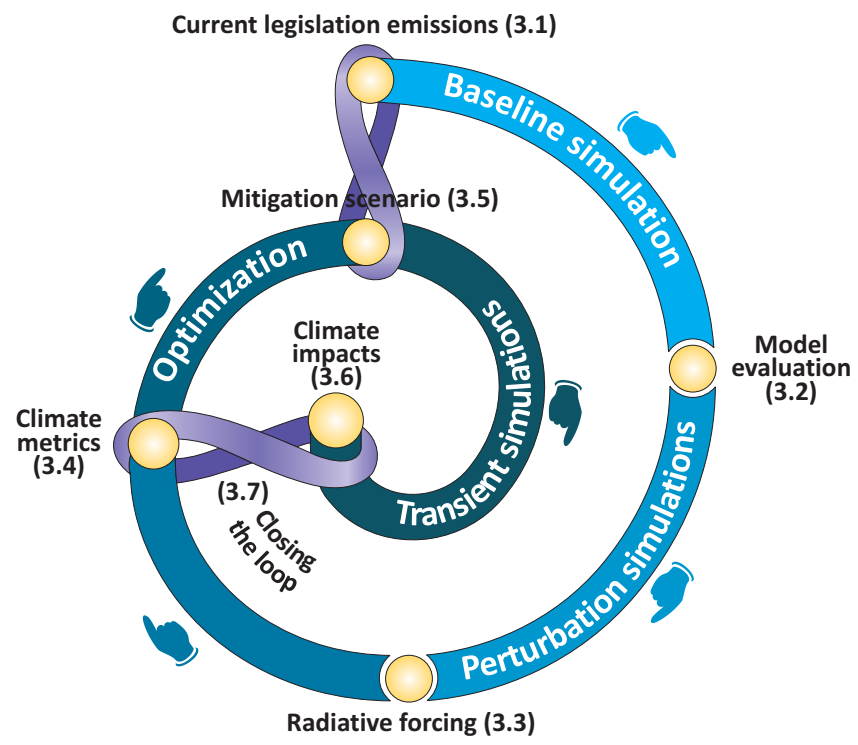

Figure 1. Schematic of the ECLIPSE overall methodology. Numbers in brackets correspond to section numbers in this paper.

dependently by changing the emissions of one species from one region and one season at a time (see Sect. 3.3). Based on these RF calculations, suitable metrics were chosen to allow the estimation of the climate impact of particular SLCP emissions over different time horizons (see Sect. 3.4).

These metrics were then used to generate an SLCP mitigation scenario to minimise climate impacts that could be contrasted with the current legislation scenario (see the top of Fig. 1). For this, the region-, season- and species-specific matrix of climate impact (as defined by the chosen metric) was used as an input to an integrated assessment model. All region-, season- and sector-specific emission mitigation measures with a beneficial air quality impact were then evaluated according to their expected climate benefit. Notice here that emission measures typically affect several SLCP species. For every mitigation measure, the emission reduction of ev- ery SLCP species was therefore weighted with the chosen climate metric and summed over all emitted SLCP species. Finally, all measures with beneficial air quality and climate impacts were collected in a basket defining the SLCP mitigation scenario (see Sect. 3.5).

The metrics, however, cannot fully quantify the climate response, due to the underlying simplifying assumptions, including linearity, the need to specify particular time horizons and, most importantly, the focus on one single aspect of climate change (global-mean temperature for the chosen GTP metric). Therefore, a second research path (the inner part of the spiral in Fig. 1) was taken to determine the climate response for a set of emission reductions for individual SLCP species, using a small ensemble of four advanced ESMs. Furthermore, transient climate ensemble simulations with these ESMs were run for the baseline and emission mitigation scenarios, to calculate the transient climate and air quality impacts of the mitigation scenario (see Sect. 3.6). A comparison between the climate impacts expected from the metrics and those calculated with the transient simulations (left part of the spiral in Fig. 1) closed the loop between the first and the second research path and allowed for the evaluation of the consistency of both approaches (see Sect. 3.7).

In ECLIPSE, we used multi-model ensemble results wherever possible, as these are more robust than results from an individual model. However, certain calculations could only be performed by a single model and are, thus, presented as such.

\section{Results}

\subsection{The ECLIPSE emissions}

The ECLIPSE emission data set was created with the GAINS (Greenhouse gas-Air pollution Interactions and Synergies; http://www.iiasa.ac.at/web/home/research/ researchPrograms/GAINS.en.html) model (Amann et al., 2011), which provides emissions of long-lived greenhouse 
gases and shorter-lived species in a consistent framework. The GAINS model holds essential information about key sources of emissions, environmental policies and mitigation opportunities for about 160 country regions. The model relies on exogenous projections of energy use, industrial production, and agricultural activity (ECLIPSE scenarios draw on IEA, 2012, for energy and Alexandros and Bruinsma, 2012, for agriculture) for which it distinguishes all key emission sources and control measures. More than 2000 technologies to control air pollutant emissions and at least 500 options to control GHG emissions are included.

Improvements in the emission model were made especially for China (Zhao et al., 2013; Wang et al., 2014), where large changes have occurred recently, as well as for Europe where results of the consultation process during the development of scenarios for the review of the EU National Emission Ceilings Directive (Amann and Wagner, 2014) were used. Furthermore, several sources like brick making, oil and gas production, non-ferrous metals and international shipping were reviewed and updated. Finally, a number of previously unaccounted sources were added or specifically distinguished in the model, e.g. wick lamps, diesel generators and high-emitting vehicles. The global $\mathrm{SO}_{2}$ inventory used for IPCC's 5th Assessment Report (Klimont et al., 2013) was also developed during ECLIPSE.

All emission data were gridded consistently to a resolution of $0.5^{\circ} \times 0.5^{\circ}$ longitude-latitude. The spatial proxies used in GAINS for gridding are consistent with those applied within the IPCC's Representative Concentration Pathways (RCPs) projections as described in Lamarque et al. (2010) and as further developed within the Global Energy Assessment project (GEA, 2012). They were, however, modified to accommodate more recent year-specific information where available, e.g. on population distribution, open biomass burning, location of oil and gas production, and livestock-specific spatial production patterns (Klimont et al., 2013, 2015b). Emissions were also temporally allocated: monthly distribution was provided for all sources and for the residential heating emissions were based on ambient air temperature (see Stohl et al., 2013).

For the first time in a global emission inventory, emissions from flaring of associated gas in oil production were considered directly, including spatial distribution. For BC, these emissions constitute only about $3 \%$ of the global total. However, owing to emissions in Russia, they constitute about one third of all $\mathrm{BC}$ emissions north of $60^{\circ} \mathrm{N}$ and two thirds of all emissions north of $66^{\circ} \mathrm{N}$. Stohl et al. (2013) found that the gas flaring emissions contribute $42 \%$ of all $\mathrm{BC}$ found in the Arctic near the surface, and this has improved the performance of the ECLIPSE models in the Arctic.

Figure 2 shows global anthropogenic ECLIPSE emissions for three developed scenarios (Klimont et al., 2015a, b):

- Current legislation (CLE) includes current and planned environmental laws, considering known delays and fail- ures up to now but assuming full enforcement in the future.

- No further control (NFC) uses the same assumptions as CLE until 2015 but no further legislation is introduced subsequently, even if currently committed. This leads to higher emissions than in CLE for most pollutants.

- The ECLIPSE SLCP mitigation (MIT) scenario includes all measures with beneficial air quality and climate impact (according to the climate metric; see Sect. 3.4 and 3.5).

Different versions of the ECLIPSE inventory (available on request from http://eclipse.nilu.no; also available from http://www.iiasa.ac.at/web/home/research/ researchPrograms/Global_emissions.html) have been developed and were available at different times for different tasks (Klimont et al., 2015a, b). We describe here the version 5, which was used for the transient climate model simulations (Sect. 3.6). For model evaluation (Sect. 3.2) and climate perturbation simulations in Sect. 3.6, versions 4 and 4 a were used that, for the CLE scenario, were very similar to version 5 (Klimont et al., 2015a, b).

During the past few decades, there was strong growth in $\mathrm{CO}_{2}$ emissions, but the SLCP emissions have followed a different trajectory, at least at the global level. For example, the $\mathrm{SO}_{2}$ emissions have been decreasing since 1990, with a temporary increase between 2000 and 2005 (Klimont et al., 2013), owing to strong policies and drastic reductions in $\mathrm{Eu}-$ rope and North America. The strong development in Asia was offset at the global level by these reductions but in the future, emissions of $\mathrm{SO}_{2}$ grow again in the CLE scenario, primarily due to a strong increase in India (Klimont et al., 2013). In fact, also some other SLCPs (e.g. $\mathrm{NO}_{x}$ ) show signs of a rebound around the years 2020-2025, when most of the existing policies will have been fully introduced (Klimont et al., 2015a, b). This is driven by increasing fossil fuel use and thus coupled to increasing $\mathrm{CO}_{2}$ emissions. In the case of BC, GAINS does not predict further growth in emissions, mostly because current policies to reduce coal use in China for cooking and heating seem to be effective and because of the introduced diesel legislation.

The NFC scenario has higher SLCP emissions than the CLE scenario, showing the importance of actual introduction of already planned policies. However, the NFC scenario still might be optimistic as it actually does not assume any failure or further delays in enforcement of pre-2015 laws. The MIT scenario, which shows deep cuts in the emissions of some species, is the result of a climate-optimised SLCP reduction scenario and is described in Sect. 3.5.

Figure 2 indicates a large spread in possible future emission pathways, which for the air pollutants is larger than anticipated in the RCP scenarios, shown by the grey shading. $\mathrm{RCP}$ scenarios focused on building future emission scenarios 

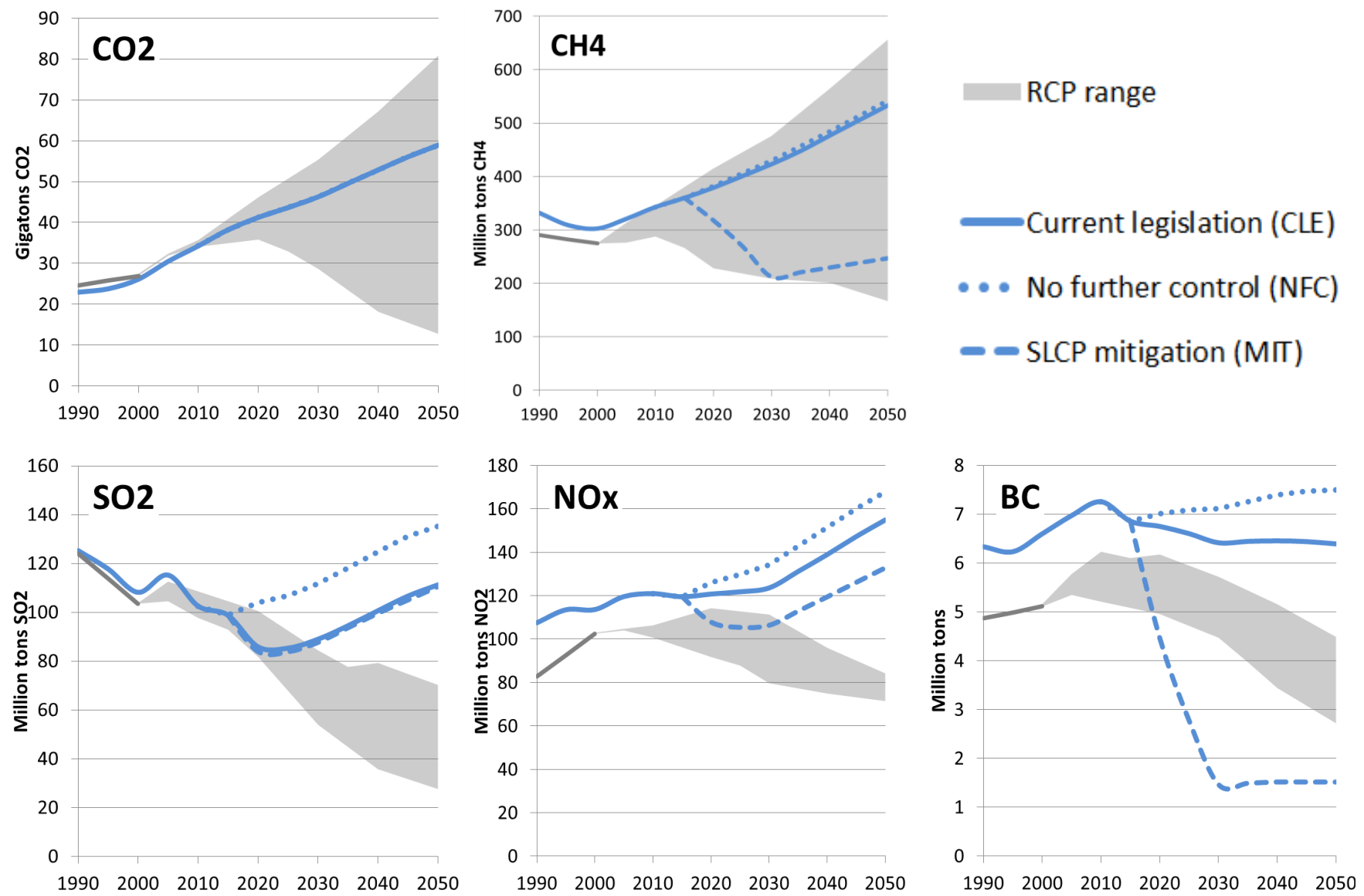

Figure 2. Global annual anthropogenic emissions of $\mathrm{CO}_{2}, \mathrm{CH}_{4}$ and key air pollutants $\left(\mathrm{SO}_{2}, \mathrm{NO}_{x}\right.$ and $\left.\mathrm{BC}\right)$ for the current legislation (CLE), no further controls (NFC) and ECLIPSE SLCP mitigation scenario. Units are Gt for $\mathrm{CO}_{2}$ and Mt for the SLCPs. Also shown for comparison is the range of the RCP emission scenarios (grey shading).

with different RF from long-lived GHGs while for air pollutants all assumed a very similar path, strongly linked with the economic growth (Amann et al., 2013). Consequently all air pollutant emissions decline strongly towards 2050 in all RCP scenarios. This is not the case for the ECLIPSE emissions, and the spread is larger than the RCP spread despite the fact that all scenarios follow the same energy use projection.

Emissions from international shipping differ between the ECLIPSE emission versions 4 and 5. Version 4a still drew on the work done for the RCP scenarios, while for the version 5 data set, the historical emissions rely on the results of Endresen et al. (2007), with activity data projected with growth rates from IEA (2012). This allowed us to model region-specific regulation, i.e. specifically in the emission control areas, and long-term targets to reduce the sulfur content of fuels. For aviation, the emissions originate from Lee at al. (2009) and are consistent with the RCP scenarios.

Non-agricultural, open biomass burning emissions are not calculated in the GAINS model and, for the model simulations, were therefore taken from the Global Fire Emission Database (GFED), version 3.1 (van der Werf et al.,
2010) for the years 2008 and 2009, and held constant in simulations of future scenarios. Biogenic emissions originate from the MEGAN database (Guenther et al., 2012; http://lar.wsu.edu/megan/).

\subsection{Model evaluation}

Using the ECLIPSE version 4a CLE emissions, simulations were carried out with a range of models. In addition to the four ESMs used in ECLIPSE (HadGEM3, ECHAM6HAM2, NorESM1-M and CESM1/CAM5.2; see Baker et al., 2015a for descriptions of these models), three CTMs and a Lagrangian particle dispersion model were used (see Table 2). All models were run for core periods in 2008 and 2009, when several aircraft campaigns took place in China and the Arctic, but most models simulated the full 20082009 period. Some models were also run for longer periods and were evaluated together with other models. For instance, in a comparison against aircraft measurements, Samset et al. (2014) found that the models systematically overpredict $\mathrm{BC}$ concentrations in the remote troposphere, especially at higher altitudes. They concluded that the BC lifetime in the 
Table 2. Overview of the ECLIPSE models and how they were set up for the years 2008-2009.

\begin{tabular}{|c|c|c|c|c|c|}
\hline Model name & Model type* & Horizontal/vertical resolution & Meteorological fields & $\begin{array}{l}\text { Periods simulated/ out- } \\
\text { put temporal resolution }\end{array}$ & References \\
\hline FLEXPART & LPDM & Meteorological input $1^{\circ} \times 1^{\circ}, 92 \mathrm{~L}$ & $\begin{array}{l}\text { ECMWF operational } \\
\text { analyses }\end{array}$ & $\begin{array}{l}2008-2009 \\
3 \mathrm{~h}\end{array}$ & Stohl et al. $(1998,2005)$ \\
\hline OsloCTM2 & CTM & $2.8^{\circ} \times 2.8^{\circ}, 60 \mathrm{~L}$ & ECMWF IFS forecasts & $\begin{array}{l}2008-2009 \\
3 \mathrm{~h}\end{array}$ & Myhre et al. (2009), Skeie et al. (2011) \\
\hline EMEP & CTM & $1^{\circ} \times 1^{\circ}, 20 \mathrm{~L}$ & ECMWF operational & $2008-2009,24 \mathrm{~h}$ & Simpson et al. (2012) \\
\hline TM4-ECPL & CTM & $2^{\circ} \times 3^{\circ}, 34 \mathrm{~L}$ & ECMWF ERA-interim & $\begin{array}{l}2008-2009 \\
24 \mathrm{~h}\end{array}$ & $\begin{array}{l}\text { Kanakidou et al. (2012), Daskalakis et } \\
\text { al. (2015) }\end{array}$ \\
\hline WRF-CMAQ & $\mathrm{CTM}$ & $50 \mathrm{~km} \times 50 \mathrm{~km}, 23 \mathrm{~L}$ & NCEP & $2008,24 \mathrm{~h}$ & Im et al. (2013) \\
\hline WRF-Chem & CTM & $50 \mathrm{~km} \times 50 \mathrm{~km}, 49 \mathrm{~L}$ & Nudged to FNL & $\begin{array}{l}\text { March-August } 2008 \\
3 \mathrm{~h}\end{array}$ & Grell et al. (2005), Zaveri et al. (2008) \\
\hline NorESM & ESM & $1.9^{\circ} \times 2.5^{\circ}, 26 \mathrm{~L}$ & $\begin{array}{l}\text { Internal, observed } \\
\text { SST prescribed }\end{array}$ & $\begin{array}{l}2008-2009 \\
3 \mathrm{~h}\end{array}$ & $\begin{array}{l}\text { Kirkevåg et al. (2013), Bentsen et } \\
\text { al. (2013) }\end{array}$ \\
\hline ECHAM6-HAM2 & ESM & $1.8^{\circ} \times 1.8^{\circ}, 31 \mathrm{~L}$ & $\begin{array}{l}\text { ECMWF } \\
\text { re-analysis }\end{array}$ & $\begin{array}{l}\text { March-August, } \\
2008,1 \mathrm{~h}\end{array}$ & $\begin{array}{l}\text { Stevens et al. (2013), Zhang et } \\
\text { al. (2012) }\end{array}$ \\
\hline HadGEM3 & ESM & $1.9^{\circ} \times 1.3^{\circ}, 63 \mathrm{~L}$ & ECMWF ERA-interim & $\begin{array}{l}\text { March-June, Novem- } \\
\text { ber 2008, January, May } \\
\text { and November } 2009 \\
2 \mathrm{~h}\end{array}$ & Hewitt et al. (2011), Mann et al. (2010) \\
\hline CESM-CAM4 & ESM & $1.9^{\circ} \times 2.5^{\circ}, 26 \mathrm{~L}$ & Internal & $\begin{array}{l}\text { Was not evaluated for } \\
2008-2009 \text {; only used } \\
\text { for } 2000-2050 \text { simula- } \\
\text { tions }\end{array}$ & Gent et al. (2011) \\
\hline
\end{tabular}

* Chemistry transport model (CTM), Lagrangian particle dispersion model (LPDM), Earth system model (ESM).

models is too long. A follow-up study suggested that the best match to aircraft observations could be achieved with strongly increased $\mathrm{BC}$ emissions and decreased lifetimes (Hodnebrog et al., 2014). Daskalakis et al. (2015) derived changes in the local lifetime of $\mathrm{BC}$ up to $150 \%$ associated with the use of different amounts and spatial distribution of fire emissions in the same chemistry transport model, demonstrating the dependence of BC lifetime on its emissions. Tsigaridis et al. (2014) found systematic underprediction of OA near the surface as well as a large model divergence in the middle and high troposphere. They attributed these discrepancies to missing or underestimated OA sources, the removal parameterisations as well as uncertainties in the temperaturedependent partitioning of secondary OA in the models. As a consequence of these studies, ECLIPSE models were improved in terms of emissions (Klimont et al., 2015a, b), secondary OA formation (Tsigaridis et al., 2014) and removal parameterisations (Samset et al., 2014; Hodnebrog et al., 2014).

The improved ECLIPSE models were evaluated against global data sets such as aerosol optical depth (AOD), finemode AOD and absorption AOD derived from data of the Aeronet sun photometer network, as well as against various measurements of aerosol and gas-phase species (Schulz et al., 2015). Here, we focus on a more detailed regional model evaluation for eastern Asia, Europe and the Arctic using satellite, airborne and ground-based measurements of pollutant gases $\left(\mathrm{CO}, \mathrm{NO}_{2}, \mathrm{O}_{3}\right.$ and $\left.\mathrm{SO}_{2}\right)$ and aerosols (Eckhardt et al., 2015; Quennehen et al., 2015). For eastern Asia in August-September 2008 (Fig. 3, left two columns), data were averaged over three urban and five rural sites. The models have difficulties reproducing the urban concentrations, due to their coarse resolution. However, surprisingly most models overestimated the urban $\mathrm{SO}_{2}$ mixing ratios. This could be related to power plant emissions that are actually occurring outside urban boundaries, being placed into the coarse urban model grid cells. For urban $\mathrm{NO}_{2}$, models deviate less systematically from observations, with both overestimates and underestimates, and the model mean captures the observations. For rural $\mathrm{NO}_{2}$, also the individual models deviate less from the measured concentrations, indicating that the individual model biases for urban $\mathrm{NO}_{2}$ are very likely mainly due to the limited model resolution and not to biases in emissions and/or chemical processes. The measured concentrations of $\mathrm{O}_{3}$ at the rural sites are matched relatively well (agreement within the range of the temporal distribution at individual sites) but $\mathrm{SO}_{2}$ is generally overestimated there as well. The most severe problem at rural sites, however, is a systematic underestimation of $\mathrm{CO}$ mixing ratios, which was attributed to underestimated $\mathrm{CO}$ lifetimes in the models (Quennehen et al., 2015).

A similar comparison was made for Europe with background measurements taken from stations of the European Monitoring and Evaluation Programme (EMEP) (Fig. 3, 

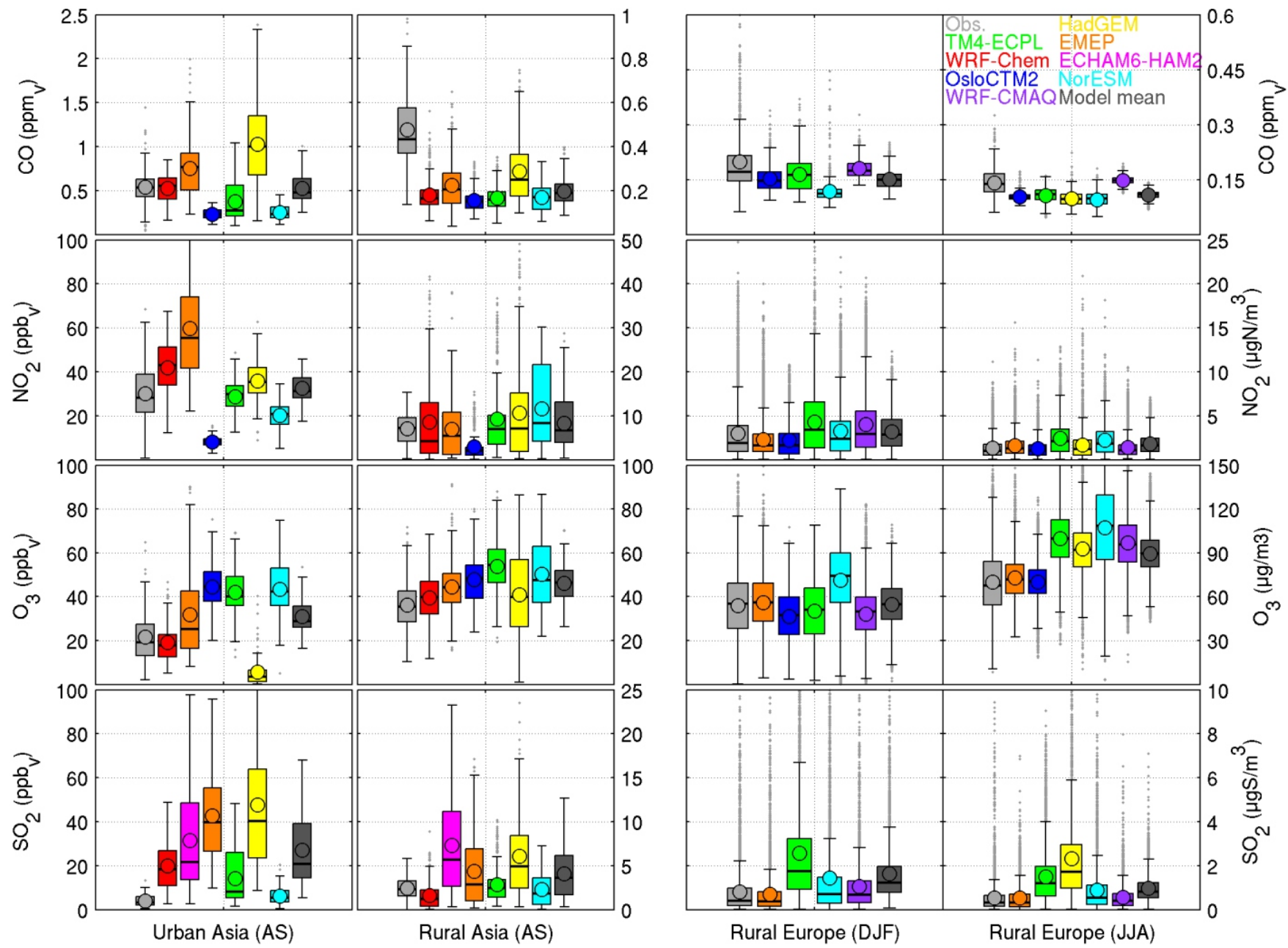

Figure 3. Box and whiskers plots showing the frequency distribution of measured and modelled $\mathrm{CO}, \mathrm{NO}_{2}, \mathrm{O}_{3}$ and $\mathrm{SO}_{2}$ mixing ratios or concentrations representative for background stations in urban and rural areas in East Asia during August and September 2008 (two left panel columns) and for rural background stations in Europe for winter (December-February, DJF) and summer (June-August, JJA) 2008 (two right panel columns). Circles and central lines show the means and the medians, respectively; box edges represent the 25th and the 75th percentiles. For East Asia, results are averaged over several sites: Beijing, Inchon and Seoul for the urban areas, and Gosan, Kunsan, Kangwha, Mokpo and Taean for rural areas. Results for individual sites can be found in Quennehen et al. (2015). For Europe, daily mean observed values are averaged over all stations of the European Monitoring and Evaluation Programme (EMEP) network with available data. Model data are treated like the observations and only the days with available observations are taken into account.

right two columns for winter and summer; see also Schulz et al., 2015). Overall, over Europe the ECLIPSE model mean captures the mean observations with the exception during summer for $\mathrm{CO}$ that is underestimated (as in Asia). Summertime $\mathrm{O}_{3}$ is overestimated by many models at rural locations over Europe and Asia suggesting too much photochemical production downwind of emission regions.

Satellite-derived AOD measurements were reproduced quite well by the models over China and Europe (Fig. 4). Evaluation of individual aerosol components over Asia (Quennehen et al., 2015) shows an overestimation of the ECLIPSE model-mean surface BC in urban China in summer 2008, which is probably due to the short-term mitigation measures taken during the Olympic Games. Over Europe, ECLIPSE models satisfactorily simulate surface BC observations both in winter and summer (Fig. 4). However, problems were identified over India: Gadhavi et al. (2015) found that $\mathrm{BC}$ concentrations are strongly underestimated in southern India even when aerosol removal processes in one model were completely switched off in the region. Furthermore, observed AOD values in northern India are larger than those simulated by all but two of the ECLIPSE models (Fig. 4). This suggests that the emissions of $\mathrm{BC}$ and precursors of other aerosols are underestimated for India in the ECLIPSE emission data set. This could be related to the rapid recent growth of emissions in India (Klimont et al., 2013), which 


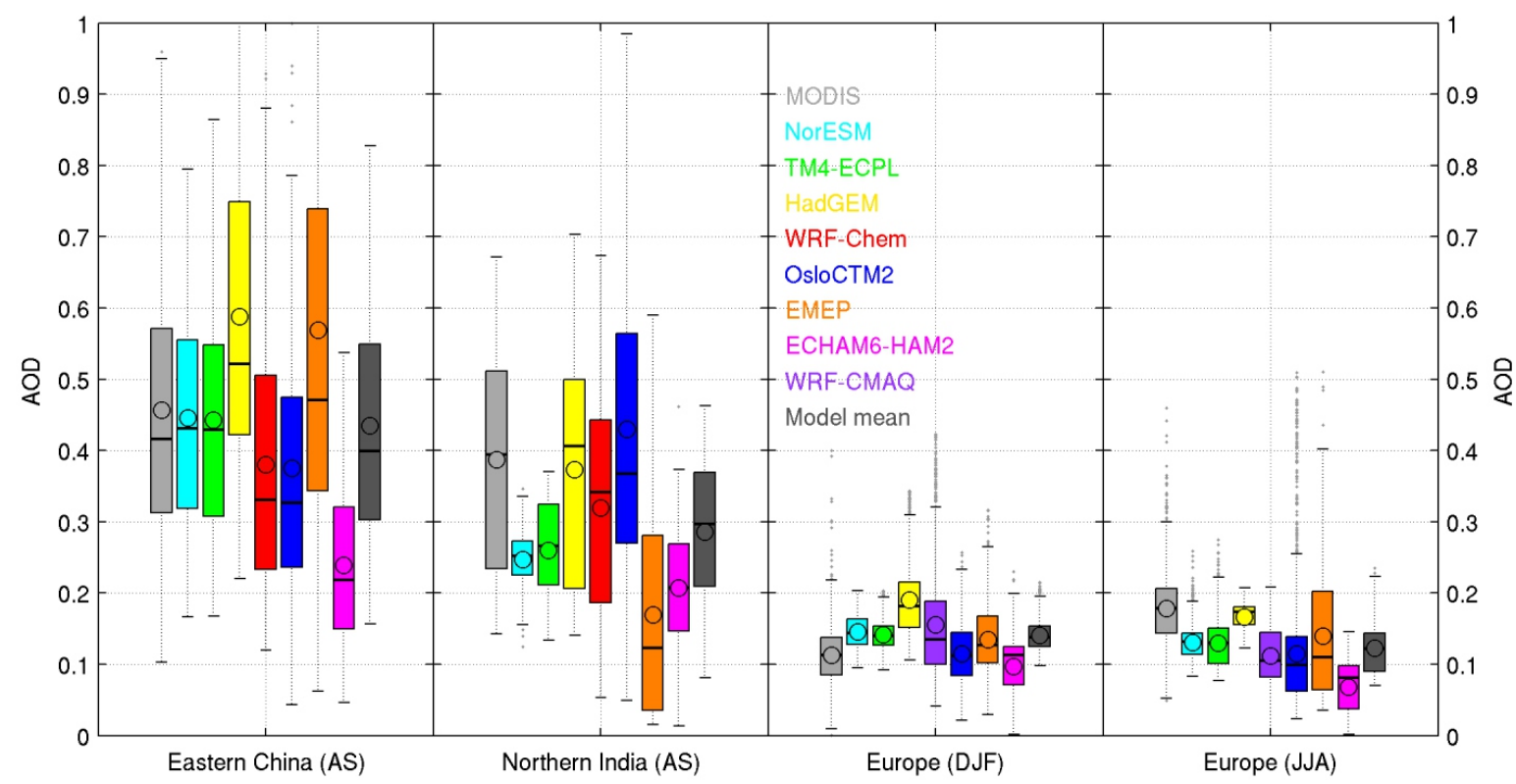

Figure 4. Comparison of satellite-derived (MODIS) and modelled aerosol optical depth (AOD) at wavelengths of $550 \mathrm{~nm}$ over eastern China and northern India (for area definition; see Quennehen et al., 2015) in August-September 2008, and Europe $\left(14.5^{\circ} \mathrm{W}-34.5^{\circ} \mathrm{E}, 35.5-74.5^{\circ} \mathrm{N}\right)$ in winter (December-February, DJF) and summer (June-August, JJA) of 2008. Mean values (circles), medians (central lines), 25th and 75th percentiles (boxes) and range of other data excluding outliers (whiskers) are shown.

may be underestimated in the inventories, as well as with problems capturing the true spatial distribution of emissions in India.

The Arctic was shown previously to be a particularly challenging region for aerosol model simulations (e.g. Shindell et al., 2008). Aerosol loadings in the Arctic are generally much lower than in populated regions and the Arctic encompasses only a small fraction of the Earth. Therefore, impacts of even large relative errors in the modelled aerosol concentrations in the Arctic on global radiative forcing and global climate response are relatively small. Nevertheless, identification of model biases in this remote region is important as it can lead to improved process understanding, especially of the aerosol removal mechanisms. An evaluation of the ECLIPSE models over the Arctic was coordinated with the Arctic Monitoring and Assessment Programme (AMAP, 2015). Comparisons were made for $\mathrm{BC}$ and sulfate for six ground stations and during six aircraft campaigns (Eckhardt et al., 2015). As an example, a comparison of the $\mathrm{BC}$ concentrations simulated by the ECLIPSE models with measured equivalent $\mathrm{BC}$ is shown in Fig. 5 for the stations Zeppelin on Svalbard, Pallas in Finland and Tiksi in Siberia. For Zeppelin, most models clearly underestimate the observed concentrations during winter and spring, whereas for Pallas which is closer to source regions, the models tend to overestimate. In general, the model performance (also at other Arctic sites, not shown) is better than in previous comparisons (e.g. Shindell et al., 2008). However, very large model underestimates were found for Tiksi, from where measurement data have only recently become avail- able. Another ECLIPSE study showed that also the snow $\mathrm{BC}$ concentrations are generally underestimated by models in northern Russia but overestimated elsewhere in the Arctic (Jiao et al., 2014). It is therefore likely that the model underestimates are caused by too low BC emissions in Russia in the ECLIPSE CLE data set. Yttri et al. (2014) attribute this at least partly to an underestimation of residential wood burning, based on levoglucosan measurements made at Zeppelin. Eckhardt et al. (2015) suggested that also $\mathrm{SO}_{2}$ emissions in northern Russia are underestimated. ECLIPSE models participating in the AMAP (2015) assessment also showed a systematic underestimation in CO concentrations in the Arctic and a lack of model skill in simulating reactive nitrogen species important for $\mathrm{O}_{3}$ production.

An important finding of the model-measurement comparisons is that overall the ESMs show a similar performance as the CTMs. This is encouraging for the further use of the ESMs for determining the climate impacts (Sect. 3.6). The comparisons led to some further improvements of the ECLIPSE emissions for version 5, prior to their use for transient climate model simulations. For instance, wick lamps were identified as an important emission source in India, the inclusion of which improved the agreement with the observations in a model sensitivity study (Gadhavi et al., 2015). Other enhancements (e.g. re-gridding of non-ferrous smelter emissions to improve $\mathrm{SO}_{2}$ emissions in Russia as suggested by Eckhardt et al., 2015) came too late for the climate impact studies and were only made in version 5 a. 

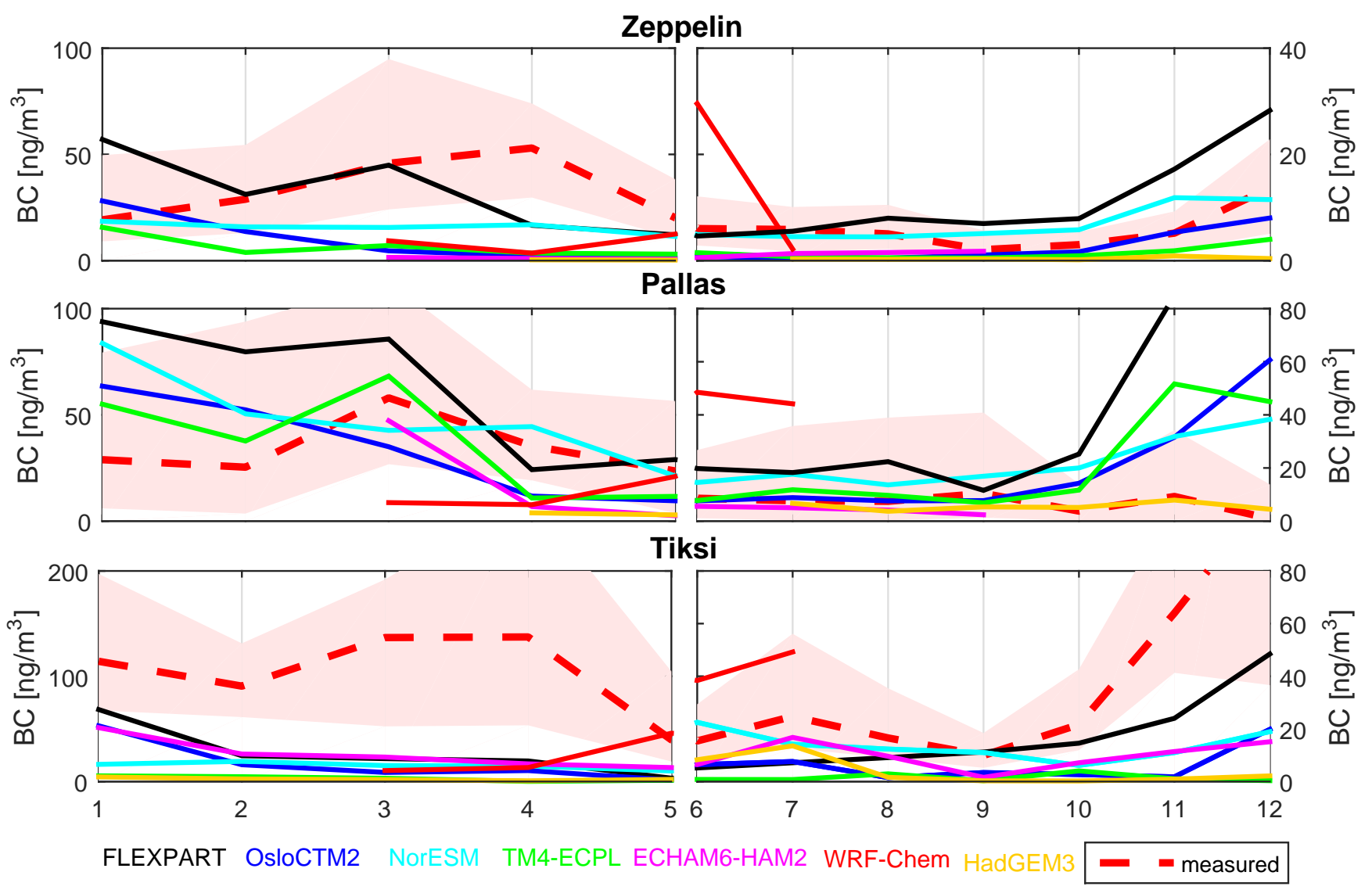

Figure 5. Monthly (month is displayed on the abscissa) median observed and modelled BC concentrations for the stations Zeppelin on Svalbard $\left(11.9^{\circ} \mathrm{E}, 78.9^{\circ} \mathrm{N}\right.$; top), Pallas in Finland $\left(24.12^{\circ} \mathrm{E}, 67.97^{\circ} \mathrm{N}\right.$; middle) and Tiksi in Siberia $\left(128.9^{\circ} \mathrm{E}, 71.6^{\circ} \mathrm{N}\right.$; bottom), for late winter-spring (left column) and summer-autumn (right column) for the years 2008-2009 (for Tiksi, measured values were available only from July 2009 to June 2010). The red dashed lines connect the observed median values, the light red shaded areas span from the 25 th to the 75th percentile of the observations. Modelled median values are shown with lines of different colour according to the legend. Notice that different concentration scales are used for individual panels and also for January-May (axis on left hand side) and June-December (axis on right hand side) periods. Modified from Eckhardt et al. (2015).

Another aspect of model evaluation is to determine the capability of models to reproduce past trends, and this was tested over Europe. Strong reductions of aerosol emissions occurred over Europe since the 1980s due to air quality legislation in western Europe, and since the early 1990s due to economic restructuring in eastern Europe. This emission reduction is manifest, for example, in strongly increasing trends in surface solar radiation ("solar brightening") and visibility (Stjern et al., 2011), but also in a stronger warming trend compared to the earlier period in which aerosol emissions increased (Cherian et al., 2014). The "historical" simulations contributed to the 5th Coupled Model Intercomparison Project (CMIP5; Taylor et al., 2012) using previous versions of the ECLIPSE ESMs were assessed for continental Europe, and compared to observations from the Global Energy Balance Archive (Gilgen et al., 1998) and the Climatic Research Unit (CRU) of the University of East Anglia (CRUTS-3.10, Mitchell and Jones, 2005). The 1960-1980 period shows a strong "solar dimming" (reduction in surface solar radiation) and small warming, since the greenhouse-gasinduced warming is offset by the aerosol forcing. The period 1990-2005, in turn, shows the solar brightening, and a much stronger warming. All three tested models are able to reproduce this strong increase in warming trend to within their uncertainties (Fig. 6), suggesting that the climate response to aerosol changes is captured despite the masking influence of natural climate variability on these trends. However, the absolute amplitude of the trends is not equally well captured by all models, indicating that the skill of the ECLIPSE (and other) ESMs to simulate temperature trends responding to changing aerosol emissions is limited. This is due to both limitations in the models themselves, the emission input, as well as the influence of natural climate variability. 

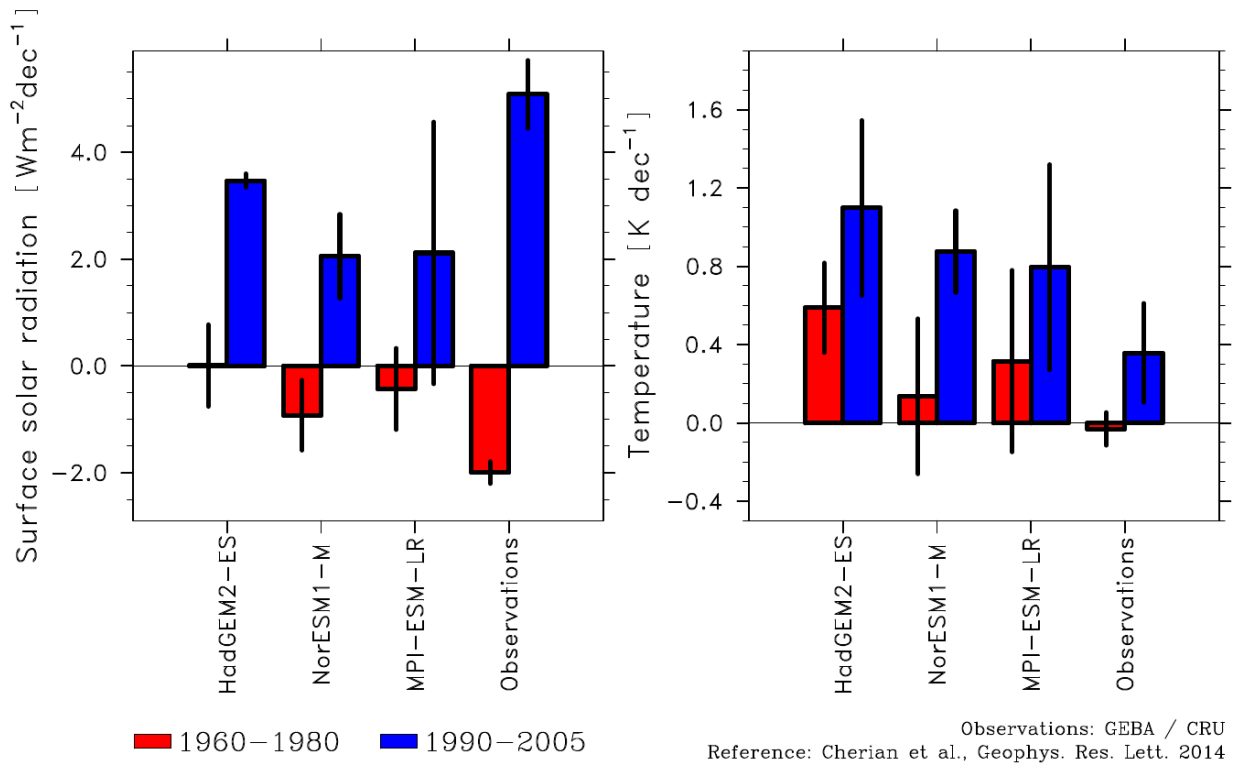

Figure 6. Linear trends in (left) surface solar radiation and (right) near-surface temperature increase per decade over continental Europe from the "historical" simulations in the CMIP5 archive contributed by previous versions of three ECLIPSE ESMs. The period 1960-1980 is shown in red, the period 1990-2005 in blue.

\subsection{Radiative forcing}

To provide input to the metrics needed for designing a mitigation scenario, dedicated model simulations by three ESMs (ECHAM6-HAM2, HadGEM3, NorESM) and a CTM (OsloCTM2) were used to establish a matrix of specific RF (Bellouin et al., 2015) by season and region of emission. Specific RF (SRF) is defined as the RF per unit change in emission rate once the constituents have reached equilibrium and is given in $\mathrm{mW} \mathrm{m}^{-2}\left(\mathrm{Tg} \mathrm{yr}^{-1}\right)^{-1}$. To estimate SRF, the emissions of eight short-lived species (BC, OA, $\mathrm{SO}_{2}, \mathrm{NH}_{3}$, $\mathrm{NO}_{x}, \mathrm{CO}, \mathrm{CH}_{4}$ and NMVOCs) were reduced by $20 \%$ compared to their ECLIPSE baseline. These species cause RF themselves and/or lead to the perturbation of radiative forcers (e.g. $\mathrm{O}_{3}$ ). The regional reductions were made for Europe and China, as well as for the global shipping sector and for a rest-of-the-world region. To account for seasonal differences in SRF, separate reductions were applied for May-October and November-April. Henceforth, we will refer to these as Northern Hemisphere (NH) "summer" and "winter". Notice that in our case the sign of SRF is opposite to that of RF, because the imposed emission changes are negative. A reduction of a warming species gives negative RF values but positive SRF values. It is important to note that SRF excludes rapid adjustments in the atmosphere, with the exception that $\mathrm{BC}$ semi-direct effects were calculated explicitly, and stratospheric temperature adjustments were included for $\mathrm{O}_{3}$ and $\mathrm{CH}_{4}$.

Models generally agreed on the sign of RF and the ranking of the efficiency of the different emitted species, but disagreed quantitatively (see Bellouin et al., 2015 for details).
The best estimate of a species' RF was considered to be the average of all models, with the model spread indicating its uncertainty. However, not all models have calculated RF for all species or have accounted for all processes. For instance, all models were able to quantify the aerosol direct effect but only three quantified the first indirect effect. For BC aerosols only one model quantified the snow albedo effect and the semi-direct effect explicitly. Therefore, mean RF values were determined by averaging across all available models for each process separately. In most cases, all four models were available for this, but for some processes fewer models had to be used.

Figure 7 shows the resulting SRF for reductions in the emissions of $\mathrm{SO}_{2}, \mathrm{NO}_{x}, \mathrm{CH}_{4}$ and $\mathrm{BC}$ and the processes contributing to the total forcing, for Europe, China and on global average. The globally averaged SRF was obtained by adding $\mathrm{RF}$ for Europe, China and rest of the world, then normalising to global emission change. The SRF values are the largest for $\mathrm{BC}$, but note that global emissions of $\mathrm{BC}$ are smaller than for the other species. In addition, the semi-direct effect of BC potentially offsets a considerable fraction of the aerosol direct RF and RF due to deposition on snow. However, quantifying the semi-direct effect has large uncertainties because internal variability of the climate system masks tropospheric adjustments to $\mathrm{BC}$ perturbations. This means that the sign of total SRF exerted by decreases in BC emissions may be negative, if a weak $\mathrm{BC}$ direct effect is more than compensated by a strong semi-direct effect. Nevertheless, the ECLIPSE BC SRF best estimate of about $50 \mathrm{~mW} \mathrm{~m}^{-2}$ $\left(\mathrm{Tg}[\mathrm{C}] \mathrm{yr}^{-1}\right)^{-1}$ when semi-direct effects are included is not an outlier compared to previous estimates, which range from 

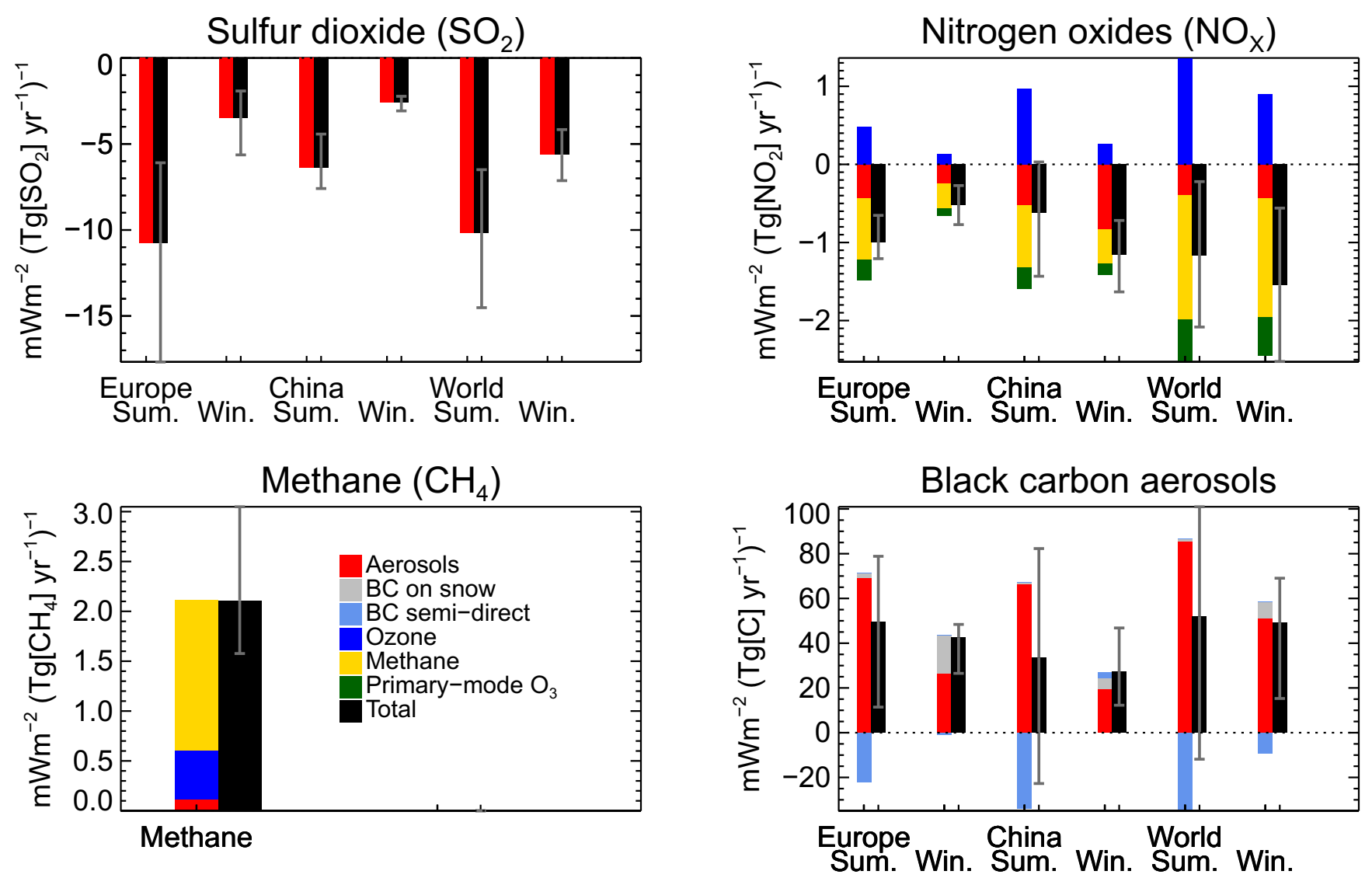

Figure 7. The ECLIPSE estimates of specific radiative forcing (SRF; $\mathrm{mWm}^{-2}$ per $\mathrm{Tg}^{-1}$ of emission rate change) for reductions in the emissions of $\mathrm{SO}_{2}, \mathrm{NO}_{x}, \mathrm{CH}_{4}$, and $\mathrm{BC}$ aerosols in Europe, China and the global average, separately for NH summer (Sum., May-October) and NH winter (Win., November-April). Shown are values averaged over all five models, with the error bars indicating the full range of the model estimates. Colours indicate the contribution of different forcing mechanisms. Notice that for $\mathrm{CH}_{4}$ regionality was not accounted for because, due to its longer lifetime, forcing does not depend on the emission region.

24 to $108 \mathrm{~mW} \mathrm{~m}^{-2}\left(\mathrm{Tg}[\mathrm{C}] \mathrm{yr}^{-1}\right)^{-1}$ according to Table 23 of Bond et al. (2013). Moreover, ECLIPSE simulations indicate that the magnitude of the semi-direct effect is smaller than the direct aerosol effect (Hodnebrog et al., 2014; Samset and Myhre, 2015), in agreement with most, but not all, previous studies (see Table 23 of Bond et al., 2013). Reductions in the emissions of light scattering aerosols such as sulfate stemming from its precursor $\mathrm{SO}_{2}$ induce a negative SRF. The RF values of aerosols are generally larger for summer emissions than for winter emissions because of the stronger insolation. However, there are exceptions to this. For instance, the BC deposition on snow is more effective for winter emissions because of the larger snow extent in winter and spring and partial preservation of deposited BC into spring. Aerosol SRF is also larger in magnitude for Europe than for China, most likely because of different cloud regimes which are differently affected by semi-direct and indirect aerosol effects.

For $\mathrm{NO}_{x}$, SRF is uncertain because decreases in $\mathrm{NO}_{x}$ emissions perturb tropospheric chemistry in two opposite ways, working on different timescales: first, they reduce tro- pospheric $\mathrm{O}_{3}$ concentrations, thus exerting a positive SRF. Second, they increase $\mathrm{CH}_{4}$ concentrations, thus exerting a negative SRF, with an additional $\mathrm{CH}_{4}$-induced change in $\mathrm{O}_{3}$. ECLIPSE accounts for those two pathways, and quantifies a third, whereby reductions in $\mathrm{NO}_{x}$ emissions suppress nitrate aerosol formation and its associated RF. ECLIPSE is therefore able to confirm with confidence the earlier quantification (Myhre et al., 2013a) that $\mathrm{NO}_{x}$ exerts a negative SRF, because the $\mathrm{O}_{3}$ response is not sufficient to offset the combined $\mathrm{CH}_{4}$ and nitrate response. For $\mathrm{CH}_{4}$, ECLIPSE finds a relatively large range of SRF estimates from the models, reflecting the differences in methane lifetime and methane's effects on ozone and aerosols.

The $\mathrm{BC}$ radiative forcing is very uncertain and needs some discussion. When scaled to $100 \% \mathrm{BC}$ reductions and reported annually, ECLIPSE $\mathrm{BC}$ total $\mathrm{RF}$ and its range are $0.28(0.02-0.46) \mathrm{W} \mathrm{m}^{-2}$. Neglecting semi-direct effects, those numbers become $0.41(0.11-0.48) \mathrm{W} \mathrm{m}^{-2}$. These values are at the stronger end of the multi-model ACCMIP (Atmospheric Chemistry and Climate Model Intercompari- 

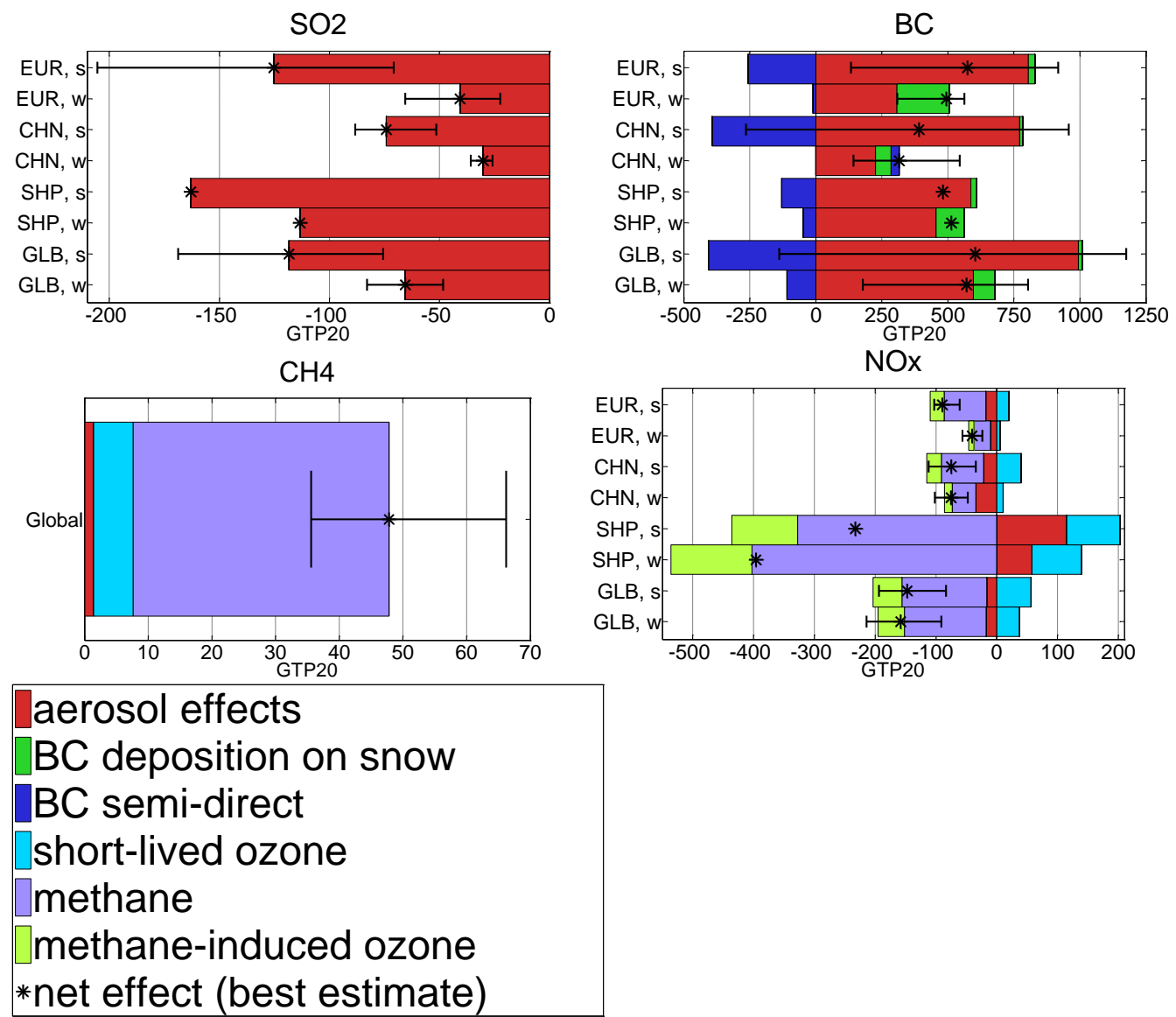

Figure 8. $\mathrm{GTP}_{20}$ values for SLCPs, relative to an equal mass emission of $\mathrm{CO}_{2}$, for all regions and seasons, decomposed by processes and based on the RF values shown in Fig. 7. The regions included are Europe (EUR), China (CHN), global (GLB), and the shipping sector considered separately (SHP), all for both NH summer (s, May-October) and NH winter (w, November-April). Uncertainty bars reflect model spread. Only two models calculated effects of emissions from shipping and there no uncertainty range is given.

son Project) estimate of $0.24 \pm 0.1 \mathrm{~W} \mathrm{~m}^{-2}$ (Shindell et al., 2013) and the AeroCom estimate of $0.18 \pm 0.07 \mathrm{~W} \mathrm{~m}^{-2}$ (Myhre et al., 2013b). In contrast, ECLIPSE estimates are at the middle or weak end of the relatively large estimates that were reported in several recent assessments: $0.45(0.30-0.60) \mathrm{W} \mathrm{m}^{-2}$ in UNEP/WMO (2011), $0.71(0.08-$ $1.27) \mathrm{W} \mathrm{m}^{-2}$ in Bond et al. (2013), and $0.40(0.08-$ $0.8) \mathrm{W} \mathrm{m}^{-2}$ in Boucher et al. (2013). The estimates in UNEP/WMO (2011) are skewed towards higher values by accounting for semi-empirical estimates, which include a brown-carbon contribution, the possibility that BC semidirect forcing is the same sign as direct forcing (even though semi-direct forcing opposes the sign of direct forcing in most models) and assuming a high efficacy of BC deposition forcing. The large observationally constrained estimates of $\mathrm{BC}$ forcing by Bond et al. (2013), which influenced the IPCC estimate (Boucher et al., 2013) are due to strong scaling using Aeronet absorbing AOD measurements. However, these measurements are highly uncertain and probably biased and the resulting high $\mathrm{BC}$ RF values have recently been called into question by several studies (Wang et al., 2014; Samset et al., 2014; Wang et al., 2015). There are several reasons for this. First, the scaled models have substantially higher BC abundances globally than supported by BC measurements. Wang et al. (2014) and Samset et al. (2014) argue that BC residence time has to be relatively short to fit observed remote BC concentrations. Furthermore, Wang et al. (2015) showed that the fairly low resolution of global models induces an artificial negative bias when comparing to AERONET stations in Asia. Consequently, in ECLIPSE we have not scaled simulated $\mathrm{RF}$ values for $\mathrm{BC}$ but have used native model results.

\subsection{Climate metrics}

ECLIPSE explored various options for climate metrics. In addition to selecting the most useful metric for designing the mitigation scenario, the project also made conceptual developments. Collins et al. (2013) developed further the application of Regional Temperature change Potential (RTP) presented by Shindell et al. (2012) by accounting for the location of emissions, thereby opening for regionality for both drivers 
and responses. Collins et al. (2013) also expanded the GTP concept by tentatively including the climate-carbon feedback for the non- $\mathrm{CO}_{2}$ gases. So far, this feedback has only been included for the reference gas $\mathrm{CO}_{2}$ which means that GTPs (and GWPs) tend to underestimate the relative effect of non$\mathrm{CO}_{2}$ components (Myhre et al., 2013a). Furthermore, Shine et al. (2015) present a new metric named the Global Precipitation change Potential (GPP), which is designed to gauge the effect of emissions on the global water cycle. Of particular relevance for SLCPs is their demonstration of a strong near-term effect of $\mathrm{CH}_{4}$ on precipitation change and the role of sustained emissions of $\mathrm{BC}$ and sulfate in suppressing precipitation.

Aamaas et al. (2013) investigated several different metrics and showed that emissions of $\mathrm{CO}_{2}$ are important regardless of what metric and time horizon is used, but that the importance of SLCP varies greatly depending on the metric choices made. MacIntosh et al. (2015) considered the errors made when calculating RF and climate metrics from multimodel ensembles in different ways. They showed that the mean metric values are relatively robust but the estimation of uncertainties is very dependent on the methodology adopted. Finally, Lund et al. (2014a) applied climate metrics to quantify the climate impacts of BC and co-emitted SLCPs from on-road diesel vehicles, and Lund et al. (2014b) considered the special case of a fuel switch from diesel to biodiesel.

As explained in Sect. 3.5, climate metrics were used in ECLIPSE to identify specific sets of air pollution reduction measures that result in net positive climate effects (i.e. reduced warming), considering the impacts on all co-controlled substances. Based on the RF results shown in Sect. 3.3, Aamaas et al. (2015) calculated regional and seasonal GTP and GWP metrics for the SLCP emissions, for various time horizons, and explored their properties. Of all the explored metrics, the pollution control analysis was carried out for $\mathrm{GWP}_{100}$ and $\mathrm{GTP}_{20}$, as these two metrics showed large differences in their quantifications. It was found, however, that the emerging basket of emission control measures was very similar for both, although the ranking of the potential climate impacts of individual measures was sometimes different, with a larger effect of $\mathrm{CH}_{4}$-related measures for the $\mathrm{GWP}_{100}$ metric (due to the higher value assigned to $\mathrm{CH}_{4}$ by this metric with a longer time horizon).

In the following, we concentrate our analysis on the $\mathrm{GTP}_{20}$ metric, which is shown in Fig. 8 for a pulse emission relative to an equal mass emission of $\mathrm{CO}_{2}$ for a selected number of species. The metric builds on and reflects important aspects of the RF forcing values shown in Fig. 7. For example, for most species $\mathrm{GTP}_{20}$ values for summer are larger than values for winter (see, e.g. results for $\mathrm{SO}_{2}$ ), and values for Europe are larger than values for Asia. While $\mathrm{SO}_{2}$ only has negative values (i.e. reduction of $\mathrm{SO}_{2}$ always leads to warming), the opposite is true for $\mathrm{CH}_{4}$. Figure 8 also shows the contribution from different processes to the total $\mathrm{GTP}_{20}$ metric, and for $\mathrm{BC}$ and $\mathrm{NO}_{x}$ they often have a different sign and their magnitude strongly depends on the emission region and season. While all of this was accounted for in GAINS (see Sect. 3.5), it is clear that this makes the choice of mitigation options more uncertain, and this is further complicated by the fact that $\mathrm{BC}$ and $\mathrm{NO}_{x}$ emissions are always associated with co-emissions of other SLCPs (e.g. OA). The $\mathrm{GTP}_{20}$ metric was also determined for all other SLCPs (not shown).

For the implementation of mitigation measures, a pulse emission metric is not very realistic, as measures are normally introduced gradually, become more effective with time, and are usually maintained indefinitely. Therefore, we also considered versions of the GTP and GWP metrics for sustained emission measures and a linear ramp-up of emission measures over a 15-year time period (Aamaas et al., 2015; see also Boucher and Reddy, 2008). We chose the ramp-up version of the $\mathrm{GTP}_{20}$ metric for designing our mitigation scenario with the GAINS model (see Sect. 3.5), as it most realistically reflects the implementation of mitigation measures. Notice that the ramp-up version of the $\mathrm{GTP}_{20}$ metric can be derived directly from its pulse emission version, by linear combination of emission pulses (see Aamaas et al., 2015, for details). Figure 8 shows the pulse emission version because pulse emissions are building blocks for various versions of the metrics, including the ramp-up version.

To go beyond global-mean temperature, it is also possible to calculate regional surface temperature changes using the RTP concept of Shindell and Faluvegi (2009). This concept maps RF in one given latitude band to the temperature response in several other latitude bands and was adopted by Aamaas et al. (2015). For the mapping, we used the pre-calculated RTP coefficients of Shindell and Faluvegi (2009). Even though the coefficients are likely model dependent, we had to use these values because they are not available from any other model (and specifically not from the ECLIPSE models). The coefficients also seem fairly robust in comparison with the response to historical aerosol forcing in several other models (Shindell, 2012). We made two additions, however, for $\mathrm{BC}$ in the Arctic and $\mathrm{BC}$ on snow using the method of Lund et al. (2014a) with results from Samset et al. (2013) and Flanner (2013). Using the RTP concept and RF calculations from Sect. 3.3 (Bellouin et al., 2015), we calculated absolute regional temperature change potentials (ARTPs) for the set of components, regions and seasons for which ECLIPSE has determined RF values (Fig. 7). Following Collins et al. (2013), the ARTPs were used to estimate transient surface warming using an impulse response function for temperature response from Boucher and Reddy (2008) (as was also used for the GTP calculations). Details of the method and ARTP values will be given in Aamaas et al. (2015) and results of the ARTP calculations will be used in Sect. 3.7 for comparisons with transient ESM runs. 


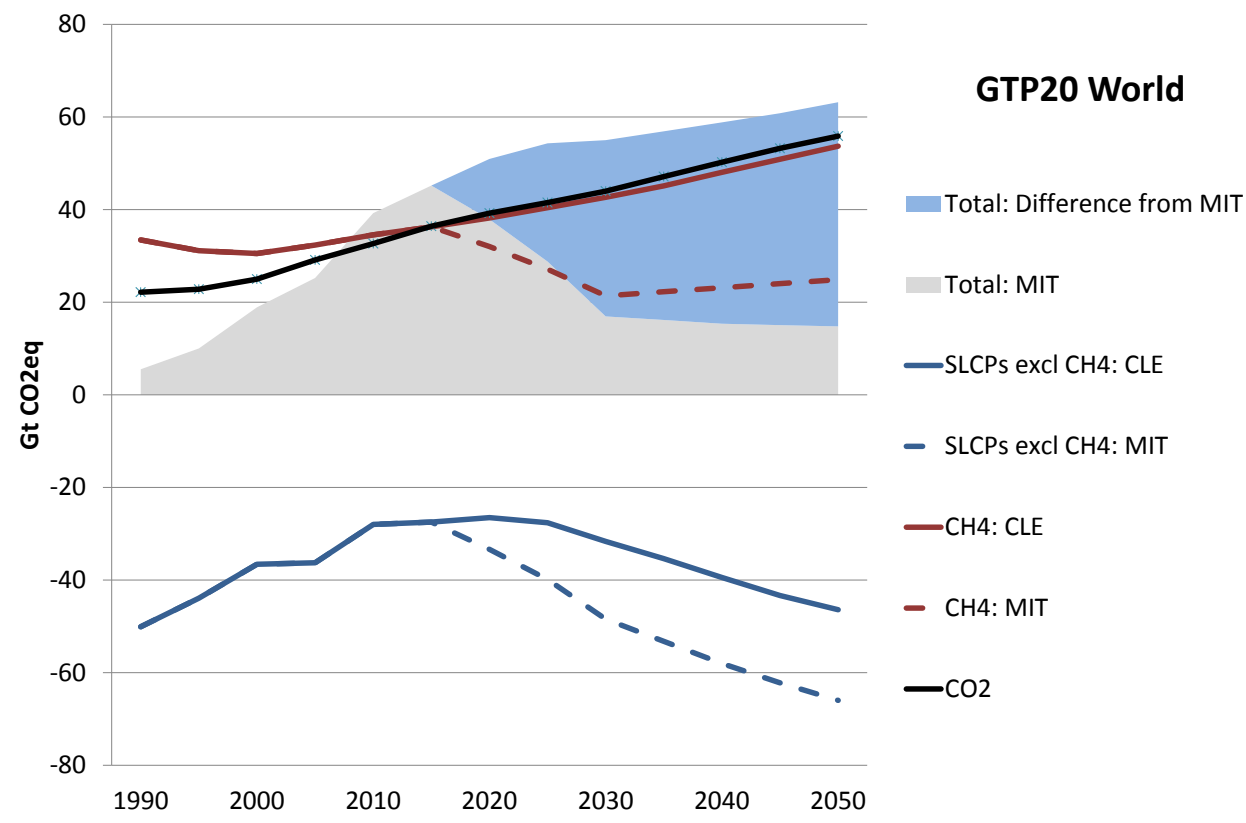

Figure 9. $\mathrm{CO}_{2}$-equivalent emissions (Gt) determined with the $\mathrm{GTP}_{20}$ metric, as a function of time, for global emissions of the current legislation (CLE) and SLCP mitigation (MIT) scenarios. Lines show the values for individual forcing components $\left(\right.$ black $\mathrm{CO}_{2}$, red $\mathrm{CH}_{4}$, blue other SLCPs), while the shaded areas show the total $\mathrm{CO}_{2}$-equivalent emissions from all SLCPs and $\mathrm{CO}_{2}$. The blue shading indicates the mitigation potential of MIT, compared to CLE.

\subsection{Emission mitigation and air quality impacts}

For designing a climate-optimised SLCP emission mitigation scenario, the $\mathrm{CO}_{2}$-equivalent SLCP emissions were minimised using the GAINS model. For this, the numerical values of the $\mathrm{GTP}_{20}$ metric for the final year 2035 for each species, region and season were implemented into GAINS. The ramp-up version of this metric assumes a linear implementation of mitigation measures between the years 2015 and 2030 and thereafter a full implementation. Mitigation measures typically affect several species at the same time. For instance, controlling BC emissions leads to a "cocontrol" of OA and other species. The $\mathrm{GTP}_{20}$ metric values are different for all of these species and can be of different sign, and it is important to determine the net impact of a mitigation measure across all affected species. In practice, the species-specific metric values were weighted with the emission factors to obtain the net metric value for each of the $\sim 2000$ mitigation measures in every one of the 168 regions considered in GAINS, and for summer and winter periods separately. These measures were subsequently ranked according to their $\mathrm{CO}_{2}$-equivalent total net climate impact as measured by the $\mathrm{GTP}_{20}$ metric, and all measures with a beneficial climate and air quality impact were included in the MIT scenario basket (Klimont et al., 2015b); this approach is consistent with that taken by UNEP/WMO (2011) and Shindell et al. (2012).

The mitigation basket contains three groups of measures: (1) measures that affect emissions of $\mathrm{CH}_{4}$ that can typi- cally be centrally implemented (e.g. by large energy companies, municipalities) and which also impact background $\mathrm{O}_{3}$; (2) technical measures that reduce the emissions of $\mathrm{BC}$, mainly for small stationary and mobile sources; and (3) nontechnical measures to eliminate $\mathrm{BC}$ emissions, e.g. through economic and technical assistance to the poorest population. While about 220 GAINS model measures were collected in the mitigation basket, they were merged into representative measure groups. For example, high emitters are calculated for each of the GAINS transport subsectors and fuels, while here removing high emitters is represented by one "measure". Similarly for cooking stoves, GAINS estimates mitigation potential for various types of fuels, but all of these are included further into one category "clean cooking stoves". Also for $\mathrm{CH}_{4}$, losses from gas distribution are calculated for several GAINS end use sectors while here the mitigation potential is reported under one measure where leaks from low pressure pipelines are reduced. Finally, for NMVOCs all of the solvent-related options in GAINS (over 50) are categorised as one measure reducing losses from solvent use activities. Considering the above, about 50 "measures" represent the about 220 GAINS options that were included in the mitigation basket. The 17 most effective measures contribute $80 \%$ of the total climate benefit, according to the $\mathrm{GTP}_{20}$ metric, with $\mathrm{CH}_{4}$ measures contributing about $47 \%$ and $\mathrm{BC}$-focused measures contributing $33 \%$. These measures are listed in Table 3. It is interesting to notice that the top $\mathrm{CH}_{4}$ and $\mathrm{BC}$ focused measures both concern the oil and gas industry and specifically the venting or flaring of associated gas. 
Table 3. Top-17 mitigation measures contributing together more than $80 \%$ of the climate benefit. Measures are ranked by importance starting from the top. Methane measures contribute about $47 \%$ of the benefits according to the $\mathrm{GTP}_{20}$ metric, while $33 \%$ are attributed to BC-focused measures; $20 \%$ are contributed by measures not listed here.

\begin{tabular}{|c|c|}
\hline Methane measures & Measures targeting $\mathrm{BC}$ reduction \\
\hline $\begin{array}{l}\text { Oil and gas industry: } \\
\text { recovery and use (rather than venting or flaring) of associated } \\
\text { gas }\end{array}$ & $\begin{array}{l}\text { Oil and gas industry: } \\
\text { improving efficiency and reducing gas flaring }\end{array}$ \\
\hline $\begin{array}{l}\text { Oil and gas industry (unconventional): } \\
\text { reducing emissions from unintended leaks during production } \\
\text { (extraction) of shale gas }\end{array}$ & $\begin{array}{l}\text { Transport: } \\
\text { eliminating high-emitting vehicles (super-emitters) }\end{array}$ \\
\hline $\begin{array}{l}\text { Coal mining: } \\
\text { reducing (oxidising) emissions released during hard coal min- } \\
\text { ing (ventilation air } \mathrm{CH}_{4} \text { ) }\end{array}$ & $\begin{array}{l}\text { Residential-commercial: } \\
\text { clean biomass cooking stoves }\end{array}$ \\
\hline $\begin{array}{l}\text { Waste: } \\
\text { municipal waste - waste paper separation, collection, and recy- } \\
\text { cling }\end{array}$ & $\begin{array}{l}\text { Residential-commercial: } \\
\text { replacement of kerosene wick lamps with LED lamps }\end{array}$ \\
\hline $\begin{array}{l}\text { Waste: } \\
\text { municipal food waste separation, collection and treatment in } \\
\text { anaerobic digestion (biogasification) plants }\end{array}$ & $\begin{array}{l}\text { Transport: } \\
\text { widespread Euro VI emission standards (incl. particle filters) on } \\
\text { diesel vehicles }\end{array}$ \\
\hline $\begin{array}{l}\text { Coal mining: } \\
\text { hard and brown coal - pre-mining emissions - degasification }\end{array}$ & $\begin{array}{l}\text { Industrial processes: } \\
\text { modernised (mechanised) coke ovens }\end{array}$ \\
\hline $\begin{array}{l}\text { Gas distribution: } \\
\text { replacement of grey cast iron gas distribution network }\end{array}$ & $\begin{array}{l}\text { Agriculture: } \\
\text { effective ban of open-field burning of agricultural residues }\end{array}$ \\
\hline \multicolumn{2}{|l|}{$\begin{array}{l}\text { Waste: } \\
\text { industrial solid waste (food, wood, pulp and paper, textile) - } \\
\text { recovery and incineration }\end{array}$} \\
\hline \multicolumn{2}{|l|}{$\begin{array}{l}\text { Waste: } \\
\text { wastewater treatment from paper and pulp, chemical, and food } \\
\text { industries - anaerobic treatment in digester, reactor or deep } \\
\text { lagoon with gas recovery, upgrading and use. For residen- } \\
\text { tial wastewater centralised collection with anaerobic secondary } \\
\text { and/or tertiary treatment (incl. treatment with bacteria and/or } \\
\text { flaring of residual } \mathrm{CH}_{4} \text { ) }\end{array}$} \\
\hline $\begin{array}{l}\text { Oil and gas industry (conventional): } \\
\text { reducing emissions from unintended leaks during production } \\
\text { (extraction) }\end{array}$ & \\
\hline
\end{tabular}

As can be seen in Fig. 2, the mitigation has only minor effects on $\mathrm{CO}_{2}$ emissions, but reduces most SLCPs strongly compared to the CLE scenario. By 2030, $\mathrm{CH}_{4}$ emissions are reduced by about $50 \%$ and $\mathrm{BC}$ emissions by nearly $80 \%$. $\mathrm{OA}$ is co-controlled with $\mathrm{BC}$, causing a nearly $70 \%$ (not shown) reduction of its emissions, as for some sectors $\mathrm{BC}$ outweighs the cooling effects of OA. While NOx emission reductions are in most cases also not preferred by the $\mathrm{GTP}_{20}$ metric (see Fig. 8), reductions stem from the co-control when higher Euro standards are introduced; they reduce significantly several pollutants such as $\mathrm{BC}, \mathrm{CO}, \mathrm{NMVOC}$ and also $\mathrm{NO}_{x}$ (Klimont et al., 2015a, b). By contrast, $\mathrm{SO}_{2}$ emissions are nearly the same in both the CLE and MIT scenarios, as for the key sectors emitting $\mathrm{SO}_{2}$, the warming by $\mathrm{SO}_{2}$ reductions (see Fig. 8) cannot be outweighed by co-control of species whose reduction would lead to cooling. Thus, $\mathrm{SO}_{2}$ reductions are largely avoided.

The global $\mathrm{CO}_{2}$-equivalent emissions (calculated using the $\mathrm{GTP}_{20}$ metric values) are shown as a function of time in Fig. 9. Values are shown for CLE and MIT and are split into contributions from $\mathrm{CH}_{4}$ and other SLCP emissions. For comparison, $\mathrm{CO}_{2}$ emissions are also shown. On the short timescale of the $\mathrm{GTP}_{20}$ metric, $\mathrm{CH}_{4}$ and $\mathrm{CO}_{2}$ emissions are nearly equally important in the CLE scenario. The $\mathrm{CO}_{2}-$ equivalent emissions of $\mathrm{CH}_{4}$ are, however, reduced by $50 \%$ in MIT. The $\mathrm{CO}_{2}$-equivalent emissions for the other SLCPs 


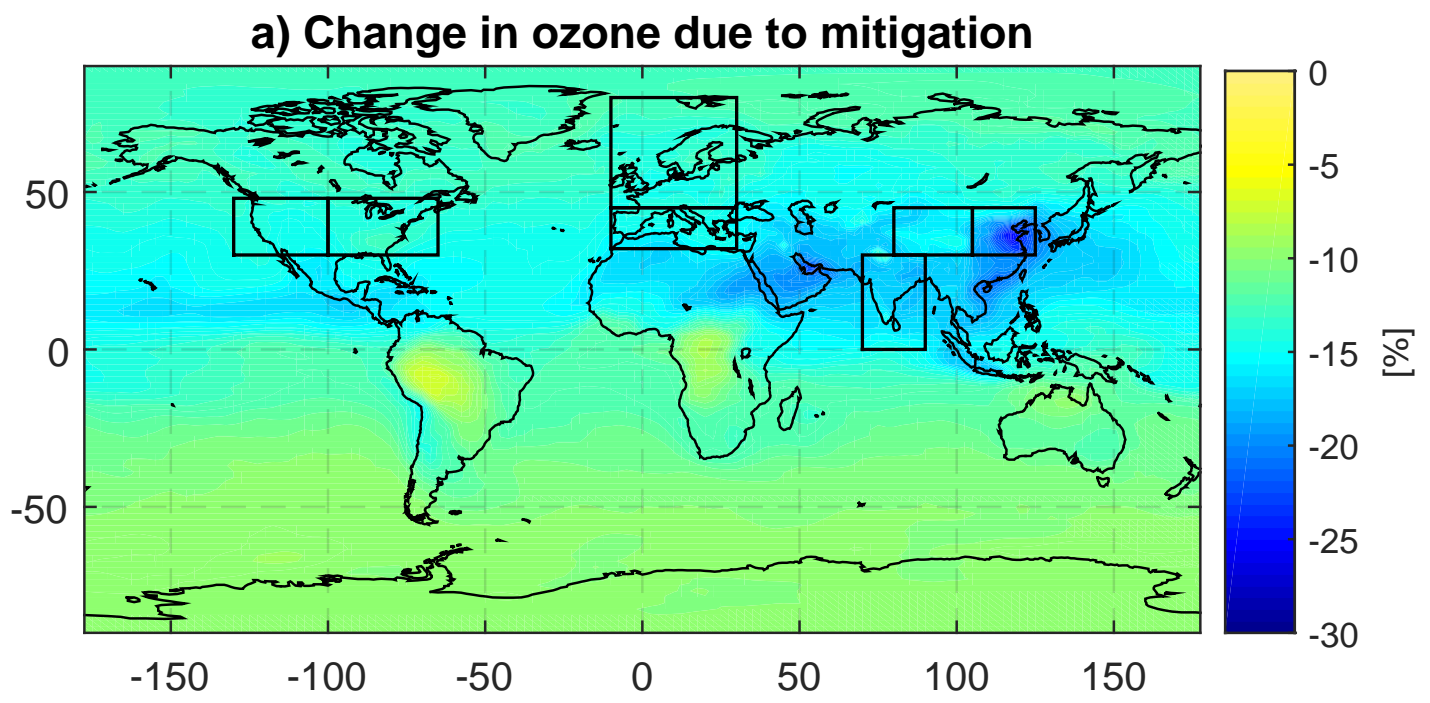

b) Change in $\mathrm{PM}_{2.5}$ due to mitigation

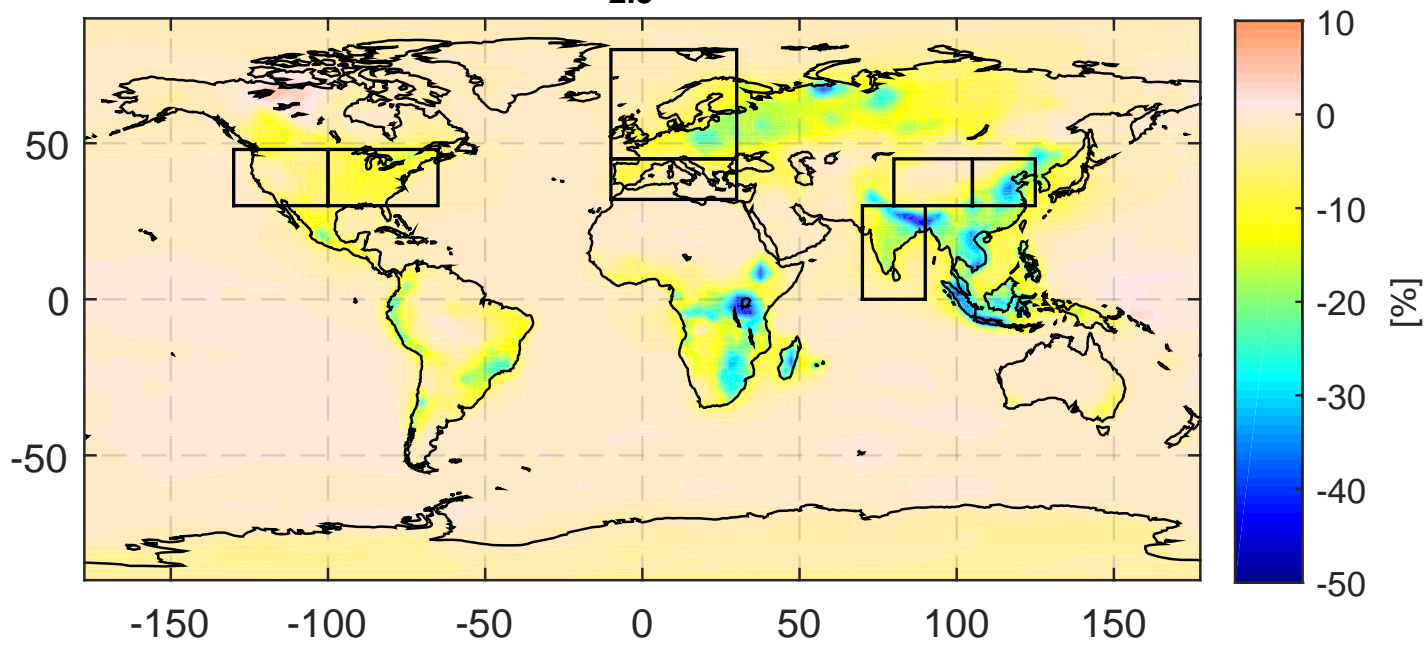

Figure 10. Relative difference maps (in \%) for the surface concentrations of $\mathrm{O}_{3}$ and $\mathrm{PM}_{2.5}$, as obtained from simulations based on the emission mitigation (MIT) scenario and the current legislation (CLE) scenario, i.e. (100 $\times$ (MIT - CLE)/CLE). Shown are mean concentration differences for the period 2041-2050 and averaged over model results from OsloCTM2, NorESM and HadGEM. The black boxes define the regions used in Table 4.

are negative in both scenarios, indicating that in total they have a cooling impact. As the mitigation reduces preferentially warming components, this cooling becomes even stronger in the MIT case. The total $\mathrm{CO}_{2}$-equivalent emissions (including $\mathrm{CO}_{2}$ emissions) are reduced substantially in the MIT scenario (blue shaded area in Fig. 9 shows the reduction), for example by about $70 \%$ in the year 2030 . About $56 \%$ of this reduction is due to $\mathrm{CH}_{4}$ measures and $\sim 44 \%$ is due to other measures. It is important to notice that the effect of the SLCP mitigation is relatively large for the rather short time horizon of the $\mathrm{GTP}_{20}$ metric; it would be smaller for a longer time horizon. Similarly, the relative importance of $\mathrm{CH}_{4}$ compared to other SLCP emissions would be increased for a longer time horizon.
Surface concentrations of SLCPs resulting from the CLE and MIT scenarios were determined from the various model simulations. Figure 10 shows maps of the model-mean relative differences for $\mathrm{O}_{3}$ and $\mathrm{PM}_{2.5}$ for the last decade (20412050) of the transient simulations and Table 4 reports differences for several regions shown with boxes in Fig. 10. Concentrations of $\mathrm{O}_{3}$ (Fig. 10, upper panel) are reduced globally, with reductions of more than $12 \%$ in most of the Northern Hemisphere and the strongest reductions of up to about $20 \%$ occurring in East Asia. For instance, in eastern China (see Table 4$), \mathrm{O}_{3}$ is reduced by $19.3 \%(16.0-24.4 \%)$. BC and OA concentrations (not shown) were also globally reduced, with $\mathrm{BC}$ reductions reaching more than $80 \%$. For sulfate (not shown), the relative changes are much smaller than for BC 
Table 4. Relative differences $(\%)$ in $\mathrm{O}_{3}$ and $\mathrm{PM}_{2.5}$ surface concentrations between simulations using the mitigation (MIT) and current legislation (CLE) scenarios (given as $100 \times($ MIT - CLE)/CLE) for several regions and for the final decade of the simulations (2041-2050). The regions correspond to the boxes shown in Fig. 10. Except for the Mediterranean, only the land-based grid cells inside the boxes were used. Mean values and full model ranges for the three models NorESM, HadGEM and OsloCTM2 are reported. To exclude effects of changes in sea salt and dust emissions caused by natural variability and emission responses to forced changes in meteorological conditions, sea salt and dust concentrations were kept at CLE levels for the purpose of these calculations.

\begin{tabular}{lrrrr}
\hline Region & $\mathrm{O}_{3}$ & $\begin{array}{r}\mathrm{O}_{3} \\
\text { mean }(\%)\end{array}$ & $\begin{array}{r}\mathrm{PM}_{2.5} \\
\text { mean }(\%)\end{array}$ & $\begin{array}{r}\mathrm{PM}_{2.5} \\
\text { range (\%) }\end{array}$ \\
\hline Northern Europe & -13.7 & {$[-15.9,-11.1]$} & -12.5 & {$[-17.6,-7.3]$} \\
Southern Europe & -14.9 & {$[-17.0,-12.3]$} & -2.3 & {$[-3.1,-1.5]$} \\
Mediterranean & -15.1 & {$[-17.8,-12.6]$} & -1.6 & {$[-2.3,-1.0]$} \\
Eastern China & -19.3 & {$[-24.4,-16.0]$} & -16.3 & {$[-23.2,-11.8]$} \\
Western China & -15.8 & {$[-17.9,-12.8]$} & -2.2 & {$[-4.3,-1.0]$} \\
India & -17.1 & {$[-22.8,-12.7]$} & -19.8 & {$[-22.5,-17.9]$} \\
Eastern United States & -13.6 & {$[-15.7,-10.3]$} & -8.8 & {$[-11.7,-3.6]$} \\
Western United States & -14.3 & {$[-16.1,-11.5]$} & -4.5 & {$[-8.7,-1.4]$} \\
\hline
\end{tabular}

and $\mathrm{OA}$ and both increases and decreases occur - a consequence of the relatively small global $\mathrm{SO}_{2}$ emission reductions (see Fig. 2). Changes in $\mathrm{PM}_{2.5}$ concentrations (Fig. 10, lower panel) are smaller because of large contributions from natural sources (e.g. sea salt, dust, wildfire emissions). $\mathrm{PM}_{2.5}$ concentrations in the SLCP source regions were reduced by typically $10-20 \%$ and up to nearly $50 \%$ in smaller regions. Reductions are strongest in Asia, for instance 19.8\% (17.9$22.5 \%$ ) in India (Table 4).

In summary, air pollutant concentrations in the MIT scenario are dramatically reduced compared to the CLE scenario, especially in the polluted (and heavily populated) source regions. This indicates the beneficial effect of the SLCP mitigation on air quality. Nevertheless, a word of caution is needed for $\mathrm{O}_{3}$. The $\mathrm{O}_{3}$ concentrations increase strongly (typically between 5 and $20 \%$, depending on region and season) between now and 2050 in the CLE scenario, because of increasing $\mathrm{CH}_{4}$ and $\mathrm{NO}_{x}$ emissions. Therefore, global-mean $\mathrm{O}_{3}$ concentrations even in the MIT scenario do not decrease substantially with time. However, strong relative $\mathrm{O}_{3}$ reductions by the mitigation are simulated in the SLCP source regions (Table 4), which more than outweigh the overall concentration increase in the CLE scenario. Therefore, population exposure to $\mathrm{O}_{3}$ decreases with time in the MIT scenario.

For Europe and Asia, the GAINS model also contains source-receptor relationships which allow for the estimation of the impacts of emissions on human health. GAINS quantifies the impacts of changes in SLCP emissions on the longterm population exposure to $\mathrm{PM}_{2.5}$ in Europe, China and India and estimates the resulting premature mortality, in terms of reduced statistical life expectancy and cases of premature deaths (Amann et al., 2011). Calculations follow the recommendations of the findings of the WHO review on health impacts of air pollution and recent analyses conducted for the Global Burden of Disease project (Lim et al., 2012), rely- ing on the results of the American Cancer Society cohort study (Pope III et al., 2002) and its re-analysis (Pope III et al., 2009). It uses cohort- and country-specific mortality data extracted from life table statistics to calculate for each cohort the baseline survival function over time. Notice, however, that, in contrast to the changes of pollutant concentrations presented in Fig. 10, the quantification of human health impacts is based on results from a single model.

Using GAINS, we estimate that in the EU the loss of statistical life expectancy will be reduced from 7.5 months in 2010 to 5.2 months in 2030 in the CLE scenario. The ECLIPSE mitigation measures (MIT) would reduce statistical life shortening by another 0.9 months (Fig. 11, upper panel), resulting in 4.3 months of reduction in life expectancy. This value is only slightly above the target of 4.1 months that has been set by the European Commission in its 2013 Clean Air Policy proposal (EC, 2013). Population in non-EU countries would gain approximately 1 month life expectancy from the implementation of the ECLIPSE measures in 2030 (Fig. 11, upper panel).

In China and India, the potential health gains from the implementation of the ECLIPSE measures are significantly larger, however, starting from a substantially higher level of life shortening due to $\mathrm{PM}_{2.5}$ (Fig. 11, lower panel). In China, the ECLIPSE measures would in the year 2030 extend the life expectancy of the population by approximately 1.8 months and reduce the premature deaths attributable to $\mathrm{PM}_{2.5}$ by $150000-200000$ cases per year.

In India, rapid increase in energy consumption, together with lacking regulations on emission controls for important sources (e.g. power generation) and poor enforcement of existing laws (e.g. for vehicle pollution controls) will lead to a steep increase in $\mathrm{PM}_{2.5}$ levels. If no saturation of health impacts is assumed for such high levels (there are no cohort studies available for such high concentrations), with conservative assumptions GAINS estimates approximately 850000 

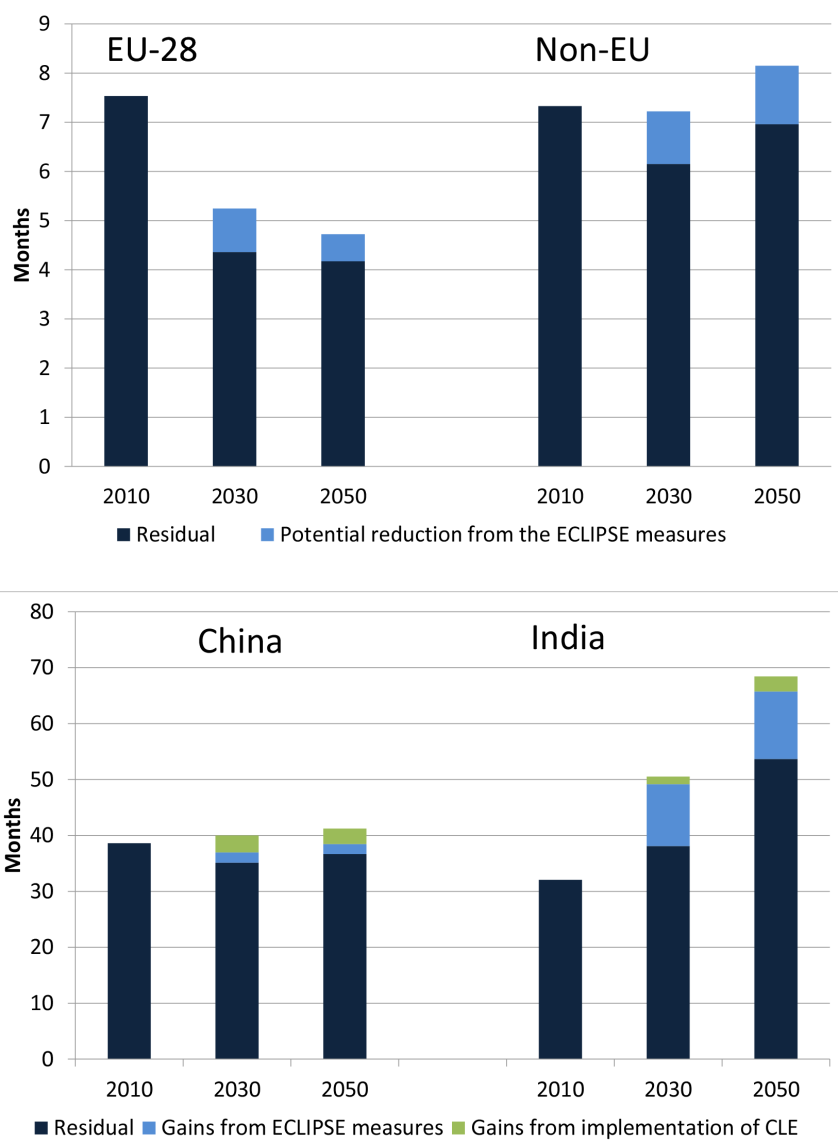

Figure 11. Loss of statistical life expectancy (months) due to the exposure to $\mathrm{PM}_{2.5}$ in Europe, for EU-28 and non-EU countries (upper panel) and for China and India (lower panel). The black bars give the values for the mitigation (MIT) scenario, whereas the blue increments show the difference to the current legislation (CLE) scenario. For India and China, green bars indicate the gains from the implementation of the CLE scenario.

cases annually of premature deaths from air pollution in 2010. For 2030, $\mathrm{PM}_{2.5}$ exposure would increase by more than $50 \%$, and at the same time the population would increase and age. Combined, these factors would let the premature deaths from air pollution grow by approximately $125 \%$ to 1.9 million cases in 2030, with another doubling to 3.7 million cases in 2050. Against this background, the ECLIPSE measures would avoid more than 400000 cases of premature deaths in 2030 and almost 700000 in 2050. Using the loss in statistical life expectancy as an alternative metric, the ECLIPSE measures would gain 11-12 months in life expectancy for the Indian population (Fig. 11, lower panel).

\subsection{Climate impacts}

The climate impacts of SLCPs were determined with four ESMs (HadGEM3, NorESM, ECHAM6-HAM2/MPIOM, and CESM-CAM4) in two different experiments. In the first experiment, still part of the outer loop of the spiral in Fig. 1, all land-based anthropogenic emissions of each of $\mathrm{SO}_{2}, \mathrm{OA}$ and $\mathrm{BC}$ were removed one at a time and the models were run to equilibrium; in the other experiment, the mitigation scenario described in Sect. 3.5 was followed in a series of transient ensemble model runs, constituting the inner spiral loop in Fig. 1. Note that all ESMs implicitly include the semidirect effect, while for the radiative forcing calculations this was calculated explicitly by only one model.

For the first experiment, the four ESMs, with full ocean coupling were run for a control simulation and a perturbation run for 50 years, after a spin-up period to equilibrium. The control simulation used ECLIPSE V4a emissions for the year 2008 (except for CESM-CAM4, which used year 2000 emissions). For the perturbation, $100 \%$ of the landbased emissions of the three individual species were removed in turn to achieve discernible climate responses. While only three ESMs ran the experiments for $\mathrm{SO}_{2}$ and $\mathrm{OA}$, all four ESMs ran the $\mathrm{BC}$ experiment and three of these used two or three ensemble members each. Only NorESM included the effect of albedo reduction by $\mathrm{BC}$ deposited on snow and ice. This experiment is described in detail in Baker et al. (2015a), where more detailed descriptions of the models used can also be found. Here, we provide a synthesis of the results.

When removing $\mathrm{SO}_{2}$ emissions, all three models show an increase of global-mean surface temperature (Fig. 12a) by $0.69 \mathrm{~K}(0.40-0.84 \mathrm{~K})$ on average. Here, the first value is the multi-model mean, whereas the values in brackets give the full range of results obtained with the individual models. We will keep this notation throughout the rest of the paper, unless otherwise noted. The zonal-mean temperature change is positive at all latitudes and increases with latitude in the Northern Hemisphere, reaching $2.46 \mathrm{~K}(1.38-3.31 \mathrm{~K})$ at the North Pole (Fig. 13a). It is also positive for most regions of the Earth and is more positive over the continents than over the oceans (Baker et al., 2015a). The models also agree that removing $\mathrm{SO}_{2}$ emissions results in an increase in global-mean precipitation (Fig. 12b), which is in line with the expected impact from a global temperature increase. The precipitation increases are particularly strong over India and China because of a northward shift of the Intertropical Convergence Zone (ITCZ; see Fig. 13b), which is in accordance with previous studies (e.g. Broccoli et al., 2006).

The response to removing anthropogenic $\mathrm{BC}$ emissions, $-0.05 \mathrm{~K}(-0.15$ to $+0.08 \mathrm{~K})$, is much smaller than the $\mathrm{SO}_{2}$ response and the models do not all agree on the sign of the global-mean response. The multi-model mean is slightly negative (Fig. 12a) but within $\pm 0.5 \mathrm{~K}$ everywhere on the globe (not shown) and the zonal-mean temperature response differs from model to model (Fig. 13c). The NorESM model shows the strongest cooling in the Arctic, likely because it is the only model accounting for snow albedo changes. Precipitation changes from removing $\mathrm{BC}$ emissions are also small, but consistently positive in all models (Fig. 12b) despite the cooling in most models. This is consistent with calculations 
a) Surface temperature change

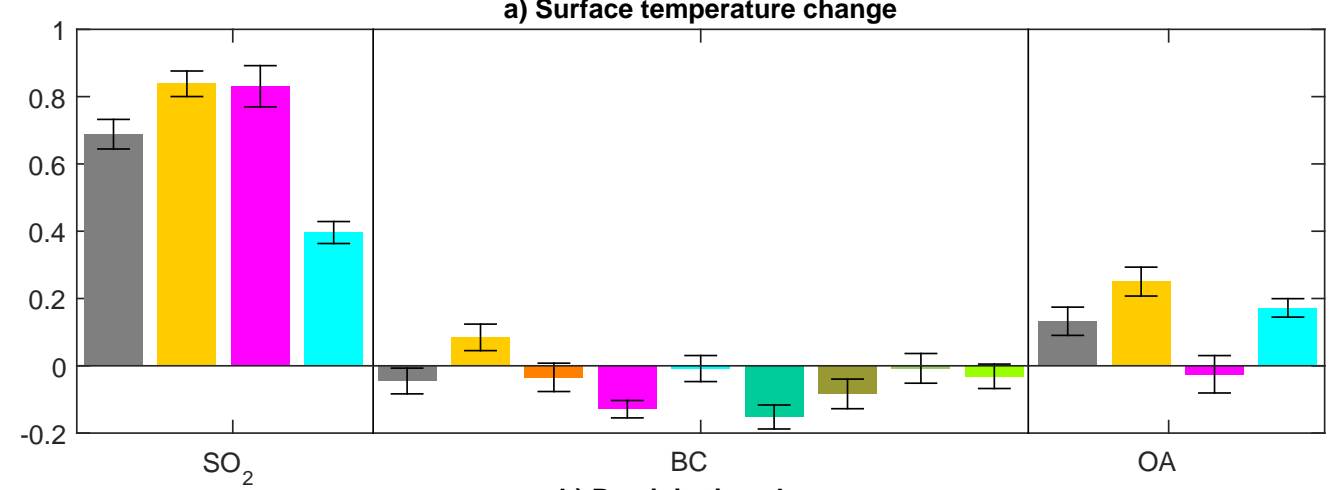

b) Precipitation change

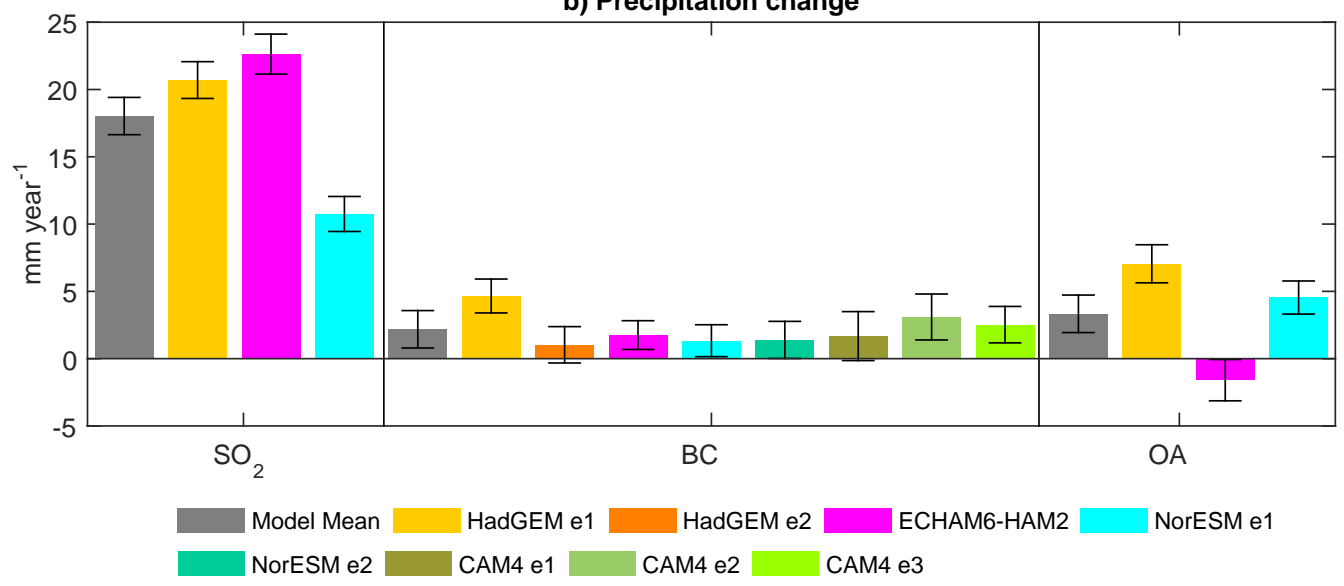

Figure 12. Global-mean annual average changes in (a) surface temperature and (b) precipitation averaged over all land areas excluding ice sheets, from the four ESMs (one was run only for BC), for a complete removal of all land-based emissions of a particular species, compared to the ECLIPSE version 4 baseline emissions for the year 2008 (CESM-CAM4 used the year 2000). The plot shows results averaged over 50-year model simulations; for HadGEM and NorESM (CESM-CAM4), two (three) ensemble members each were run for BC (named e1, e2, e3 in the labels). Error bars are $95 \%$ confidence intervals in the mean, based on 50 annual means from each model and thus only reflect the uncertainty of the mean caused by natural variability within each model.

of the relationship between atmospheric RF and precipitation change in Andrews et al. (2010) and Kvalevåg et al. (2013) (see also Shine et al., 2015). The multi-model temperature response to removing OA emissions is similar to that for removing $\mathrm{SO}_{2}$, but much weaker overall (Figs. 12a and 13e).

In summary, the emission perturbation studies show that elimination of anthropogenic $\mathrm{SO}_{2}$ emissions leads to robust warming, elimination of $\mathrm{OA}$ also leads to - albeit much weaker - warming, whereas elimination of $\mathrm{BC}$ leads to a small temperature response with substantial differences between the models but slight cooling in the multi-model mean. This could be due to the different sizes of the indirect and semi-direct effects of BC in different models, shown in ECLIPSE (Hodnebrog et al., 2014), and possibly to unforced responses of climate system components, especially sea ice, that happen to counteract the small temperature response.

The second ESM experiment simulated the transient responses to the climate-optimised SLCP mitigation of Sect. 3.5 (Baker et al., 2015b). For this, the four ESMs ran three ensemble members each for both the CLE and MIT sce- nario until the year 2050. The CLE scenario resulted in an increase of global-mean surface temperature of $0.70 \pm 0.14 \mathrm{~K}$ (the value following the " \pm " sign gives the standard deviation obtained from all ensemble members) between the years 2006 and 2050 in the multi-model ensemble mean. A large part of this increase is a response to increasing $\mathrm{CO}_{2}$ concentrations, and consequently the MIT scenario also showed a (albeit smaller) temperature increase. As we here are mainly interested in the response to the SLCP mitigation, we only consider the difference between the MIT and the CLE scenario in the following. Time series of the global-mean temperature difference between the two scenarios are shown in Fig. 14. There is a considerable spread between individual ensemble members even from the same model. This reflects simulated natural climate variability superimposed on the response to the SLCP mitigation, which makes diagnosis of the latter difficult. Systematically negative global-mean temperature responses emerge only when the mitigation measures are fully implemented. The multi-model mean global temperature (MIT-CLE) difference is $-0.22 \pm 0.07 \mathrm{~K}$ for the final 
a) Response to $\mathrm{SO}_{2}$ perturbation

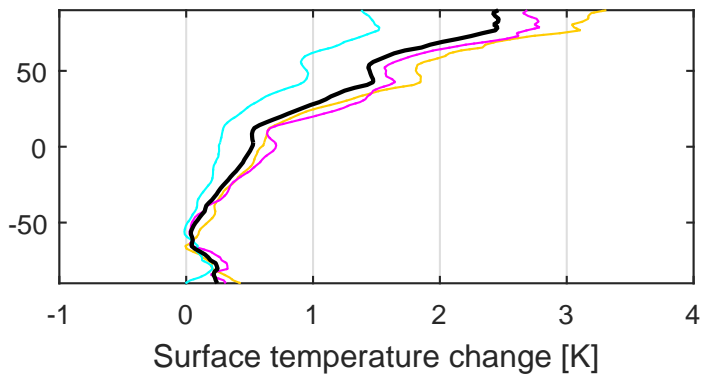

c) Response to $\mathrm{BC}$ perturbation

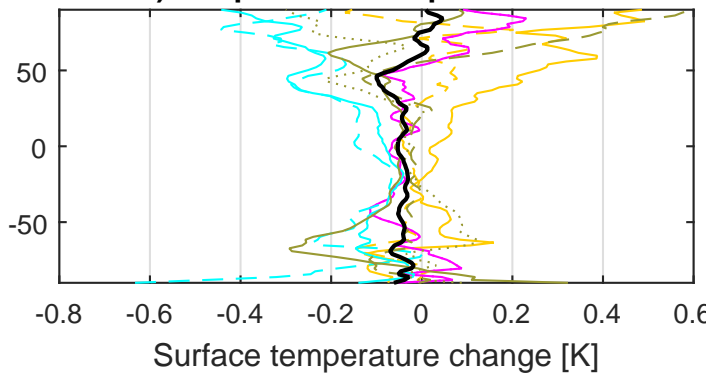

e) Response to OA perturbation

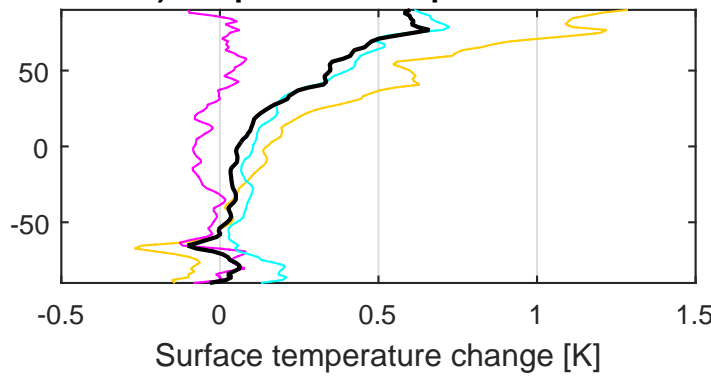

b) Response to $\mathrm{SO}_{2}$ perturbation

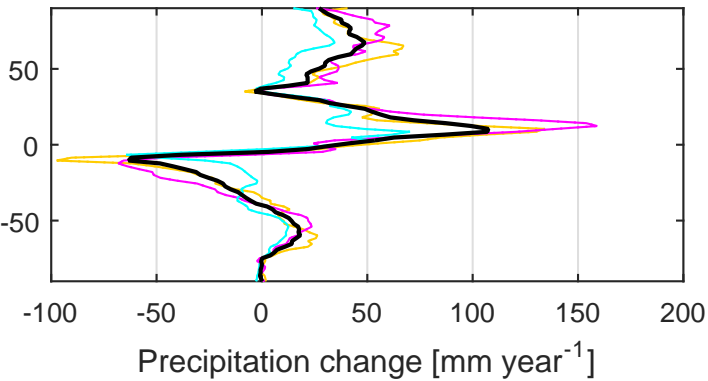

d) Response to $\mathrm{BC}$ perturbation

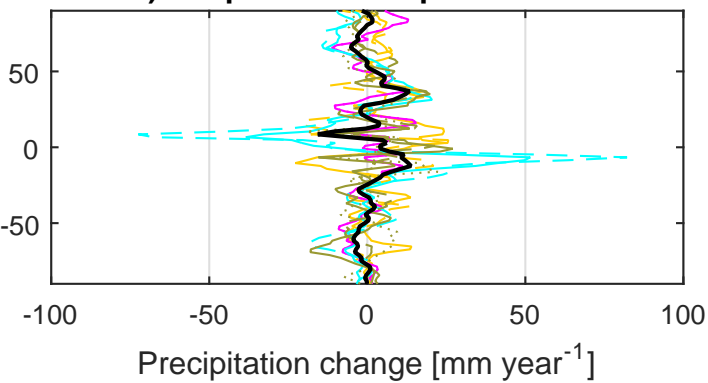

e) Response to OA perturbation

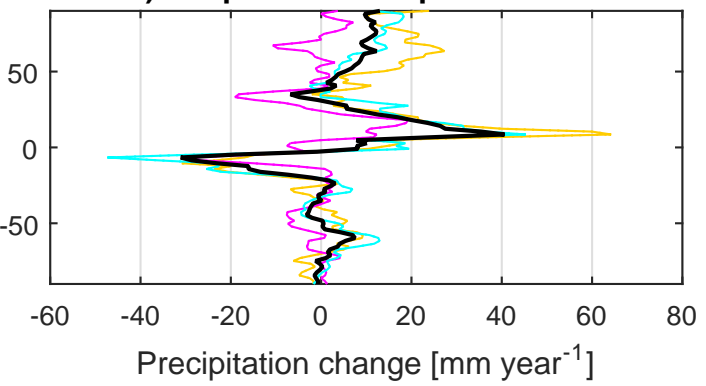

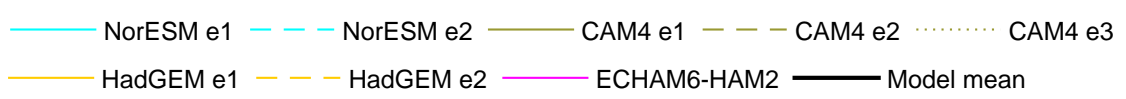

Figure 13. Annual mean changes in zonal-mean surface temperature (left panels a, c, e) and precipitation (right panels $\mathbf{b}, \mathbf{d}, \mathbf{f})$ for a complete removal of all land-based emissions of (a-b) $\mathrm{SO}_{2},(\mathbf{c}-\mathbf{d}) \mathrm{BC}$, and (e-f) OA. For BC, some models ran two or three ensemble members (e1, e2, e3). Notice the differences in scales between different panels.

10 years, confirming that the mitigation could be successful in reducing the warming of the CLE scenario.

The relative cooling is particularly strong over the continents and the weakest over the northern North Atlantic (not shown), similar to the response patterns seen in the perturbation simulations. Figure 15 shows mean temperature responses for the last decade of the simulation, for various regions. The strongest relative cooling between MIT and CLE of about $0.44 \mathrm{~K}(0.39-0.49 \mathrm{~K})$ are found for the Arctic, with peak values of about $0.62 \mathrm{~K}(0.37-0.84 \mathrm{~K})$ occurring in autumn (winter values are similar). Over Europe, differences are more consistent between models and more strongly negative in the southern parts than in the northern parts (see also
Fig. 16). This can be explained by the larger natural climate variability in northern Europe. Mainly small and inconsistent results are found over India, due to model differences in the shift of the ITCZ, whereas changes over China and North America are consistently negative from (almost) all models and for all seasons.

The precipitation responses are less robust which, in the tropics, is due to model differences in the migration of the ITCZ. Nevertheless, there are regions with consistent responses of all models. Of particular interest is the precipitation increase over southern Europe (Fig. 16). Seen against the background of expected warming and drying in the Mediterranean area due to $\mathrm{CO}_{2}$-driven climate change, the precipi- 


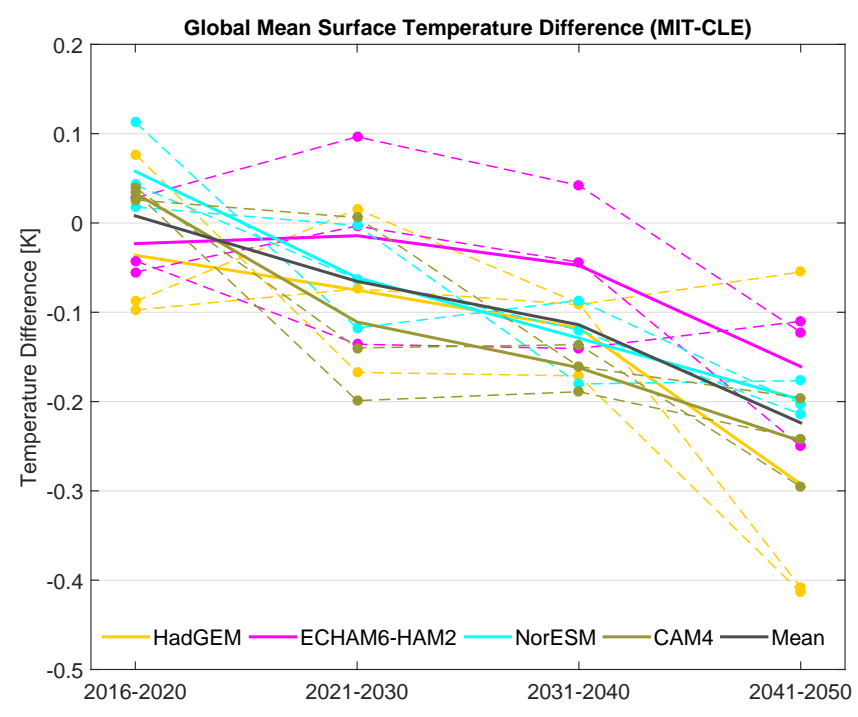

Figure 14. Time evolution of differences in global-mean surface temperature between transient simulations following the mitigation (MIT) and the current legislation (CLE) scenario, i.e. (MIT-CLE), for the four ECLIPSE models. Negative values mean that temperatures are lower in the MIT than in the CLE scenario. The ensemble means for each model are shown as thick lines, whereas the individual ensemble members are shown with thin lines.

tation increase due to the SLCP mitigation would be beneficial, especially given the fact that it is strongest from spring to autumn (Fig. 17), with 15 (6-21) $\mathrm{mm} \mathrm{yr}^{-1}$ increase (corresponding to more than $4 \%(2-6 \%)$ of total precipitation) and combined with a temperature reduction that is also the largest during that period (Fig. 15). Thus, our mitigation approach would help to alleviate drought and water shortages in the Mediterranean area in summer, as they are expected for the future (Orlowsky and Seneviratne, 2012).

In the aerosol perturbation experiments, we have seen that $\mathrm{SO}_{2}$ emission reductions lead to strong warming and $\mathrm{OA}$ reductions to weaker warming, whereas $\mathrm{BC}$ emission reductions lead to much weaker and model-dependent cooling. While the $\mathrm{GTP}_{20}$ metric attributes $\sim 44 \%$ of the reduction in $\mathrm{CO}_{2}$-equivalent emissions to $\mathrm{BC}$-related measures, it was interesting to clarify whether this is reflected in the transient climate model simulations, and how this fraction changes with time. For this, two additional experiments with four ensemble members each were run with one ESM (CESM-CAM4) with a slab-ocean representation (for greater computational efficiency): one with all emission reductions (MIT), and one with only $\mathrm{CH}_{4}$ emission reductions (MIT- $\mathrm{CH}_{4}$-only). Ozone reductions resulting from $\mathrm{CH}_{4}$ emission measures are included in the MIT$\mathrm{CH}_{4}$-only simulations, whereas $\mathrm{O}_{3}$ changes from non- $\mathrm{CH}_{4}$ measures are omitted. The two experiments yielded a relatively similar temporal characteristic of global-mean temperature difference (see Fig. 18), where the MIT scenario led to $0.45 \pm 0.04 \mathrm{~K}$ less warming than CLE, and the MIT- $\mathrm{CH}_{4}$ - only scenario led to $0.41 \pm 0.04 \mathrm{~K}$ less warming than CLE for the final decade of the simulation (2041-2050). The difference between the two scenarios is not significant, owing to the small number of ensemble members. Thus, the simulations indicate a dominant $(\sim 90 \%)$ role of $\mathrm{CH}_{4}$ emission reductions and a small $(\sim 10 \%)$ but perhaps non-negligible role of non- $\mathrm{CH}_{4}$ mitigation measures for reducing the warming by 2041-2050.

Notice that the warming reduction for the MIT scenario with the slab-ocean version of the CESM-CAM4 model is twice as strong as with the more realistic full-ocean version shown in Fig. 14. However, given the results with the slabocean version, a dominant role of $\mathrm{CH}_{4}$ in the mitigation is likely also for the full-ocean simulations. In fact, this adds to the explanation of why the temperature response in Fig. 14 emerges from natural variability only about 10 years (i.e. approximately the lifetime of $\mathrm{CH}_{4}$ ) after the start of the mitigation measures.

We have seen in Sect. 3.5 that the chosen set of mitigation measures also leads to considerable reductions in $\mathrm{PM}$ and $\mathrm{O}_{3}$ and thus improves air quality. If implemented as such, the mitigation package as a whole would therefore have beneficial impacts on both air quality and climate. However, the experiments conducted here also suggest that the co-benefits for climate and air quality result mainly from $\mathrm{CH}_{4}$ mitigation, which improves air quality (via clear reductions of the background surface $\mathrm{O}_{3}$ concentrations) and reduces warming considerably. The co-benefits of the non- $\mathrm{CH}_{4}$ SLCP mitigation measures, on the other hand, are quite limited. These measures improve air quality strongly (via reductions of PM concentrations and $\mathrm{O}_{3}$ ) but reduce warming only slightly. This does not of course mean that all of the individual measures have small co-benefits. For instance, it is likely that mitigating sources with the highest BC/OA ratio would lead to larger co-benefits. Partly, the small co-benefits for the non$\mathrm{CH}_{4}$ SLCP measures are a result of the design of our MIT scenario, which was based on the $\mathrm{GTP}_{20}$ metric and this seems to suggest a stronger warming reduction due to non$\mathrm{CH}_{4}$ SLCP measures than seen in the transient ESM simulation results. The consistency between the two approaches will be discussed in the next section, but it is clear that if the metric was too "optimistic" with respect to the achievable warming reductions by non- $\mathrm{CH}_{4}$ SLCP mitigation measures, some individual measures will have been included in the MIT basket, which in the transient simulations might have actually led to warming enhancement instead of warming reduction.

\subsection{Closing the loop: Climate impacts from metric calculations and transient model simulations, and applications of the metrics}

The purpose of this section is to compare the climate impacts of the SLCP mitigation as estimated with the metrics and as obtained from the transient simulations, as well as to show applications of the metrics. A perfect agreement between the 
a) Northern Europe

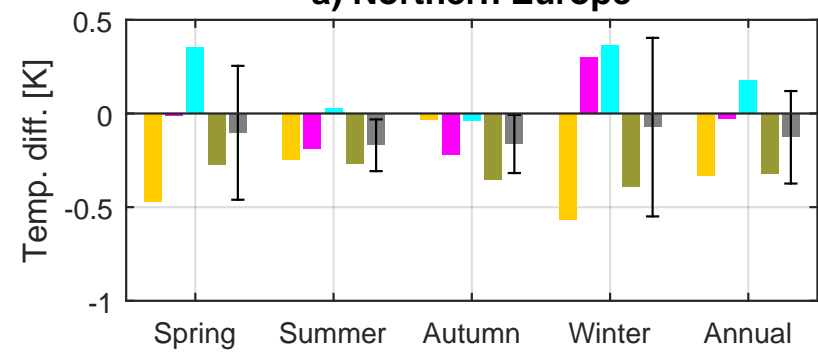

c) India

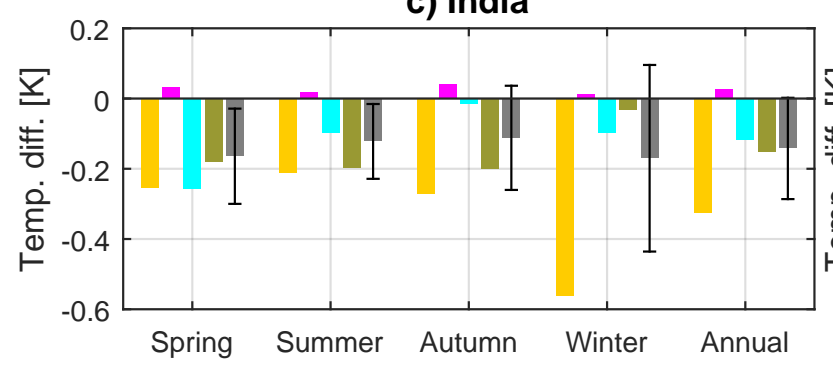

e) Arctic

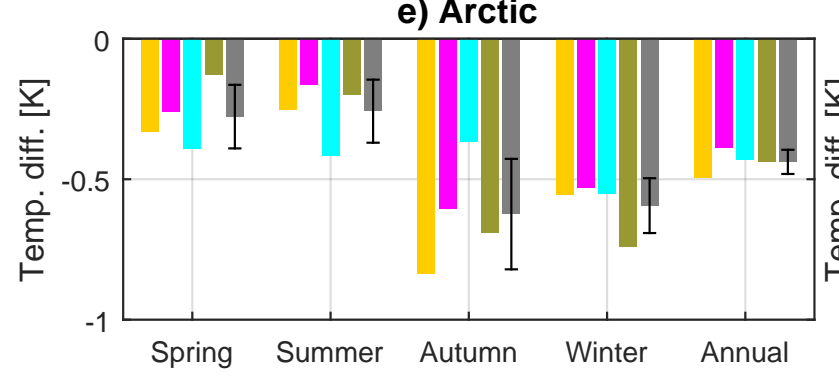

g) Global Mean

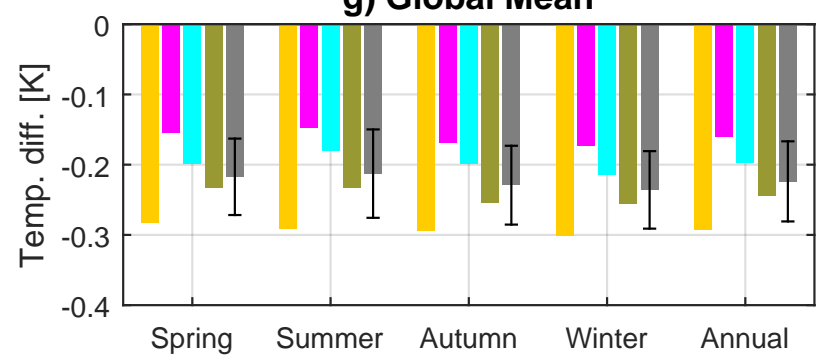

b) Southern Europe

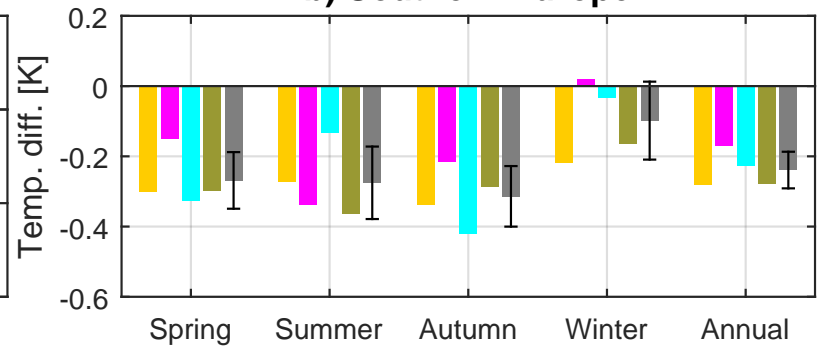

d) China

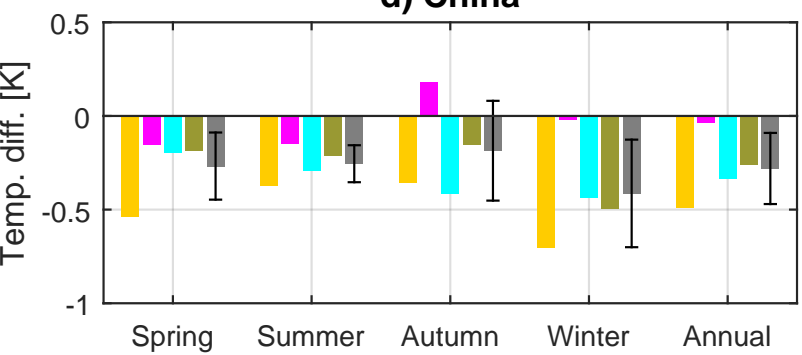

f) North America

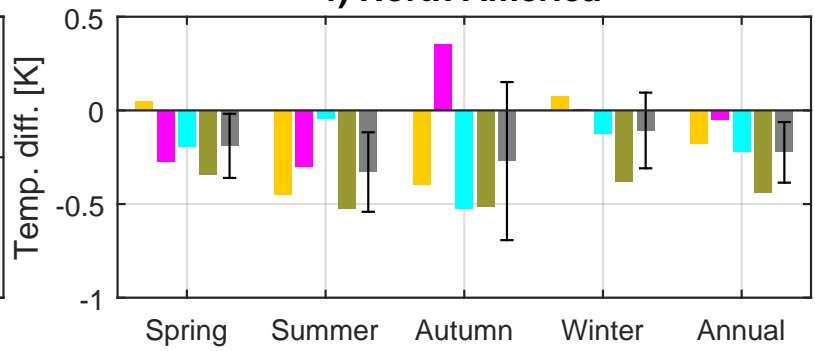

Figure 15. Seasonal and annual mean differences in surface temperatures (in K) in various regions (a-f) and for the whole globe (g) between transient simulations of the mitigation (MIT) and the current legislation (CLE) scenario, i.e. (MIT-CLE), averaged over the last 10 years of the simulations (2041-2050). Regions are defined as (a) $45-65^{\circ} \mathrm{N}, 10^{\circ} \mathrm{W}-65^{\circ} \mathrm{E}$, (b) $30-45^{\circ} \mathrm{N}, 10^{\circ} \mathrm{W}-65^{\circ} \mathrm{E}$, (c) $7-35^{\circ} \mathrm{N}, 68^{\circ} \mathrm{E}-90^{\circ} \mathrm{E},(\mathbf{d}) 24-$ $48^{\circ} \mathrm{N}, 80-132^{\circ} \mathrm{E}$, (e) $60-90^{\circ} \mathrm{N}, 180^{\circ} \mathrm{W}-180^{\circ} \mathrm{E}$, (f) $30-60^{\circ} \mathrm{N}, 120-50^{\circ} \mathrm{W}$. Results are shown for the four ECLIPSE models individually and for the multi-model mean. Negative values mean that temperatures are lower in the MIT than in the CLE scenario. Error bars on the model-mean values show the standard deviations of the individual model results.

two methods cannot be expected, as the metrics assume linearity of the climate response to all individual forcing contributions and are also valid for a specific time horizon. Furthermore, after using the RF values calculated in ECLIPSE, the methodology adopted to calculate the GTP values uses a representation of both the size and time dependence of the response derived from one particular (pre-ECLIPSE) ESM calculation. Since the different ESMs used in ECLIPSE have a diverse range of climate sensitivities and different representations of uptake of heat by the oceans, this is a further important reason why exact agreement should not be expected. The metrics are also calculated for a specific climate and are less accurate for periods with a changed climate. One example is the BC snow albedo effect, which is gradually reduced over time because the snow and ice extent decreases as the climate warms. On the other hand, diagnosis of temperature 

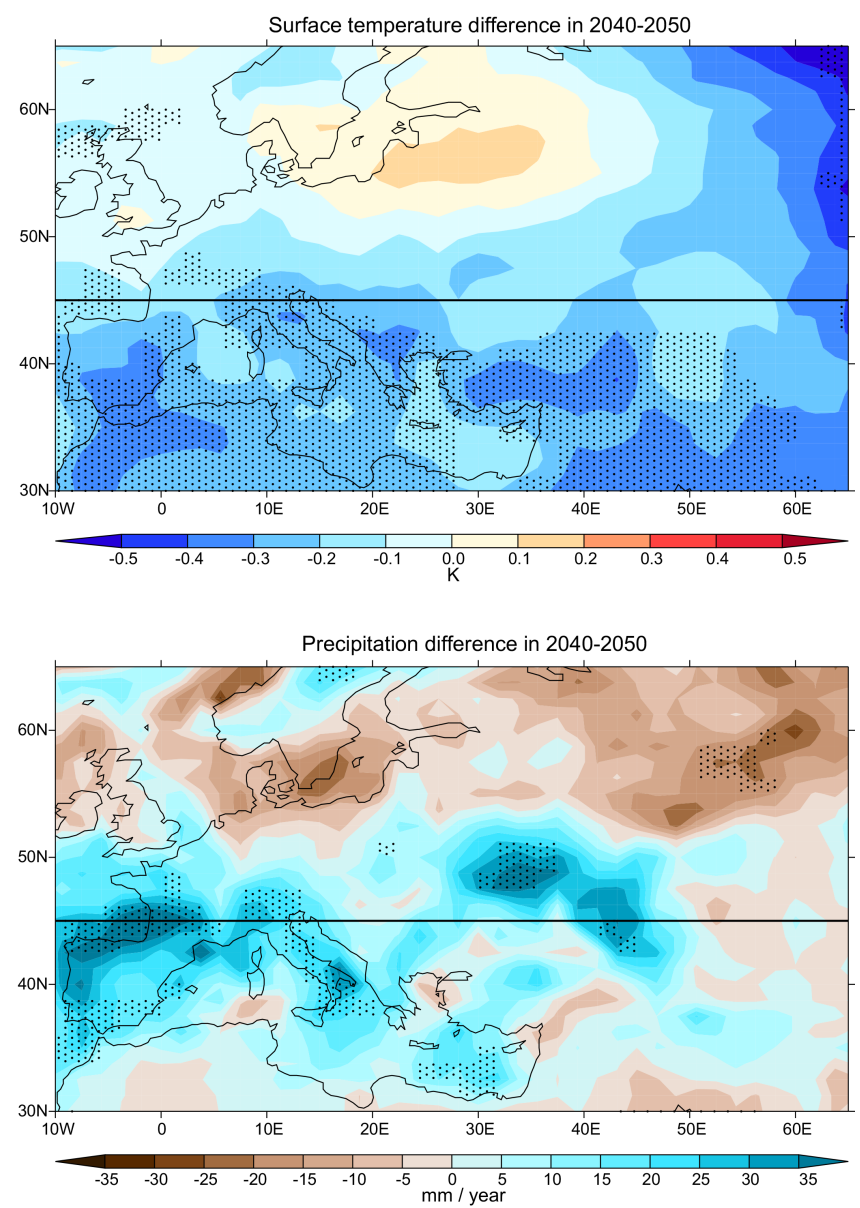

Figure 16. Annual average differences in (top) surface temperature and (bottom) precipitation over Europe between the transient simulations based on the mitigation (MIT) and the current legislation (CLE) scenario, averaged over the last 10 years of the simulations (2041-2050). Stippling shows where all four models agree on the sign of the response. The thick horizontal line distinguishes the southern and northern Europe boxes. In the top panel, negative values mean that temperature in the MIT scenario is lower than in the CLE scenario; in the bottom panel, positive values mean that there is more precipitation in the MIT than in the CLE scenario.

responses from the transient climate simulations is also associated with large error bars because of natural climate variability. Nevertheless, a comparison of the two methods is an important consistency check but, to our knowledge, has never been done before for a SLCP mitigation scenario and using an ensemble of ESMs.

The ARTP metric described in Sect. 3.5, applied over a series of timescales, allows for calculation of the regional (in broad latitude bands) temperature response from the reduction of individual species in the mitigation basket as a function of time. Based on these regional responses a total global-mean response is derived which can be compared directly with the global-mean temperature difference between the MIT and CLE transient simulations in the ESMs.
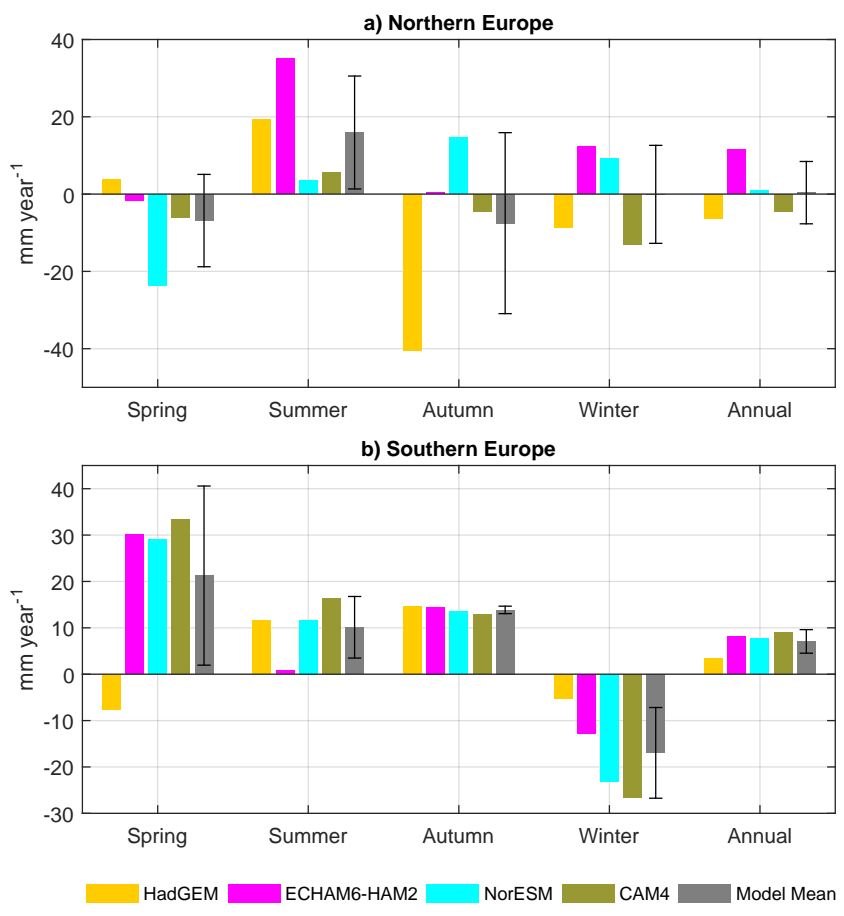

Figure 17. Seasonal and annual mean differences in precipitation (in $\mathrm{mm} \mathrm{yr}^{-1}$ ) over northern (a) and southern (b) Europe between transient simulations of the mitigation (MIT) scenario and the current legislation (CLE) scenario, averaged over the last 10 years of the simulations (2041-2050). Regions are defined as in Fig. 15a, b. Results are shown for the four ECLIPSE models individually and for the multi-model mean. Positive values mean that MIT simulations have more precipitation than CLE simulations. Error bars on the model-mean values show the standard deviations of the individual model results.

The ARTPs depend on the global climate sensitivity assumed for the impulse response function used (Shindell et al., 2012). To provide a consistent comparison with the ESM transient simulations, the ARTPs have been scaled by the individual climate sensitivities for each ESM. Furthermore, not all the ESMs include all components and forcing mechanisms in their transient simulations, e.g. only NorESM includes the forcing due to $\mathrm{BC}$ deposited on snow and ice. To make a consistent comparison, ARTP contributions were summed only over the components and processes included in each ESM. Figure 19 shows the global-mean temperature responses using the ARTP method, which can be compared directly with the temperature changes obtained by the transient ESM simulations shown in Fig. 14. The solid lines in Fig. 19 show the total global temperature response of the mitigation, while the dashed lines show the contribution from $\mathrm{CH}_{4}$ reductions only. For the last decade of the simulation (2041-2050) both the ESMs and ARTPs give a mean global response of $-0.22 \mathrm{~K}$. The ranges of the estimates based on the four models are also very similar $(-0.15$ to $-0.29 \mathrm{~K}$ for the ESMs, and -0.13 to $-0.33 \mathrm{~K}$ for the ARTPs). Note, how- 


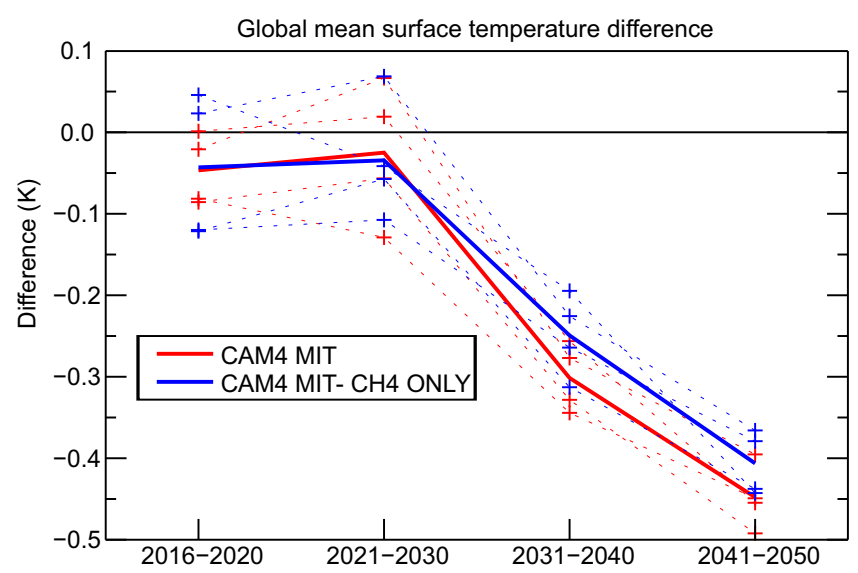

Figure 18. Time evolution of differences in global-mean surface temperature between transient simulations following the mitigation (MIT) and the current legislation (CLE) scenario (i.e. MIT-CLE), as simulated by the CESM-CAM4 model with a slab-ocean representation. One experiment (red lines) included all emission reductions of the MIT scenario, whereas another experiment (blue lines) included only the $\mathrm{CH}_{4}$ emission reductions of the MIT scenario. Ensemble mean results are shown with thick lines, individual ensemble members with thin lines.

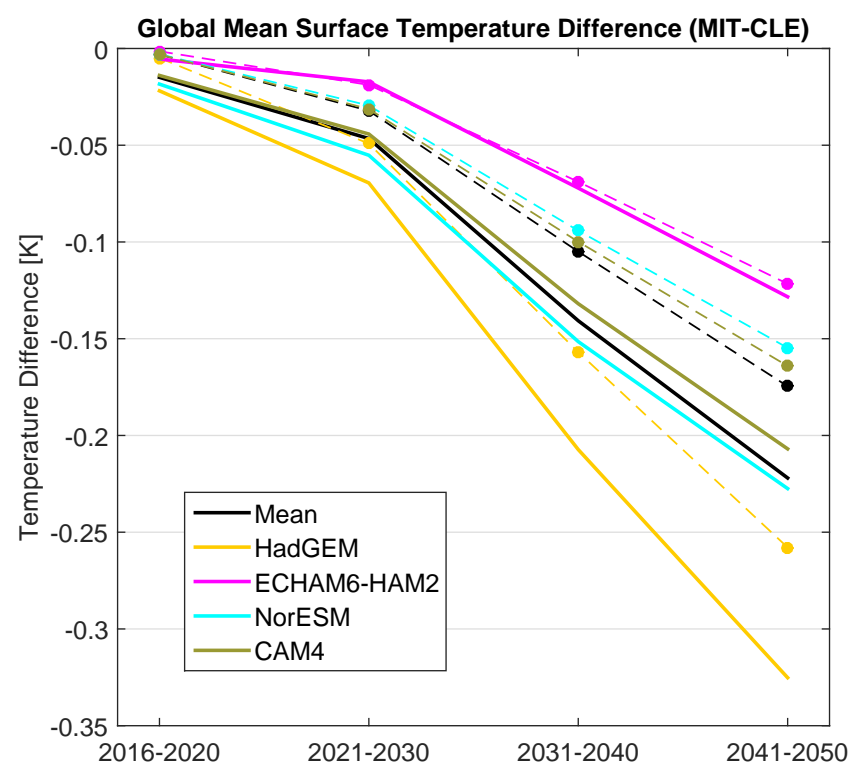

Figure 19. Time evolution of difference in global-mean surface temperature for the MIT and CLE scenario calculated with the ARTP-based method. Solid lines are the total difference (MITCLE), while the dashed lines give the responses to $\mathrm{CH}_{4}$ mitigation only. The solid lines can be compared directly with the results from the transient model simulations shown in Fig. 14.

ever, that the factors contributing to these ranges are not the same in these two estimates. For the ESMs, the differences in radiative forcing, the models' climate sensitivities and internal variability determine the range, while for the ARTPbased estimate the differences in which processes causing RF are included in each model and the model's climate sensitivities are accounted for. The ranking of the responses between the individual models are, however, not identical. Nevertheless, based on these results we conclude that for the globalmean response to SLCP mitigation the ARTP-based method simulates well the full ESM simulations to estimate the impact of SLCP mitigation.

The ARTP-based method suggests a larger contribution of non- $\mathrm{CH}_{4}$ SLCPs to the temperature response for the 20412050 decade ( $22 \%$; see dashed lines in Fig. 19) than the transient simulations using the slab-ocean version of the CESM-CAM4 model discussed in the previous section $(\sim 10 \%)$. One reason for this disagreement is that many of the BC-related measures included in the mitigation basket were relatively $\mathrm{OA}$ rich and this makes their net temperature response extremely uncertain, especially when aerosol indirect effects and the semi-direct effect are considered. An even larger contribution (44\%) of non- $\mathrm{CH}_{4}$ SLCPs to the $\mathrm{CO}_{2}-$ equivalent emission reductions of the MIT scenario was obtained with the $\mathrm{GTP}_{20}$ metric directly (see Sect. 3.5). However, this value is valid only for the temperature response in the year 2035, for which the relative contribution of the non- $\mathrm{CH}_{4}$ SLCPs (which are shorter-lived than $\mathrm{CH}_{4}$ ) is larger than for later years. As the diagnostic uncertainties for a single year are very large for the transient ESM simulations, we abstain from comparisons. Direct comparisons are anyway not meaningful, since the metrics include all recognised RF mechanisms, whereas most ESMs lack some of these (e.g. snow albedo changes by $\mathrm{BC}$ ).

To further investigate the ability of a simplified metrics method to represent the regional response simulated by the ESMs, we use the ARTPs to estimate the response in four broad latitude bands and these results can be compared to the corresponding results from the ESMs. Figure 20 shows the 20-year mean results (2031-2050) for both methods. The general pattern of the responses with largest impact for the main source region at Northern Hemisphere mid-latitudes (NHML) and in the Arctic is well captured by the ARTP method. However, as expected the agreement between the estimates is not as good as for the global mean (correlation coefficient of 0.68 for the 16 data points). The ARTP-based estimates are close to the ESM means for the NHML and the tropics, while for the Arctic and for the Southern Hemisphere (SH) the ARTP method underestimates the response simulated by the ESMs. The reason for the more pronounced Arctic amplification in our ESMs than for the ARTPs is probably a less pronounced Arctic amplification in the model of Shindell and Faluvegi (2009), from where the RTP-coefficients were taken. For future development and use of the ARTP method, RTP-coefficients are needed also from other ESMs.

The motivation for establishing these ARTPs is that after quality control they provide policy makers with a relatively simple tool to quantify how sectorial emissions (i.e. by region, sector and component) contribute to temperature change over time in broad latitude bands. Figure 21 illus- 

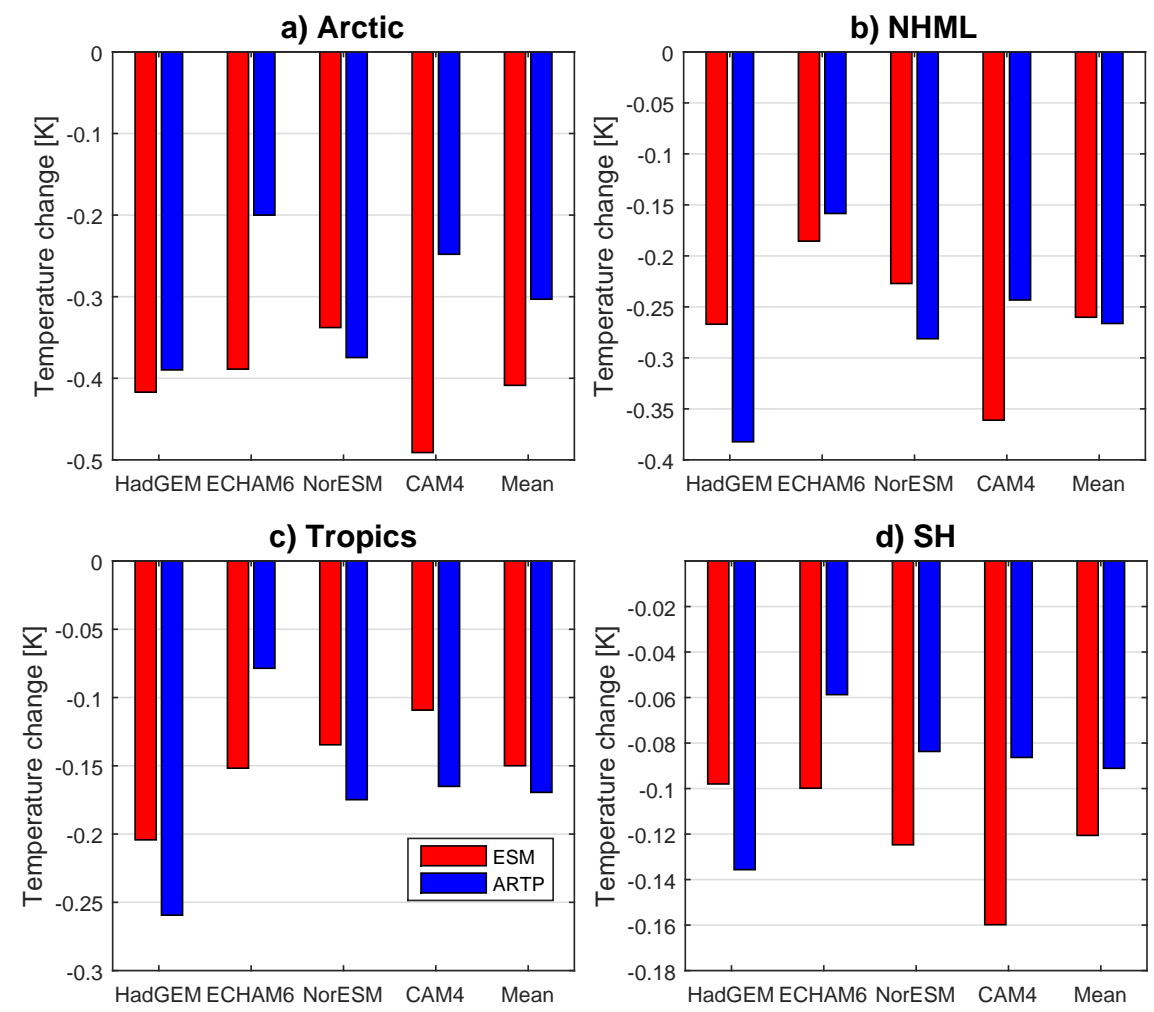

Figure 20. Temperature changes (MIT-CLE) in four latitude bands (Arctic, Northern Hemisphere Mid-Latitudes (NHML), tropics and Southern Hemisphere) calculated with the ESMs and ARTP-based method. Mean changes over the 2031-2050 period are shown for individual models and the mean over the models. Notice the different temperature scales.

trates this potential for the MIT scenario. It shows the responses (mean of the ARTP-based estimates for the four ESMs) for mitigation taking place in Europe, China and globally. The larger relative impact on the Arctic by mitigation of European emissions compared to mitigation in China is clearly seen, while the impact for NHML is about three times larger in absolute terms for mitigation of SLCPs in China. These results can then easily be further analysed by separating the impact by emitted species (Fig. 21, panel d), or by separating the impact of a single emission sector. Figure 22, for instance, shows the estimated impact on Arctic temperatures by global mitigation of SLCPs from the residential heating and cooking sector, broken down to contributions from individual SLCP species. Notice that it would be prohibitively expensive to run an ensemble of ESM simulations that is large enough to detect the small temperature response resulting from such minute emission changes.

\section{Conclusions}

ECLIPSE has come to a number of important scientific conclusions, which are also of high relevance for climate and air quality policy:
- ECLIPSE has created a new inventory for anthropogenic SLCP emissions, including scenarios for the future. An important finding is the large range of possible future developments of anthropogenic SLCP emissions, which even for a single future energy pathway substantially exceeds the range of SLCP emissions given in IPCC's RCPs. The large range results from the uncertainties of future air quality policies, as well as from the expected level of implementation and enforcement of existing policies (Klimont et al., 2015a, b).

- Detailed comparisons between measured and modelled distributions of aerosol, $\mathrm{O}_{3}$ and other SLCP gases have shown that for many substances the models are in good agreement with available background observations. The model performance of the ESMs is similar to that of CTMs. For BC, in particular, the agreement between models and measurements has improved for the Arctic (Eckhardt et al., 2015), which is partly the result of accounting for emissions from gas flaring and emission seasonality (Stohl et al., 2013). Outside the Arctic, a reduction of the BC lifetime led to improvements (Samset et al., 2014). Nevertheless, our comparisons suggest underestimates of $\mathrm{BC}$ and aerosol precursor emissions in high latitude Russia and in India. Furthermore, 

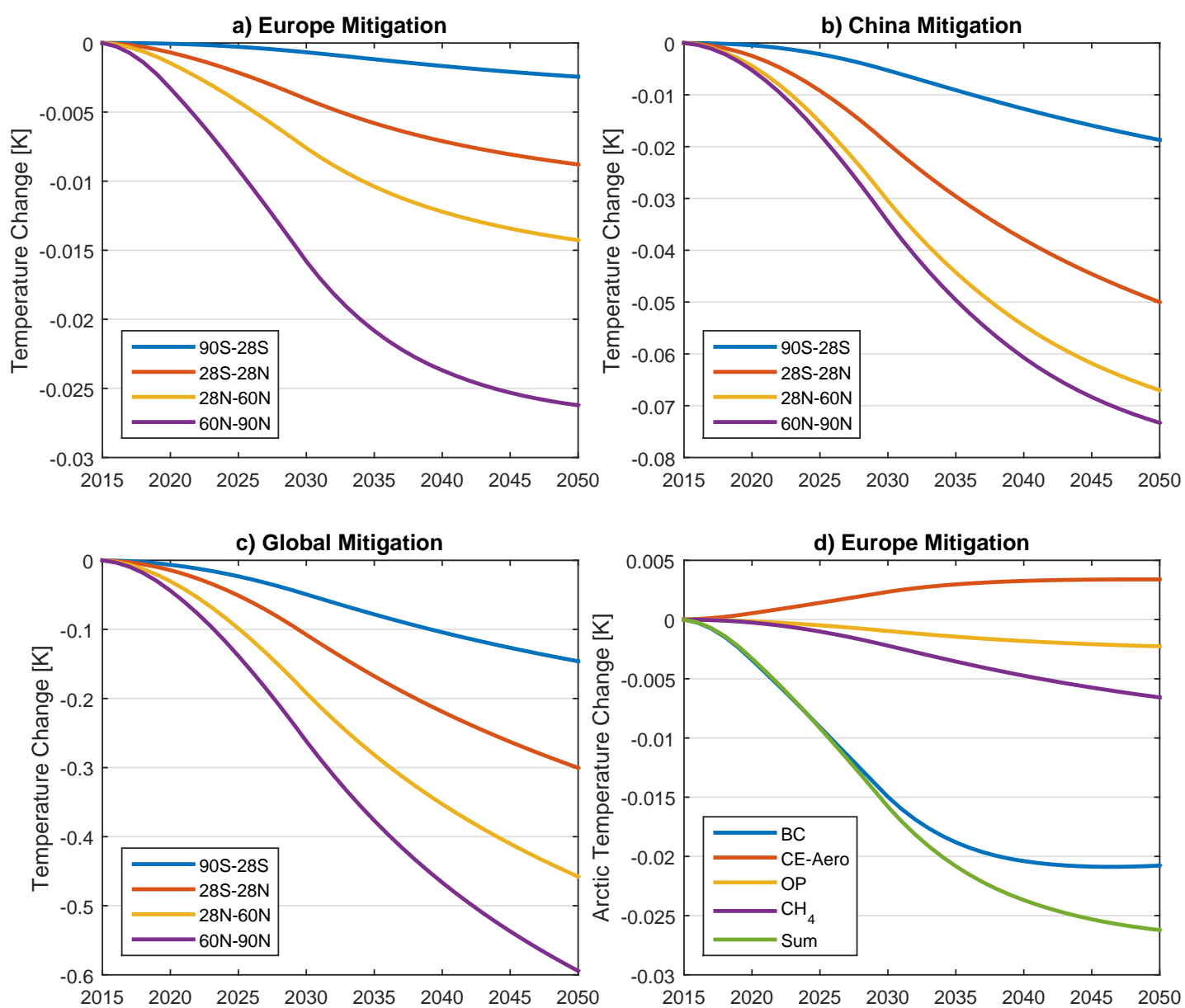

Figure 21. Annual mean surface temperature changes estimated by the ARTP method. Panels (a-c): changes in four latitude bands due to ECLIPSE mitigation scenario (MIT-CLE) for mitigation in Europe (a), China (b) and globally (c). Panel (d): Arctic temperature changes due to mitigation of individual components from Europe. CE-Aero: co-emitted aerosol (precursor) species $\left(\mathrm{OA}, \mathrm{SO}_{2}\right.$ and $\left.\mathrm{NH}_{3}\right), \mathrm{OP}$ : Ozone precursors $\left(\mathrm{NO}_{x}, \mathrm{CO}\right.$ and NMVOCs). Note the different scales on the vertical axes.

it was found that $\mathrm{SO}_{2}$ concentrations are overestimated and $\mathrm{CO}$ concentrations are underestimated by the models (Quennehen et al., 2015) at the surface in Asia and Europe during summer and autumn. The CO underestimate is likely associated with a too short CO lifetime in the models. Ozone, on the other hand, is generally overestimated at rural locations. Such discrepancies may affect model responses to emission perturbations and thus radiative forcing.

- Earth system models can reproduce the accelerated upward trend of surface temperature over Europe that was observed when aerosol precursor emissions were reduced in the 1990s (leading to solar brightening), after a period of emission growth in the 1960s-1980s (leading to solar dimming) (Cherian et al., 2014).

- ECLIPSE performed detailed multi-model calculations of RF for all considered SLCP species, as a function of emission region and season. It is found that the absolute values of specific RF for aerosols are generally larger in summer than in winter (Bellouin et al., 2015). It is found that the semi-direct effect on clouds, although highly uncertain, can potentially offset a considerable fraction of the direct positive RF of BC. This, together with reduced $\mathrm{BC}$ lifetimes, causes the net RF for BC calculated in ECLIPSE to be only weakly positive, which is different from most previous studies.

- $\mathrm{NO}_{x}$ emissions affect the concentrations of $\mathrm{O}_{3}, \mathrm{CH}_{4}$ and nitrate aerosols. The first effect leads to positive RF, while the latter two cause negative RF. We have quantified all these effects and can state with confidence that the current net $\mathrm{RF}$ of global historical $\mathrm{NO}_{x}$ emissions is negative. The forward looking metrics GWP and GTP for $\mathrm{NO}_{x}$ are negative as well, except for short time horizons.

- ECLIPSE had a focus on calculation and testing of emission metrics, which led to a better understanding of 


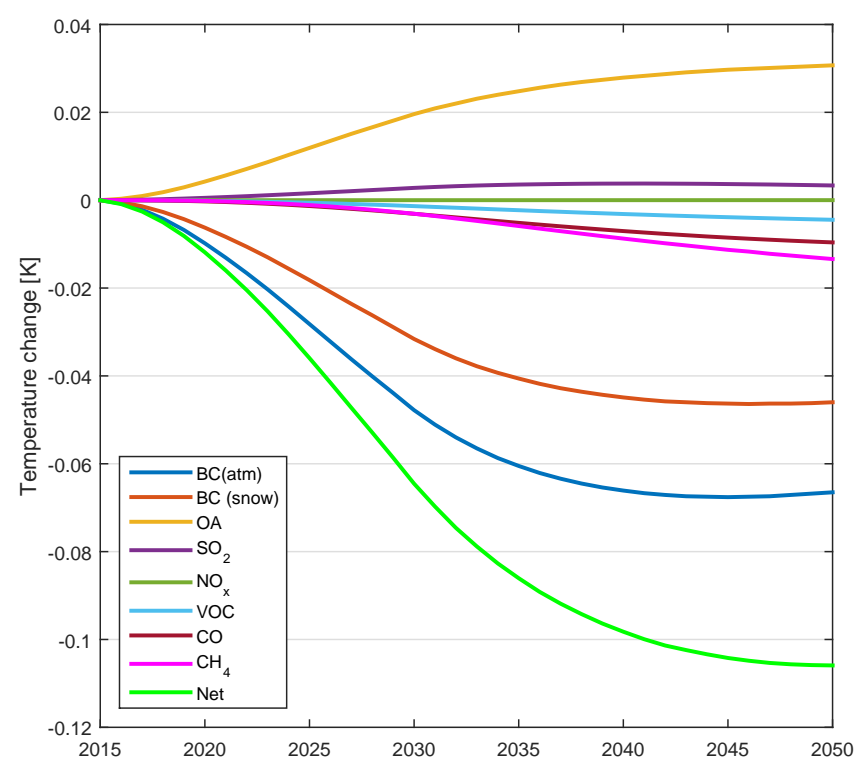

Figure 22. Total Arctic surface temperature change (K) by global mitigation of residential burning (heating and cooking) in the ECLIPSE emission scenario (MIT-CLE), as obtained with the ARTP method.

existing metrics (Aamaas et al., 2013), further development of the applications of the RTP concept (Collins et al., 2013) and introduction of new metric concepts such as the Global Precipitation change Potential (GPP) by Shine et al. (2015). After careful consideration of the alternatives, we chose a 15 -year ramp-up version (i.e. assuming a linear implementation of measures) of the $\mathrm{GTP}_{20}$ metric for designing a SLCP mitigation scenario.

- The $\mathrm{GTP}_{20}$ metric was implemented into the GAINS model to identify mitigation measures (MIT) that have beneficial impacts on both air quality and climate. We find that the 17 most important mitigation measures would contribute more than $80 \%$ of the climate benefits according to the $\mathrm{GTP}_{20}$ metric. The top measures both for $\mathrm{CH}_{4}$ and $\mathrm{BC}$ mitigation are to prevent the venting (for $\mathrm{CH}_{4}$ ) and flaring (for $\mathrm{BC}$ ) of gas associated with the oil production. For $\mathrm{CH}_{4}$, measures on shale gas production, waste management and coal mines were also important. For non- $\mathrm{CH}_{4}$ SLCPs, elimination of highemitting vehicles and wick lamps, as well as reducing emissions from coal and biomass stoves, agricultural waste, solvents and diesel engines were also important.

- Full implementation of these measures (the MIT scenario) would reduce global anthropogenic emissions of $\mathrm{CH}_{4}$ and $\mathrm{BC}$ by 50 and $80 \%$, respectively. As a result of co-control with $\mathrm{BC}$, emissions of organic aerosols would also be reduced by $70 \%$, whereas emissions of $\mathrm{CO}_{2}$ and $\mathrm{SO}_{2}$ would hardly be changed. Based on the $\mathrm{GTP}_{20}$ metric, the $\mathrm{CO}_{2}$-equivalent emissions (including
$\mathrm{CO}_{2}$ emissions) would be decreased by about $70 \%$ in the year 2030, with about $56 \%$ of the decrease caused by $\mathrm{CH}_{4}$ measures and $44 \%$ caused by non- $\mathrm{CH}_{4}$ SLCP measures.

- The mitigation scenario would reduce surface concentrations of $\mathrm{O}_{3}$ and $\mathrm{PM}_{2.5}$ globally compared to the CLE scenario, with $\mathrm{BC}$ reductions of more than $80 \%$ in some areas. We estimate that in the EU the loss of statistical life expectancy due to air pollution will be reduced from 7.5 months in 2010 to 5.2 months in 2030 in the CLE scenario. The MIT measures would gain another 0.9 months. Substantially, larger health improvements from SLCP measures are estimated for China (1.8 months) and India (11-12 months).

- Climate impacts of SLCP emissions were simulated with four ESMs with full ocean coupling. Equilibrium simulations that removed all land-based anthropogenic emissions of $\mathrm{SO}_{2}, \mathrm{BC}$ and $\mathrm{OA}$ in turn showed robust global-mean increase in surface temperatures of $0.69 \mathrm{~K}$ $(0.40-0.84 \mathrm{~K})$ for $\mathrm{SO}_{2}$ removal and smaller warming for OA removal (Baker et al., 2015a). The global-mean temperature response to $\mathrm{BC}$ removal was slightly negative: $-0.05 \mathrm{~K}(-0.15$ to $0.08 \mathrm{~K})$. The relatively small global response to $\mathrm{BC}$ emission reductions was attributed to strong (while uncertain) indirect and semidirect effects, which partly offset the direct aerosol radiative effect.

- Climate impacts of the MIT scenario were investigated with ESM ensemble transient simulations of both the CLE and MIT scenario (Baker et al., 2015b). Multimodel ensemble mean global-mean surface temperature in the CLE scenario increased by $0.70 \pm 0.14 \mathrm{~K}$ between the years 2006 and 2050. The ensemble mean globalmean surface warming for the last decade of the simulation (2041-2050) was, however, $0.22 \pm 0.07 \mathrm{~K}$ weaker for the MIT scenario, demonstrating the effect of the SLCP mitigation. The response was strongest in the Arctic, with warming reduced by about $0.44 \mathrm{~K}(0.39-$ $0.49 \mathrm{~K})$.

- In addition to global annual mean temperature change, there are other climate parameters that are of relevance for policy decisions (e.g. changes in precipitation, regional temperatures). The SLCP reductions in the MIT scenario led to particularly beneficial climate responses in southern Europe, where the surface warming was reduced by about $0.3 \mathrm{~K}$ from spring to autumn and precipitation rates were increased by about $15(6-21) \mathrm{mm} \mathrm{yr}^{-1}$ $\left(15 \mathrm{~mm} \mathrm{yr}^{-1}\right.$ corresponding to more than $4 \%$ of total precipitation), compared to the CLE scenario. Thus, the mitigation could help to alleviate expected future drought and water shortages in the Mediterranean region. 
- Additional ESM transient simulations, which only included the $\mathrm{CH}_{4}$ emission reductions, led to a global warming reduction that amounted to about $90 \%$ of the reduction produced by the simulations using the full set of measures for the final decade of the simulations (2041-2050). This suggests that, for longer time horizons, the net climate benefits from our chosen non- $\mathrm{CH}_{4}$ SLCP mitigation measures in terms of global annual mean temperature change are limited, probably due to small forcing and co-emitted cooling species. Nevertheless, if implemented as such, the mitigation package as a whole would have beneficial impacts on both air quality and climate, and for the latter, also in other climate variables than global annual mean temperature change such as regional changes in temperature and precipitation.

- For the first time, ECLIPSE compared the temperature response to an SLCP mitigation scenario as it is given by climate metrics (using the ARTP method) and as it is simulated with transient ESM simulations. This is crucial for the application of metrics, which - because of their simplicity and flexibility - are very relevant in a policy context where they can substitute full ESM simulations which are expensive and impractical for small perturbations. Both approaches give a global mean reduced warming of the surface temperatures by $0.22 \mathrm{~K}$ (and similar uncertainty ranges) for the period 2041-2050. Also the large-scale pattern of the response (with strongest warming reductions in the Arctic) is reproduced similarly by both methods, even though the agreement is not as good as the global mean.

- The metrics-based approach and the transient model simulations agree less on the relative contribution of $\mathrm{CH}_{4}$ and non- $\mathrm{CH}_{4}$ SLCP mitigation measures to the reduced warming. While the metrics-based approach suggests that the non- $\mathrm{CH}_{4}$ measures account for $22 \%$ of the global-mean temperature response for 2041-2050, the transient simulations result in a contribution from non- $\mathrm{CH}_{4}$ measures of only about $10 \%$. One reason for this disagreement is that many of the BC-related measures included in the mitigation basket were relatively $\mathrm{OA}$ rich and this makes their net temperature response more uncertain, especially when aerosol indirect effects are considered. Furthermore, small cooling influences are easily masked by unforced variability in fully coupled climate simulations.

- The major share of the cooling effect in our SLCP mitigation scenario is contributed by $\mathrm{CH}_{4}$ reductions, with $20-30 \%$ of the difference in near-term globalmean climate warming from the reduction of non- $\mathrm{CH}_{4}$ SLCPs (multi-model range $0.01-0.06 \mathrm{~K}$ for time periods from 2021-2040, according to metrics-based estimates). Thus, to maximise climate co-benefits of non$\mathrm{CH}_{4}$ SLCPs, sources with the highest BC / OA emission ratios should be addressed with priority. At the same time, air pollution policies should consider mitigation of $\mathrm{CH}_{4}$, with clear co-benefits for climate warming and air quality via reduced surface $\mathrm{O}_{3}$ concentrations.

- The ECLIPSE mitigation scenario has been developed to be representative of a mitigation strategy that considers both climate and air quality, assuring reduced climate forcing without detrimental impact on air quality; as a matter of fact, strong air quality cobenefits were identified. Real-world scenarios are likely to favour particular policy objectives and will also consider the costs for the mitigation measures. More work is therefore needed to explore a larger range of scenarios. By demonstrating the efficiency and capacity of the metrics-based approach to quantify temperature changes and its consistency with transient climate model simulations, ECLIPSE has opened the way to explore a large number of such scenarios. This would be an impossible task if transient climate ensemble model simulations were needed for each.

- The number of models contributing to the ECLIPSE project was relatively small. While the models were shown to be largely representative of results obtained from larger model ensembles, this makes quantification of mean values and especially uncertainties (e.g. of RF or temperature response) dependent on the particular properties of the ECLIPSE models. For a more comprehensive quantification of uncertainties, it is therefore recommended to repeat the modelling exercises presented in this paper with a larger international model ensemble.

Acknowledgements. The research leading to these results has received funding from the European Union Seventh Framework Programme (FP7/2007-2013) under grant agreement no. 282688 - ECLIPSE. Some partners are involved in the Nordic Centre of Excellence eSTICC (eScience Tools for Investigating Climate Change), funded by Nordforsk. We thank D. Shindell and an anonymous referee for their comments, which helped to improve this paper.

Edited by: Y. Balkanski

\section{References}

Aamaas, B., Peters, G. P., and Fuglestvedt, J. S.: Simple emission metrics for climate impacts, Earth Syst. Dynam., 4, 145-170, doi:10.5194/esd-4-145-2013, 2013.

Aamaas B., Berntsen, T. K., Fuglestvedt, J. S., Shine, K. P., and Bellouin, N.: Multimodel emission metrics for regional emissions of short lived climate forcers, Atmos. Chem. Phys. Discuss., submitted, 2015. 
Amann, M. and Wagner, F.: A Flexibility Mechanism for Complying with National Emission Ceilings for Air Pollutants, TSAP Report \#15, Version 1.0, International Institute for Applied Systems Analysis IIASA, Laxenburg, Austria, 2014.

Amann, M., Bertok, I., Borken-Kleefeld, J., Cofala, J., Heyes, C., Höglund-Isaksson, L., Klimont, Z., Nguyen, B., Posch, M., Rafaj, P., Sandler, R., Schöpp, W., Wagner, F., and Winiwarter, W.: Cost-effective control of air quality and greenhouse gases in Europe: Modeling and policy applications, Environ. Model. Softw., 26, 1489-1501, doi:10.1016/j.envsoft.2011.07.012, 2011.

Amann, M., Klimont, Z., and Wagner, F.: Regional and global emissions of air pollutants: Recent trends and future scenarios, Annu. Rev. Environ. Res., 38, 31-55, 2013.

AMAP: AMAP Assessment 2015: Black Carbon and Ozone as Arctic Climate Forcers, Arctic Monitoring and Assessment Programme (AMAP), Oslo, Norway, in preparation, 2015.

Andreae, M. O., Jones, C. D., and Cox, P. M.: Strong present-day aerosol cooling implies a hot future, Nature, 435, 1187-1190, 2005.

Andrews, T., Forster, P. M., Boucher, O., Bellouin, N., and Jones, A.: Precipitation, radiative forcing and global temperature change, Geophys. Res. Lett., 37, L14701, doi:10.1029/2010GL043991, 2010.

Anenberg, S. C., Schwartz, J., Shindell, D., Amann, M., Faluvegi, G., Klimont, Z., Janssens-Maenhout, G., Pozzoli, L., van Dingenen, R., Vignati, E., Emberson, L., Muller, N. Z., West, J. J., Williams, M., Demkine, V., Hicks, W. K., Kuylenstierna, J., Raes, F., and Ramanathan, V.: Global air quality and health cobenefits of mitigating near-term climate change through methane and black carbon emission controls, Environ. Health Perspect., 120, 831-839, doi:10.1289/ehp.1104301, 2012.

Arneth, A., Unger, N., Kulmala, M., and Andreae, M. O.: Clean the air, heat the planet?, Science, 326, 672-673, doi:10.1126/science.1181568, 2009.

Baker, L. H., Collins, W. J., Olivié, D. J. L., Cherian, R., Hodnebrog, Ø., Myhre, G., and Quaas, J.: Climate responses to anthropogenic emissions of short-lived climate pollutants, Atmos. Chem. Phys., 15, 8201-8216, doi:10.5194/acp-15-8201-2015, 2015a.

Baker, L., Cherian, R., Quaas, J., Oliviée, D., Hodenbrog, Ø.: Transient simulations of the ECLIPSE mitigation scenario, in preparation, 2015b.

Bellouin, N., Baker, L., Hodnebrog, Ø., Oliviè, D., Cherian, R., MacIntosh, C., Samset, B., Esteve, A., Aamaas, B., Quaas, J., and Myhre, G.: Regional and seasonal and ozone precursor emissions, Atmos. Chem. Phys. Discuss., in preparation, 2015.

Bentsen, M., Bethke, I., Debernard, J. B., Iversen, T., Kirkevåg, A., Seland, Ø., Drange, H., Roelandt, C., Seierstad, I. A., Hoose, C., and Kristjánsson, J. E.: The Norwegian Earth System Model, NorESM1-M - Part 1: Description and basic evaluation of the physical climate, Geosci. Model Dev., 6, 687-720, doi:10.5194/gmd-6-687-2013, 2013.

Berntsen, T. K., Fuglestvedt, J. S., Joshi, M. M., Shine, K. P., Stuber, N., Ponater, M., Sausen, R., Hauglustaine, D. A., and Li, L.: Climate response to regional emissions of ozone precursors: sensitivities and warming potentials, Tellus, 57B, 283-304, 2005.

Berntsen, T., Fuglestvedt, J., Myhre, G., Stordal, F., and Berglen, T. F.: Abatement of greenhouse gases: does location matter?, Climatic Change, 74, 377-411, 2006.
Berntsen, T. K., Tanaka, K., and Fuglestvedt, J. S.: Does black carbon abatement hinder $\mathrm{CO}_{2}$ abatement? A letter, Climatic Change, 103, 627-633, doi:10.1007/s10584-010-9941-3, 2010.

Bond, T. C. and Sun, H. L.: Can reducing black carbon emissions counteract global warming?, Environ. Sci. Technol., 39, 59215926, 2005.

Bond, T. C., Doherty, S. J., Fahey, D. W., Forster, P. M., Berntsen, T., DeAngelo, B. J., Flanner, M. G., Ghan, S., Kärcher, B., Koch, D., Kinne, S., Kondo, Y., Quinn, P. K., Sarofim, M. C., Schultz, M. G., Schulz, M., Venkataraman, C., Zhang, H., Zhang, S., Bellouin, N., Guttikunda, S. K., Hopke, P. K., Jacobson, M. Z., Kaiser, J. W., Klimont, Z., Lohmann, U., Schwarz, J. P., Shindell, D., Storelvmo, T., Warren, S. G., and Zender, C. S.: Bounding the role of black carbon in the climate system: A scientific assessment, J. Geophys. Res., 118, 5380-5552, doi:10.1002/jgrd.50171, 2013.

Boucher, O. and Reddy, M. S.: Climate trade-off between black carbon and carbon dioxide emissions, Energy Policy, 36, 193-200, 2008, see corrigendum at: http://www.lmd.jussieu.fr/ obolmd/ PDF/Corrigendum_boucher_Reddy_Energy_Policy_2008.pdf, 2008.

Boucher, O., Randall, D., Artaxo, P., Bretherton, C., Feingold, G., Forster, P., Kerminen, V.-M., Kondo, Y., Liao, H., Lohmann, U., Rasch, P., Satheesh, S. K., Sherwood, S., Stevens, B., and Zhang, X. Y.: Clouds and Aerosols. In: Climate Change 2013: The Physical Science Basis, Contribution of Working Group I to the Fifth Assessment Report of the Intergovernmental Panel on Climate Change, edited by: Stocker, T. F., Qin, D., Plattner, G.-K., Tignor, M., Allen, S. K., Boschung, J., Nauels, A., Xia, Y., Bex, V., and Midgley, P. M., Cambridge University Press, Cambridge, United Kingdom and New York, NY, USA, 571-657, 2013.

Bowerman, N. H. A., Frame, D. J., Huntingford, C., Lowe, J. A., Smith, S.M., and Allen, M. R.: The role of short-lived climate pollutants in meeting temperature goals, Nature Clim. Change, 3, 1021-1024, doi:10.1038/nclimate2034, 2013.

Brasseur, G. P. and Roeckner, E.: Impact of improved air quality on the future evolution of climate, Geophys. Res. Lett., 32, L23704, doi:10.1029/2005GL023902, 2005.

Broccoli, A. J., Dahl, K. A., and Stouffer, R. J.: Response of the ITCZ to Northern Hemisphere cooling, Geophys. Res. Lett., 33, L01702, doi:10.1029/2005GL024546, 2006.

Cherian, R., Quaas, J., Salzmann, M., and Wild, M.: Pollution trends over Europe constrain global aerosol forcing as simulated by climate models, Geophys. Res. Lett., 41, 2176-2181, doi:10.1002/2013GL058715, 2014.

Collins, W. J., Sitch, S., and Boucher, O.: How vegetation impacts affect climate metrics for ozone precursors, J. Geophys. Res., 115, D23308, doi:10.1029/2010JD014187, 2010.

Collins, W. J., Fry, M. M., Yu, H., Fuglestvedt, J. S., Shindell, D. T., and West, J. J.: Global and regional temperature-change potentials for near-term climate forcers, Atmos. Chem. Phys., 13, 2471-2485, doi:10.5194/acp-13-2471-2013, 2013.

Daskalakis, N., Myriokefalitakis, S., and Kanakidou, M.: Sensitivity of tropospheric loads and lifetimes of short lived pollutants to fire emissions, Atmos. Chem. Phys., 15, 3543-3563, doi:10.5194/acp-15-3543-2015, 2015.

Dentener, F., Keating, T., and Akimoto, H. (Eds.): Hemispheric Transport of Air Pollution 2010 - Part A: Ozone and Particu- 
late Matter, Air Pollution Studies No. 17, United Nations, New York and Geneva, 2010.

EC: Proposal for a Directive of the European Parliament and of the Council on the reduction of national emissions of certain atmospheric pollutants and amending Directive 2003/35/EC, European Commission (EC), Brussels, Belgium, 2013.

Eckhardt, S., Quennehen, B., Olivié, D. J. L., Berntsen, T. K., Cherian, R., Christensen, J. H., Collins, W., Crepinsek, S., Daskalakis, N., Flanner, M., Herber, A., Heyes, C., Hodnebrog, Ø., Huang, L., Kanakidou, M., Klimont, Z., Langner, J., Law, K. S., Lund, M. T., Mahmood, R., Massling, A., Myriokefalitakis, S., Nielsen, I. E., Nøjgaard, J. K., Quaas, J., Quinn, P. K., Raut, J.-C., Rumbold, S. T., Schulz, M., Sharma, S., Skeie, R. B., Skov, H., Uttal, T., von Salzen, K., and Stohl, A.: Current model capabilities for simulating black carbon and sulfate concentrations in the Arctic atmosphere: a multi-model evaluation using a comprehensive measurement data set, Atmos. Chem. Phys., 15, 9413-9433, doi:10.5194/acp-15-9413-2015, 2015.

EEA, 2013: Air quality in Europe - 2013 report, EEA report 9/2013, ISBN 978-92-9213-406-8, available at: http://www.eea. europa.eu/publications/air-quality-in-europe-2013 (last access: 28 April 2014), 2013.

Endresen, Ø., Sørgård, E., Behrens, H. L., Brett, P. O., and Isaksen, I. S. A.: A historical reconstruction of ships' fuel consumption and emissions, J. Geophys. Res., 112, D12301, doi:10.1029/2006JD007630, 2007.

Flanner, M. G.: Arctic climate sensitivity to local black carbon, J. Geophys. Res. Atmos., 118, 1840-1851, doi:10.1002/jgrd.50176, 2013.

Fuglestvedt, J. S., Berntsen, T. K., Isaksen, I. S. A., Mao, H. T., Liang, X. Z., and Wang, W. C.: Climatic forcing of nitrogen oxides through changes in tropospheric ozone and methane; global 3D model studies, Atmos. Environ., 33, 961-977, 1999.

Fuglestvedt, J. S., Shine, K. P., Berntsen, T., Cook, J., Lee, D. S., Stenke, A., Skeie, R. B., Velders, G. J. M., and Waitz, I. A.: Transport impacts on atmosphere and climate: Metrics, Atmos. Environ., 44, 4648-4677, doi:10.1016/j.atmosenv.2009.04.044, 2010.

Gadhavi, H. S., Renuka, K., Ravi Kiran, V., Jayaraman, A., Stohl, A., Klimont, Z., and Beig, G.: Evaluation of black carbon emission inventories using a Lagrangian dispersion model - a case study over southern India, Atmos. Chem. Phys., 15, 1447-1461, doi:10.5194/acp-15-1447-2015, 2015.

GEA: Global Energy Assessment: Toward a Sustainable Future, Cambridge University Press, UK, 2012.

Gedney, N., Huntingford, C., Weedon, G. P., Bellouin, N., Boucher, O., and Cox, P. M.: Detection of solar dimming and brightening effects on Northern Hemisphere river flow, Nat. Geosci., 7, 796800, doi:10.1038/ngeo2263, 2014.

Gent, P. R., Danabasoglu, G., Donner, L. J., Holland, M. M., Hunke, E. C., Jayne, S. R., Lawrence, D. M., Neale, R. B., Rasch, P. J., Vertenstein, M., Worley, P. H., Yang, Z.-L., and Zhang, M.: The Community Climate System Model version 4, J. Climate, 24, 4973-4991, doi:10.1175/2011jcli4083.1, 2011.

Gilgen, H., Wild, M., and Ohmura, A.: Means and trends of shortwave irradiance at the surface estimated from global energy balance archive data, J. Climate, 11, 2042-2061, 1998

Gillett, N. P. and Matthews, H. D.: Accounting for carbon cycle feedbacks in a comparison of the global warming ef- fects of greenhouse gases, Environ. Res. Lett., 5, 034011, doi:10.1088/1748-9326/5/3/034011, 2010.

Grell, G. A., Peckham, S. E., Schmitz, R., McKeen, S. A., Frost, G., Skamarock, W. C., and Eder, B.: Fully coupled online chemistry within the WRF model, Atmos. Environ., 39, 6957-6975, 2005.

Grieshop, A. P., Reynolds, C. C. O., Kandlikar, M., and Dowlatabadi, H.: A black-carbon mitigation wedge, Nat. Geosci., 2, 533-534, 2009.

Grosse, L. Y., Lauby-Secretan, B., El Ghissassi, F., Bouvard, V., Benbrahim-Tallaa, L., Guha, N., Baan, R., Mattock, H., and Straif, K.: The carcinogenicity of outdoor air pollution, Lancet, 14, 1262-1263, 2013.

Guenther, A. B., Jiang, X., Heald, C. L., Sakulyanontvittaya, T., Duhl, T., Emmons, L. K., and Wang, X.: The Model of Emissions of Gases and Aerosols from Nature version 2.1 (MEGAN2.1): an extended and updated framework for modeling biogenic emissions, Geosci. Model Dev., 5, 1471-1492, doi:10.5194/gmd-51471-2012, 2012.

Hewitt, H. T., Copsey, D., Culverwell, I. D., Harris, C. M., Hill, R. S. R., Keen, A. B., McLaren, A. J., and Hunke, E. C.: Design and implementation of the infrastructure of HadGEM3: the nextgeneration Met Office climate modelling system, Geosci. Model Dev., 4, 223-253, doi:10.5194/gmd-4-223-2011, 2011.

Hodnebrog, Ø., Myhre, G., and Samset, B.: How shorter black carbon lifetime alters its climate effect, Nature Comm., 5, 5065, doi:10.1038/ncomms6065, 2014.

IARC: IARC monographs on the evaluation of carcinogenic risks to humans, Volume 109, Outdoor air pollution, Lyon, International Agency for Research on Cancer, in press, 2015.

IEA (International Energy Agency): Energy Technology Perspectives, 2012 - Pathways to a Clean Energy System, OECD/IEA, Paris, 2012.

Im, U., Christodoulaki, S., Violaki, K., Zampas, P., Kocak, M.,Daskalakis, N., Mihalopoulos, N., and Kanakidou, M.: Atmospheric deposition of nitrogen and sulfur over southern Europe with focus on the Mediterranean and the Black Sea, Atmos. Environ., 81, 660-670, doi:10.1016/j.atmosenv.2013.09.048, 2013.

Isaksen, I. S. A., Granier, C., Myhre, G., Berntsen, T. K., Dalsøren, S. B., Gauss, M., Klimont, Z., Benestad, R., Bousquet, P., Collins, W., Cox, T., Eyring, V., Fowler, D., Fuzzi, S., Jöckel, P., Laj, P., Lohmann, U., Maione, M., Monks, P., Prevot, A. S. H., Raes, F., Richter, A., Rognerud, B., Schulz, M., Shindell, D., Stevenson, D. S., Storelvmo, T., Wang, W.-C., van Weele, M., Wild, M., and Wuebbles, D.: Atmospheric composition change: Climate-chemistry interactions, Atmos. Environ., 43, 5138-5192, 2009.

Jackson, S. C.: Parallel pursuit of near-term and long-term climate mitigation, Science, 326, 526-527, 2009.

Jiao, C., Flanner, M. G., Balkanski, Y., Bauer, S. E., Bellouin, N., Berntsen, T. K., Bian, H., Carslaw, K. S., Chin, M., De Luca, N., Diehl, T., Ghan, S. J., Iversen, T., Kirkevåg, A., Koch, D., Liu, X., Mann, G. W., Penner, J. E., Pitari, G., Schulz, M., Seland, Ø., Skeie, R. B., Steenrod, S. D., Stier, P., Takemura, T., Tsigaridis, K., van Noije, T., Yun, Y., and Zhang, K.: An AeroCom assessment of black carbon in Arctic snow and sea ice, Atmos. Chem. Phys., 14, 2399-2417, doi:10.5194/acp-14-2399-2014, 2014.

Joshi, M., Shine, K., Ponater, M., Stuber, N., Sausen, R., and Li, L.: A comparison of climate response to different radiative forcings 
in three general circulation models: towards an improved metric of climate change, Clim. Dynam., 20, 843-854, 2003.

Kanakidou, M., Duce, R. A., Prospero, J. M., Baker, A. R., BenitezNelson, C., Dentener, F. J., Hunter, K. A., Liss, P. S., Mahowald, N., Okin, G. S., Sarin, M., Tsigaridis, K., Uematsu, M., Zamora, L. M., and Zhu, T.: Atmospheric fluxes of organic N and $\mathrm{P}$ to the global ocean, Global Biogeochem. Cy., 26, GB3026, doi:10.1029/2011gb004277, 2012.

Kawamoto, T., Pham, T. T., Matsuda, T., Oyama, T., Tanaka, M., Yu, H. S., and Uchiyama, I.: Historical review on development of environmental quality standards and guideline values for air pollutants in Japan, Int. J. Hyg. Environ. Health, 214, 296-304, doi:10.1016/j.ijheh.2011.05.007, 2011.

Kirkevåg, A., Iversen, T., Seland, Ø., Hoose, C., Kristjánsson, J. E., Struthers, H., Ekman, A. M. L., Ghan, S., Griesfeller, J., Nilsson, E. D., and Schulz, M.: Aerosol-climate interactions in the Norwegian Earth System Model - NorESM1-M, Geosci. Model Dev., 6, 207-244, doi:10.5194/gmd-6-207-2013, 2013.

Kirtman, B., Power, S. B., Adedoyin, J. A., Boer, G. J., Bojariu, R., Camilloni, I., Doblas-Reyes, F. J., Fiore, A. M., Kimoto, M., Meehl, G. A., Prather, M., Sarr, A., Schär, C., Sutton, R., van Oldenborgh, G. J., Vecchi, G., and Wang, H. J.: Near-term Climate Change: Projections and Predictability, in: Climate Change 2013: The Physical Science Basis. Contribution of Working Group I to the Fifth Assessment Report of the Intergovernmental Panel on Climate Change, edited by: Stocker, T. F., Qin, D., Plattner, G.-K., Tignor, M., Allen, S. K., Boschung, J., Nauels, A., Xia, Y., Bex, V., and Midgley, P. M., Cambridge University Press, Cambridge, United Kingdom and New York, NY, USA, 953-1028, 2013.

Klimont, Z., Smith, S. J., and Cofala, J.: The last decade of global anthropogenic sulfur dioxide: 2000-2011 emissions, Environ. Res. Lett., 8, 014003, doi:10.1088/1748-9326/8/1/014003, 2013.

Klimont, Z., Kupiainen, K., Heyes, Ch., Purohit, P., Cofala, J., Rafaj, P., Borken-Kleefeld, J., andSchoepp, W.: Global anthropogenic emissions of particulate matter, in preparation, 2015a.

Klimont, Z., Hoglund, L., Heyes, Ch., Rafaj, P., Schoepp, W., Cofala, J., Borken-Kleefeld, J., Purohit, P., Kupiainen, K., Winiwarter, W., Amann, M., Zhao, B., Wang, S. X., Bertok, I., and Sander, R.: Global scenarios of air pollutants and methane: 1990-2050, in preparation, 2015b.

Knutti, R. and Hegerl, G. C.: The equilibrium sensitivity of the Earth's temperature to radiation changes, Nat. Geosci., 1, 735753, doi:10.1038/ngeo337, 2008.

Koch, D., Bond, T. C., Streets, D., Unger, N., and van der Werf, G. R.: Global impacts of aerosols from particular source regions and sectors, J. Geophys. Res., 112, D02205, doi:10.1029/2005JD007024, 2007.

Kopp R. E. and Mauzerall, D. L.: Assessing the climatic benefits of black carbon mitigation, Proc. Natl. Acad. Sci. USA, 107, 11703-11708, 2010.

Kvalevåg, M. M., Samset, B., and Myhre, G.: Hydrological sensitivity to greenhouse gases and aerosols in a global climate model, Geophys. Res. Lett., 40, 1432-1438, 2013.

Lamarque, J.-F., Bond, T. C., Eyring, V., Granier, C., Heil, A., Klimont, Z., Lee, D., Liousse, C., Mieville, A., Owen, B., Schultz, M. G., Shindell, D., Smith, S. J., Stehfest, E., Van Aardenne, J., Cooper, O. R., Kainuma, M., Mahowald, N., McConnell, J. R., Naik, V., Riahi, K., and van Vuuren, D. P.: His- torical (1850-2000) gridded anthropogenic and biomass burning emissions of reactive gases and aerosols: methodology and application, Atmos. Chem. Phys., 10, 7017-7039, doi:10.5194/acp10-7017-2010, 2010.

Lee, D. S., Fahey, D. W., Forster, P. M., Newton, P. J., Wit, R. C. N., Lim, L. L., Owen, B., and Sausen, R.: Aviation and global climate change in the 21 st century, Atmos. Environ., 43, 3520 3537, 2009.

Lelieveld, J., Berresheim, H., Borrmann, S., Crutzen, P. J., Dentener, F. J., Fischer, H., Feichter, J.,Flatau, P. J., Heland, J., Holzinger, R., Korrmann, R., Lawrence, M. G., Levin, Z., Markowicz, K. M., Mihalopoulos, N., Minikin, A., Ramanathan, V., De Reus, M., Roelofs, G. J., Scheeren, H. A., Sciare, J., Schlager, H., Schultz, M., Siegmund, P., Steil, B., Stephanou, E. G., Stier, P., Traub, M., Warneke, C., Williams, J., and Ziereis, H.: Global air pollution crossroads over the Mediterranean, Science, 298, 794-799, 2002.

Lim, S. S., Vos, T., Flaxman, A. D., Danaei, G., Shibuya, K., AdairRohani H., Amann, M., Anderson, H. R., Andrews, K. G., Aryee, M., Atkinson, C., Bacchus, L. J., Bahalim, A. N., Balakrishnan, K., Balmes, J., Barker-Collo, S., Baxter, A., Bell, M. L., Blore, J. D., Blyth, F., Bonner, C., Borges, G., Bourne, R., Boussinesq, M., Brauer, M., Brooks, P., Bruce, N. G., Brunekreef, B., BryanHancock, C., Bucello, C., Buchbinder, R., Bull, F., Burnett, R. T., Byers, T. E., Calabria, B., Carapetis, J., Carnahan, E., Chafe, Z., Charlson, F., Chen, H., Chen, J. S., Cheng, A. T., Child, J. C., Cohen, A., Colson, K. E., Cowie, B. C., Darby, S., Darling, S., Davis, A., Degenhardt, L., Dentener, F., Des Jarlais, D. C., Devries, K., Dherani, M., Ding, E. L., Dorsey, E. R., Driscoll, T., Edmond, K., Ali, S. E., Engell, R. E., Erwin, P. J., Fahimi, S., Falder, G., Farzadfar, F., Ferrari, A., Finucane, M. M., Flaxman, S., Fowkes, F. G., Freedman, G., Freeman, M. K., Gakidou, E., Ghosh, S., Giovannucci, E., Gmel, G., Graham, K., Grainger, R., Grant, B., Gunnell, D., Gutierrez, H. R., Hall, W., Hoek, H. W., Hogan, A., Hosgood III, H. D., Hoy, D., Hu, H., Hubbell, B. J., Hutchings, S. J., Ibeanusi, S. E., Jacklyn, G. L., Jasrasaria, R., Jonas, J. B., Kan, H., Kanis, J. A., Kassebaum, N., Kawakami, N., Khang, Y. H., Khatibzadeh, S., Khoo, J. P., Kok, C., Laden, F., Lalloo, R., Lan, Q., Lathlean, T., Leasher, J. L., Leigh, J., Li, Y., Lin, J. K., Lipshultz, S. E., London, S., Lozano, R., Lu, Y., Mak, J., Malekzadeh, R., Mallinger, L., Marcenes, W., March, L., Marks, R., Martin, R., McGale, P., McGrath, J., Mehta, S., Mensah, G. A., Merriman, T. R., Micha, R., Michaud, C., Mishra, V., Mohd Hanafiah, K., Mokdad, A. A., Morawska, L., Mozaffarian, D., Murphy, T., Naghavi, M., Neal, B., Nelson, P. K., Nolla, J. M., Norman, R., Olives, C., Omer, S. B., Orchard, J., Osborne, R., Ostro, B., Page, A., Pandey, K. D., Parry, C. D., Passmore, E., Patra, J., Pearce, N., Pelizzari, P. M., Petzold, M., Phillips, M. R., Pope, D., Pope III, C. A., Powles, J., Rao, M., Razavi, H., Rehfuess, E. A., Rehm, J. T., Ritz, B., Rivara, F. P., Roberts, T., Robinson, C., Rodriguez-Portales, J. A., Romieu, I., Room, R., Rosenfeld, L. C., Roy, A., Rushton, L., Salomon, J. A., Sampson, U., Sanchez-Riera, L., Sanman, E., Sapkota, A., Seedat, S., Shi, P., Shield, K., Shivakoti, R., Singh, G. M., Sleet, D. A., Smith, E., Smith, K. R., Stapelberg, N. J., Steenland, K., Stöckl, H., Stovner, L. J., Straif, K., Straney, L., Thurston, G. D., Tran, J. H., Van Dingenen, R., van Donkelaar, A., Veerman, J. L., Vijayakumar, L., Weintraub, R., Weissman, M. M., White, R. A., Whiteford, H., Wiersma, S. T., Wilkinson, J. D., Williams, H. 
C., Williams, W., Wilson, N., Woolf, A. D., Yip, P., Zielinski, J. M., Lopez, A. D., Murray, C. J., Ezzati, M., AlMazroa, M. A., and Memish, Z. A.: A comparative risk assessment of burden of disease and injury attributable to 67 risk factors and risk factor clusters in 21 regions, 1990-2010: a systematic analysis for the Global Burden of Disease Study 2010, The Lancet, 380, 22242260, doi:10.1016/S0140-6736(12)61766-8, 2012.

Lund, M., Berntsen, T., Fuglestvedt, J., Ponater, M., and Shine, K: How much information is lost by using global-mean climate metrics? an example using the transport sector, Climate Change, 113, 949-963, 2012.

Lund, T. M., Berntsen, T. K., Heyes, C., Klimont, Z., and Samset, B. H.: Global and regional climate impacts of black carbon and coemitted species from the on-road diesel sector, Atmos. Environ., 98, 50-58, 2014a.

Lund, T. M., Berntsen, T. K., and Fuglestvedt, J. S.: Climate impacts of short-lived climate forcers versus $\mathrm{CO}_{2}$ from biodiesel: a case of the EU on-road sector, Environ. Sci. Technol., 48, 1444514454, doi:10.1021/es505308g, 2014b.

MacIntosh, C. R., Shine, K. P., and Collins, W. J.: Radiative forcing and climate metrics for ozone precursor emissions: the impact of multi-model averaging, Atmos. Chem. Phys., 15, 3957-3969, doi:10.5194/acp-15-3957-2015, 2015.

Mahowald, N.: Aerosol indirect effect on biogeochemical cycles and climate, Science, 334, 794-796, doi:10.1126/science.1207374, 2011.

Mann, G. W., Carslaw, K. S., Spracklen, D. V., Ridley, D. A., Manktelow, P. T., Chipperfield, M. P., Pickering, S. J., and Johnson, C. E.: Description and evaluation of GLOMAP-mode: a modal global aerosol microphysics model for the UKCA composition-climate model, Geosci. Model Dev., 3, 519-551, doi:10.5194/gmd-3-519-2010, 2010.

Manne, A. S. and Richels, R. G.: An alternative approach to establishing trade-offs among greenhouse gases, Nature, 410, 675677, 2001

Meinshausen, M., Meinshausen, N., Hare, W., Raper, S. C. B., Frieler, K., Knutti, R., Frame, D. J., and Allen, M. R.: Greenhouse-gas emission targets for limiting global warming to 2 degrees C, Nature, 458, 1158-1162, 2009.

Mercado, L. M., Bellouin, N., Sitch, S., Boucher, O., Huntingford, C., Wild, O., and Cox, P. M.: Impact of changes in diffuse radiation on the global land carbon sink, Nature, 458, 1014-1017, doi:10.1038/nature07949, 2009.

Mitchell, T. D. and Jones, P. D.: An improved method of constructing a database of monthly climate observations and associated high-resolution grids, Int. J. Climatol., 25, 693-712, doi:10.1002/joc.1181, 2005.

Molina, M., Zaelke, D., Sarma, K. M., Andersen, S. O., Ramanathan, V., and Kaniaru, D.: Reducing abrupt climate change risk using the Montreal Protocol and other regulatory actions to complement cuts in $\mathrm{CO}_{2}$ emissions, Proc. Natl. Acad. Sci. USA, 106, 20616-20621, 2009.

Myhre, G., Berglen, T. F., Johnsrud, M., Hoyle, C. R., Berntsen, T. K., Christopher, S. A., Fahey, D. W., Isaksen, I. S. A., Jones, T. A., Kahn, R. A., Loeb, N., Quinn, P., Remer, L., Schwarz, J. P., and Yttri, K. E.: Modelled radiative forcing of the direct aerosol effect with multi-observation evaluation, Atmos. Chem. Phys., 9, 1365-1392, doi:10.5194/acp-9-1365-2009, 2009.
Myhre, G., Fuglestvedt, J. S., Berntsen, T. K., and Lund, M. T.: Mitigation of short-lived heating components may lead to unwanted long-term consequences, Atmos. Environ., 45, 61036106, doi:10.1016/j.atmosenv.2011.08.009, 2011.

Myhre, G., Shindell, D., Breon, F.-M., Collins, W., Fuglestvedt, J., Huang, J., Koch, D., Lamarque, J.-F., Lee, D., Mendoza, B., Nakajima, T., Robock, A., Stephens, G., Takemura, T., and Zhang, H.: Anthropogenic and Natural Radiative Forcing, in: Climate Change 2013: The Physical Science Basis. Contribution of Working Group I to the Fifth Assessment Report of the Intergovernmental Panel on Climate Change, edited by: Stocker, T. F., Qin, D., Plattner, G.-K., Tignor, M., Allen, S. K., Boschung, J., Nauels, A., Xia, Y., Bex, V., and Midgley, P. M., Cambridge University Press, Cambridge, United Kingdom and New York, NY, USA, 659-740, 2013a.

Myhre, G., Samset, B. H., Schulz, M., Balkanski, Y., Bauer, S., Berntsen, T. K., Bian, H., Bellouin, N., Chin, M., Diehl, T., Easter, R. C., Feichter, J., Ghan, S. J., Hauglustaine, D., Iversen, T., Kinne, S., Kirkevåg, A., Lamarque, J.-F., Lin, G., Liu, X., Lund, M. T., Luo, G., Ma, X., van Noije, T., Penner, J. E., Rasch, P. J., Ruiz, A., Seland, Ø., Skeie, R. B., Stier, P., Takemura, T., Tsigaridis, K., Wang, P., Wang, Z., Xu, L., Yu, H., Yu, F., Yoon, J.-H., Zhang, K., Zhang, H., and Zhou, C.: Radiative forcing of the direct aerosol effect from AeroCom Phase II simulations, Atmos. Chem. Phys., 13, 1853-1877, doi:10.5194/acp-13-18532013, 2013b.

Naik, V., Mauzerall, D., Horowitz, L., Schwarzkopf, M. D., Ramaswamy, V., and Oppenheimer, M.: Net radiative forcing due to changes in regional emissions of tropospheric ozone precursors, J. Geophys. Res., 110, D24306, doi:10.1029/2005JD005908, 2005.

Olivié, D. J. L. and Peters, G. P.: Variation in emission metrics due to variation in $\mathrm{CO}_{2}$ and temperature impulse response functions, Earth Syst. Dynam., 4, 267-286, doi:10.5194/esd-4-267-2013, 2013.

Orlowsky, B. and Seneviratne, S. I.: Global changes in extreme events: regional and seasonal dimension, Climatic Change, 110, 669-696, doi:10.1007/s10584-011-0122-9, 2012.

Penner, J. E., Prather, M. J., Isaksen, I. S. A., Fuglestvedt, J. S., Klimont, Z., and Stevenson, D. S.: Short-lived uncertainty?, Nat. Geosci., 3, 587-588, doi:10.1038/ngeo932, 2010.

Pierrehumbert, R. T.: Short-Lived Climate Pollution, Annu. Rev. Earth Planet. Sci., 42, 341-379, doi:10.1146/annurev-earth060313-054843, 2014.

Pope III, C. A., Thun, M. J., Namboodiri, M. M., Dockery, D. W., Evans, J. S., and Speizer, F. E.: Particulate air pollution as a predictor of mortality in a prospective study of U.S. adults, Am. J. Respir. Crit. Care Med., 151, 669-674, 1995.

Pope III, C. A., Burnett, R. T., Thun, M. J., Calle, E. E., Krewski, D., Ito, K., Thurston, G. D.: Lung cancer, cardiopulmonary mortality, and long-term exposure to fine particulate air pollution, J. Am. Med. Assoc., 287, 1132-1141, 2002.

Pope III, C. A., Ezzati, M., Dockery, D. W.: Fine-particulate air pollution and life expectancy in the United States, New Engl. J. Med., 360, 376-386, doi:10.1056/NEJMsa0805646, 2009.

Prather, M. J., Holmes, C. D., and Hsu, J.: Reactive greenhouse gas scenarios: Systematic exploration of uncertainties and the role of atmospheric chemistry, Geophys. Res. Lett., 39, L09803, doi:10.1029/2012GL051440, 2012. 
Quaas, J., Ming, Y., Menon, S., Takemura, T., Wang, M., Penner, J. E., Gettelman, A., Lohmann, U., Bellouin, N., Boucher, O., Sayer, A. M., Thomas, G. E., McComiskey, A., Feingold, G., Hoose, C., Kristjánsson, J. E., Liu, X., Balkanski, Y., Donner, L. J., Ginoux, P. A., Stier, P., Grandey, B., Feichter, J., Sednev, I., Bauer, S. E., Koch, D., Grainger, R. G., Kirkevåg, A., Iversen, T., Seland, Ø., Easter, R., Ghan, S. J., Rasch, P. J., Morrison, H., Lamarque, J.-F., Iacono, M. J., Kinne, S., and Schulz, M.: Aerosol indirect effects - general circulation model intercomparison and evaluation with satellite data, Atmos. Chem. Phys., 9, 8697-8717, doi:10.5194/acp-9-8697-2009, 2009.

Quennehen, B., Raut, J.-C., Law, K. S., Ancellet, G., Clerbaux, C., Kim, S.-W., Lund, M. T., Myhre, G., Olivié, D. J. L., Safieddine, S., Skeie, R. B., Thomas, J. L., Tsyro, S., Bazureau, A., Bellouin, N., Daskalakis, N., Hu, M., Kanakidou, M., Klimont, Z., Kupiainen, K., Myriokefalitakis, S., Quaas, J., Rumbold, S. T., Schulz, M., Cherian, R., Shimizu, A., Wang, J., Yoon, S.-C., and Zhu, T.: Multi-model evaluation of short-lived pollutant distributions over East Asia during summer 2008, Atmos. Chem. Phys. Discuss., 15, 11049-11109, doi:10.5194/acpd-15-11049-2015, 2015.

Quinn, P. K., Bates, T. S., Baum, E., Doubleday, N., Fiore, A. M., Flanner, M., Fridlind, A., Garrett, T. J., Koch, D., Menon, S., Shindell, D., Stohl, A., and Warren, S. G.: Short-lived pollutants in the Arctic: their climate impact and possible mitigation strategies, Atmos. Chem. Phys., 8, 1723-1735, doi:10.5194/acp8-1723-2008, 2008.

Ramanathan, V. and Carmichael, G.: Global and regional climate changes due to black carbon, Nat. Geosci., 1, 221-222, 2008.

Reddy, M. S. and Boucher, O.: Climate impact of black carbon emitted from energy consumption in the world's regions, Geophys. Res. Lett., 34, L11802, doi:10.1029/2006GL028904, 2007.

Reisinger, A., Maltehausen, M., Manning, M., and Bodeker, G.: Uncertainties of global warming metrics: $\mathrm{CO}_{2}$ and $\mathrm{CH}_{4}$, Geophys. Res. Lett., 47, L14707, doi:10.1029/2010GL043803, 2010.

Rogelj, J., Schaeffer, M., Meinshausen, M., Shindell, D. T., Hare, W., Klimont, Z., Velders, G. J. M., Amann, M., and Schellnhuber, H. J.: Disentangling the effects of $\mathrm{CO}_{2}$ and short-lived climate forcer mitigation, Proc. Natl. Acad. Sci. USA, 111, 1632516330, doi:10.1073/pnas.1415631111, 2014.

Rypdal, K., Rive, N., Berntsen, T., Fagerli, H., Klimont, Z., Mideksa, T. K., and Fuglestvedt, J.: Climate and air qualitydriven scenarios of ozone and aerosol precursor abatement, Environ. Sci. Policy, 12, 855-869, 2009a.

Rypdal, K., Rive, N., Berntsen, T., Klimont, Z., Mideksa, T. K., Myhre, G., and Bieltvedt Skeie, R.: Costs and global impacts of black carbon abatement strategies, Tellus Ser. B, 61, 625-641, 2009b.

Samset, B. H. and Myhre, G.: Climate response to externally mixed black carbon as a function of altitude, J. Geophys. Res.-Atmos., 120, 2913-2927, doi:10.1002/2014jd022849, 2015.

Samset, B. H., Myhre, G., Schulz, M., Balkanski, Y., Bauer, S., Berntsen, T. K., Bian, H., Bellouin, N., Diehl, T., Easter, R. C., Ghan, S. J., Iversen, T., Kinne, S., Kirkevåg, A., Lamarque, J.F., Lin, G., Liu, X., Penner, J. E., Seland, Ø., Skeie, R. B., Stier, P., Takemura, T., Tsigaridis, K., and Zhang, K.: Black carbon vertical profiles strongly affect its radiative forcing uncertainty, Atmos. Chem. Phys., 13, 2423-2434, doi:10.5194/acp-13-24232013, 2013.
Samset, B. H., Myhre, G., Herber, A., Kondo, Y., Li, S.-M., Moteki, N., Koike, M., Oshima, N., Schwarz, J. P., Balkanski, Y., Bauer, S. E., Bellouin, N., Berntsen, T. K., Bian, H., Chin, M., Diehl, T., Easter, R. C., Ghan, S. J., Iversen, T., Kirkevåg, A., Lamarque, J.-F., Lin, G., Liu, X., Penner, J. E., Schulz, M., Seland, Ø., Skeie, R. B., Stier, P., Takemura, T., Tsigaridis, K., and Zhang, K.: Modelled black carbon radiative forcing and atmospheric lifetime in AeroCom Phase II constrained by aircraft observations, Atmos. Chem. Phys., 14, 12465-12477, doi:10.5194/acp14-12465-2014, 2014.

Schmale, J., Shindell, D., von Schneidemesser, E., Chabay, I., and Lawrence, M.: Air pollution: Clean up our skies, Nature, 515, 335-337, 2014.

Schulz, M., Olivié, D., Tsyro, S., Kanakidou, M., Myriokefalitakis, S., Daskalakis, N., Im, U., Fanourgakis, G., Hodnebrog, Ø., Skeie, R., Lund, M., Myhre, G., Bellouin, N., Rumbold, S., Collins, B., Cherian, R., and Quaas, J.: ECLIPSE Deliverable 2.1: Report on model accuracy, available at: http://eclipse.nilu. no/language/en-GB/ProjectOverview/Deliverables.aspx, last access: 18 September 2015.

Shindell, D. and Faluvegi, G.: Climate response to regional radiative forcing during the twentieth century, Nat. Geosci., 2, 294-300, doi:10.1038/ngeo473, 2009.

Shindell, D., Schulz, M., Ming, Y., Takemura, T., Faluvegi, G., and Ramaswamy, R.: Spatial scales of climate response to inhomogeneous radiative forcing, J. Geophys. Res., 115, D19110, doi:10.1029/2010JD014108, 2010.

Shindell, D., Kuylenstierna, J. C. I., Vignati, E., van Dingenen, R., Amann, M., Klimont, Z., Anenberg, S. C., Muller, N., JanssensMaenhout, G., Raes, F., Schwartz, J., Faluvegi, G., Pozzoli, L., Kupiainen, K., Höglund-Isaksson, L., Emberson, L., Streets, D., Ramanathan, V., Hicks, K., Kim Oanh, N. T., Milly, G., Williams, M., Demkine, V., and Fowler, D.: Simultaneously mitigating near-term climate change and improving human health and food security, Science, 335, 183-189, doi:10.1126/science.1210026, 2012.

Shindell, D. T.: Evaluation of the absolute regional temperature potential, Atmos. Chem. Phys., 12, 7955-7960, doi:10.5194/acp12-7955-2012, 2012.

Shindell, D. T.: The social cost of atmospheric release, Climatic Change, 130, 313-326, doi:10.1007/s10584-015-1343-0, 2015.

Shindell, D. T., Chin, M., Dentener, F., Doherty, R. M., Faluvegi, G., Fiore, A. M., Hess, P., Koch, D. M., MacKenzie, I. A., Sanderson, M. G., Schultz, M. G., Schulz, M., Stevenson, D. S., Teich, H., Textor, C., Wild, O., Bergmann, D. J., Bey, I., Bian, H., Cuvelier, C., Duncan, B. N., Folberth, G., Horowitz, L. W., Jonson, J., Kaminski, J. W., Marmer, E., Park, R., Pringle, K. J., Schroeder, S., Szopa, S., Takemura, T., Zeng, G., Keating, T. J., and Zuber, A.: A multi-model assessment of pollution transport to the Arctic, Atmos. Chem. Phys., 8, 5353-5372, doi:10.5194/acp-85353-2008, 2008.

Shindell, D. T., Lamarque, J.-F., Schulz, M., Flanner, M., Jiao, C., Chin, M., Young, P. J., Lee, Y. H., Rotstayn, L., Mahowald, N., Milly, G., Faluvegi, G., Balkanski, Y., Collins, W. J., Conley, A. J., Dalsoren, S., Easter, R., Ghan, S., Horowitz, L., Liu, X., Myhre, G., Nagashima, T., Naik, V., Rumbold, S. T., Skeie, R., Sudo, K., Szopa, S., Takemura, T., Voulgarakis, A., Yoon, J.-H., and Lo, F.: Radiative forcing in the ACCMIP historical and fu- 
ture climate simulations, Atmos. Chem. Phys., 13, 2939-2974, doi:10.5194/acp-13-2939-2013, 2013.

Shine, K. P.: The global warming potential: the need for an interdisciplinary retrial. An editorial comment, Climatic Change, 96, 467-472, 2009.

Shine, K. P., Berntsen, T. K., Fuglestvedt, J. S., and Sausen, R.: Scientific issues in the design of metrics for inclusion of oxides of nitrogen in global climate agreements, Proc. Natl. Acad. Sci. USA, 102, 15768-15773, 2005.

Shine, K. P., Berntsen, T. K., Fuglestvedt, J. S., Bieltvedt Skeie, R., and Stuber, N.: Comparing the climate effect of emissions of short- and long-lived climate agents, Philos. Trans. R. Soc., A, 365, 1903-1914, 2007.

Shine, K. P., Allan, R. P., Collins, W. J., and Fuglestvedt, J. S.: Metrics for linking emissions of gases and aerosols to global precipitation changes, Earth Syst. Dynam., 6, 525-540, doi:10.5194/esd-6-525-2015, 2015.

Simpson, D., Benedictow, A., Berge, H., Bergström, R., Emberson, L. D., Fagerli, H., Flechard, C. R., Hayman, G. D., Gauss, M., Jonson, J. E., Jenkin, M. E., Nyíri, A., Richter, C., Semeena, V. S., Tsyro, S., Tuovinen, J.-P., Valdebenito, Á., and Wind, P.: The EMEP MSC-W chemical transport model - technical description, Atmos. Chem. Phys., 12, 7825-7865, doi:10.5194/acp-127825-2012, 2012.

Sitch, S., Cox, P. M., Collins, W. J., and Huntingford, C.: Indirect radiative forcing of climate change through ozone effects on the land-carbon sink, Nature, 448, 791-794, 2007.

Skeie, R. B., Berntsen, T. K., Myhre, G., Tanaka, K., Kvalevåg, M. M., and Hoyle, C. R.: Anthropogenic radiative forcing time series from pre-industrial times until 2010, Atmos. Chem. Phys., 11, 11827-11857, doi:10.5194/acp-11-11827-2011, 2011.

Skeie, R. B., Berntsen, T., Aldrin, M., Holden, M., and Myhre, G.: A lower and more constrained estimate of climate sensitivity using updated observations and detailed radiative forcing time series, Earth Syst. Dynam., 5, 139-175, doi:10.5194/esd-5-139-2014, 2014.

Skodvin, T. and Fuglestvedt, J. S.: A comprehensive approach to climate change: Political and scientific considerations, Ambio, 26, 351-358, 1997.

Smith, S. J., Edmonds, J., Hartin, C. A., Mundra, A., and Calvin, K.: Near-term acceleration in the rate of temperature change, Nature Clim. Change, 5, 333-336, doi:10.1038/nclimate2552, 2015.

Stevens, B., Giorgetta, M., Esch, M., Mauritsen, T., Crueger, T., Rast, S., Salzmann, M., Schmidt, H., Bader, J., Block, K., Brokopf, R., Fast, I., Kinne, S., Kornblueh, L., Lohmann, U., Pincus, R., Reichler, T., and Roeckner, E.: Atmospheric component of the MPI-M Earth System Model: ECHAM6-HAM2, J. Adv. Model. Earth Syst., 5, 146-172, doi:10.1002/jame.20015, 2013.

Stjern, C. W., Stohl, A., and Kristjánsson, J. E.: Have aerosols affected trends of visibility and precipitation in Europe?, J. Geophys. Res., 116, D02212, doi:10.1029/2010JD014603, 2011.

Stohl, A. and Trickl, T.: A textbook example of long-range transport: Simultaneous observation of ozone maxima of stratospheric and North American origin in the free troposphere over Europe, J. Geophys. Res., 104, 30445-30462, 1999.

Stohl, A., Hittenberger, M., and Wotawa, G.: Validation of the Lagrangian particle dispersion model FLEXPART against large scale tracer experiments, Atmos. Environ., 32, 4245-4264, 1998.
Stohl, A., Forster, C., Frank, A., Seibert, P., and Wotawa, G.: Technical note: The Lagrangian particle dispersion model FLEXPART version 6.2, Atmos. Chem. Phys., 5, 2461-2474, doi:10.5194/acp-5-2461-2005, 2005.

Stohl, A., Klimont, Z., Eckhardt, S., Kupiainen, K., Shevchenko, V. P., Kopeikin, V. M., and Novigatsky, A. N.: Black carbon in the Arctic: the underestimated role of gas flaring and residential combustion emissions, Atmos. Chem. Phys., 13, 8833-8855, doi:10.5194/acp-13-8833-2013, 2013.

Tanaka, K., O’Neill, B. C., Rokityanskiy, D., Obersteiner, M., and Tol, R. S. J.: Evaluating Global Warming Potentials with historical temperature, Climatic Change, 96, 443-466, 2009.

Tanaka, K., Johansson, D. J. A., O’Neill, B. C., and Fuglestvedt, J. S.: Emission metrics under the $2^{\circ} \mathrm{C}$ climate stabilization target, Climatic Change, 117, 933-941, doi:10.1007/s10584-013-06938, 2013.

Taylor, K. E., Stouffer, R. J., and Meehl, G. A.: An overview of CMIP5 and the experiment design, Bull. Am. Meteorol. Soc., 93, 485-498, doi:10.1175/BAMS-D-11-00094.1, 2012.

Tragou, E. and Lascaratos, A.: Role of aerosols on the Mediterranean solar radiation, J. Geophys. Res., 108, 3025, doi:10.1029/2001JC001258, 2003.

Tsigaridis, K., Daskalakis, N., Kanakidou, M., Adams, P. J., Artaxo, P., Bahadur, R., Balkanski, Y., Bauer, S. E., Bellouin, N., Benedetti, A., Bergman, T., Berntsen, T. K., Beukes, J. P., Bian, H., Carslaw, K. S., Chin, M., Curci, G., Diehl, T., Easter, R. C., Ghan, S. J., Gong, S. L., Hodzic, A., Hoyle, C. R., Iversen, T., Jathar, S., Jimenez, J. L., Kaiser, J. W., Kirkevåg, A., Koch, D., Kokkola, H., Lee, Y. H, Lin, G., Liu, X., Luo, G., Ma, X., Mann, G. W., Mihalopoulos, N., Morcrette, J.-J., Müller, J.-F., Myhre, G., Myriokefalitakis, S., Ng, N. L., O’Donnell, D., Penner, J. E., Pozzoli, L., Pringle, K. J., Russell, L. M., Schulz, M., Sciare, J., Seland, Ø., Shindell, D. T., Sillman, S., Skeie, R. B., Spracklen, D., Stavrakou, T., Steenrod, S. D., Takemura, T., Tiitta, P., Tilmes, S., Tost, H., van Noije, T., van Zyl, P. G., von Salzen, K., Yu, F., Wang, Z., Wang, Z., Zaveri, R. A., Zhang, H., Zhang, K., Zhang, Q., and Zhang, X.: The AeroCom evaluation and intercomparison of organic aerosol in global models, Atmos. Chem. Phys., 14, 10845-10895, doi:10.5194/acp-14 10845-2014, 2014.

UNEP/WMO: Integrated Assessment of Black Carbon and Tropospheric Ozone. United Nations Environment Programme (UNEP), Nairobi, Kenya, 2011.

Unger, N., Bond, T. C., Wang, J. S., Koch, D. M., Menon, S., Shindell, D. T., and Bauer, S.: Attribution of climate forcing to economic sectors, Proc. Natl. Acad. Sci. USA, 107, 3382-3387, 2010.

van der Werf, G. R., Randerson, J. T., Giglio, L., Collatz, G. J., Mu, M., Kasibhatla, P. S., Morton, D. C., DeFries, R. S., Jin, Y., and van Leeuwen, T. T.: Global fire emissions and the contribution of deforestation, savanna, forest, agricultural, and peat fires (19972009), Atmos. Chem. Phys., 10, 11707-11735, doi:10.5194/acp10-11707-2010, 2010.

Wang, R., Balkanski, Y., Boucher, O., Ciais, P., Penuelas, J., and Tao, S.: Significant contribution of combustion-related emissions to the atmospheric phosphorus budget, Nat. Geosci., 8, 48-54, doi:10.1038/ngeo2324, 2015.

Wang, S. X., Zhao, B., Cai, S. Y., Klimont, Z., Nielsen, C. P., Morikawa, T., Woo, J. H., Kim, Y., Fu, X., Xu, J. Y., Hao, J. 
M., and He, K. B.: Emission trends and mitigation options for air pollutants in East Asia, Atmos. Chem. Phys., 14, 6571-6603, doi:10.5194/acp-14-6571-2014, 2014.

West, J. J., Fiore, A. M., Horowitz, L. W., Mauzerall, D. L.: Global health benefits of mitigating ozone pollution with methane emission controls, Proc. Natl. Acad. Sci. USA, 103, 3988-3993, 2006.

WHO: WHO Air quality guidelines for particulate matter, ozone, nitrogen dioxide and sulfur dioxide: Global update 2005 - Summary of risk assessment, 2006, available at: http://www.euro. who.int/_data/assets/pdf_file/0005/78638/E90038.pdf?ua=1 (last access: 22 April 2015), 2006.

WHO: Health effects of black carbon, Joint WHO/UNECE Task Force on Health Aspects of Air Pollutants under UNECE's Long-Range Transboundary Air Pollution Convention (LRTAP), World Health Organization, Regional Office for Europe, Copenhagen, 2012, available at: http://www.unece.org/fileadmin/DAM/env/documents/2012/air/ Health_Effects_of_Black_Carbon_report.pdf (last access: 14 May 2013), 2012.

WHO: Review of evidence on health aspects of air pollution REVIHAAP project: final technical report, 2013, available at: http://www.euro.who.int/en/health-topics/environment-andhealth/air-quality/publications/2013/review-of-evidence-onhealth-aspects-of-air-pollution-revihaap-project-final-technicalreport (last access: 29 April 2014), 2013.
Wild, O., Prather, M. J., and Akimoto, H.: Indirect long-term global radiative cooling from $\mathrm{NO}_{x}$ emissions, Geophys. Res. Lett., 28, 1719-1722, 2001.

Yttri, K. E., Lund Myhre, C., Eckhardt, S., Fiebig, M., Dye, C., Hirdman, D., Ström, J., Klimont, Z., and Stohl, A.: Quantifying black carbon from biomass burning by means of levoglucosan - a one-year time series at the Arctic observatory Zeppelin, Atmos. Chem. Phys., 14, 6427-6442, doi:10.5194/acp-14-64272014, 2014.

Zaveri, R. A., Easter, R. C., Fast, J. D., and Peters, L. K.: Model for Simulating Aerosol Interactions and Chemistry (MOSAIC), J. Geophys. Res., 113, D1320429, doi:10.1029/2007jd008782, 2008.

Zhang, K., O’Donnell, D., Kazil, J., Stier, P., Kinne, S., Lohmann, U., Ferrachat, S., Croft, B., Quaas, J., Wan, H., Rast, S., and Feichter, J.: The global aerosol-climate model ECHAM-HAM, version 2: sensitivity to improvements in process representations, Atmos. Chem. Phys., 12, 8911-8949, doi:10.5194/acp-12-89112012, 2012.

Zhao, B., Wang, S. X., Liu, H., Xu, J. Y., Fu, K., Klimont, Z., Hao, J. M., He, K. B., Cofala, J., and Amann, M.: NOx emissions in China: historical trends and future perspectives, Atmos. Chem. Phys., 13, 9869-9897, doi:10.5194/acp-13-9869-2013, 2013. 